University of New Hampshire

University of New Hampshire Scholars' Repository

Master's Theses and Capstones

Student Scholarship

Winter 2007

\title{
Investigation of cyanidin and pelargonidin contents in the genus Fragaria $\mathrm{L}$
}

Lise Bouchard Mahoney

University of New Hampshire, Durham

Follow this and additional works at: https://scholars.unh.edu/thesis

\section{Recommended Citation}

Mahoney, Lise Bouchard, "Investigation of cyanidin and pelargonidin contents in the genus Fragaria L" (2007). Master's Theses and Capstones. 336.

https://scholars.unh.edu/thesis/336

This Thesis is brought to you for free and open access by the Student Scholarship at University of New Hampshire Scholars' Repository. It has been accepted for inclusion in Master's Theses and Capstones by an authorized administrator of University of New Hampshire Scholars' Repository. For more information, please contact Scholarly.Communication@unh.edu. 


\title{
INVESTIGATION OF CYANIDIN AND PELARGONIDIN CONTENTS \\ IN THE GENUS FRAGARIA L.
}

\author{
BY \\ LISE BOUCHARD MAHONEY \\ Bachelor of Science, University of New Hampshire, 1976
}

THESIS

Submitted to the University of New Hampshire in Partial Fulfillment of the

Requirements for the Degree of

\author{
Master of Science \\ in \\ Plant Biology
}

December 2007 
UMI Number: 1449594

\section{UMI}

UMI Microform 1449594

Copyright 2008 by ProQuest Information and Learning Company.

All rights reserved. This microform edition is protected against unauthorized copying under Title 17, United States Code.

ProQuest Information and Learning Company 300 North Zeeb Road

P.O. Box 1346

Ann Arbor, MI 48106-1346 
This thesis has been examined and approved.

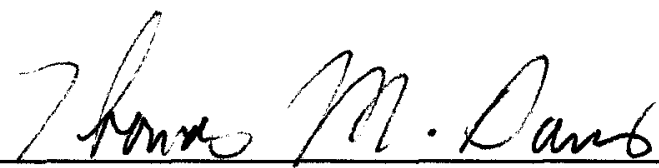

Thesis Director, Thomas M. Davis

Professor of Plant Biology and Genetics
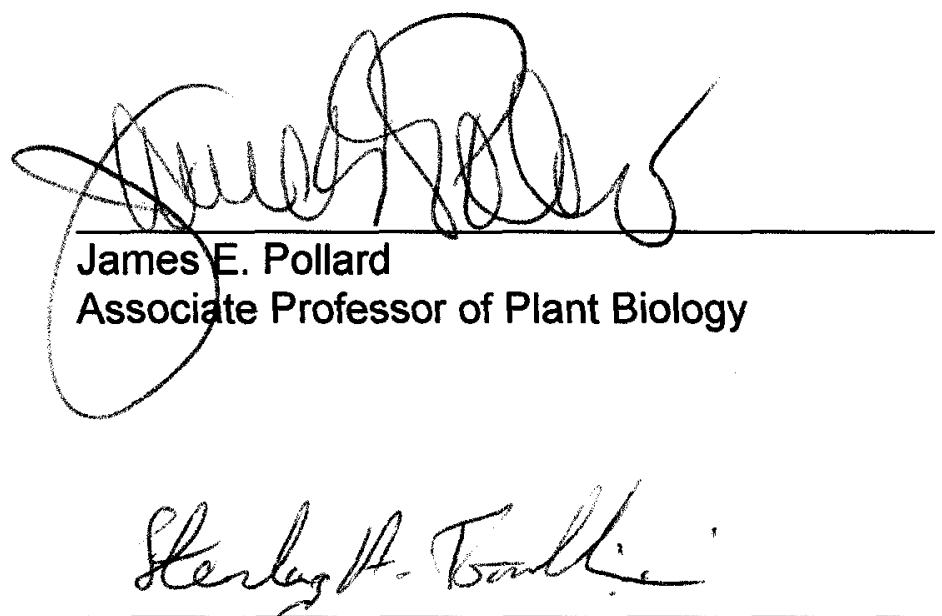

Sterling A. Tomellini

Professor of Chemistry

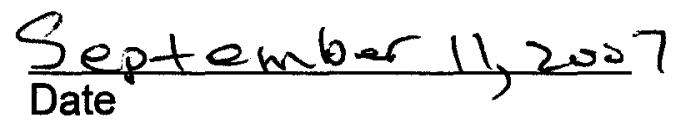




\section{DEDICATION}

I dedicate my thesis to my father Gilles E. Bouchard and to my mother Irène $M$. Bouchard whose qualities of bravery and eagerness to tackle the unknown, and tenacity to see projects to completion were instilled in me. These qualities have been my friends in completing this project. 


\section{ACKNOWLEDGEMENT}

This investigation was made possible through the financial support of the Graduate School Teaching Assistantship Program including a summer TA fellowship, the Plant Biology Department and Hatch Project NH433.

I wish to acknowledge Dr. Curran-Celentano and her staff, especially Sue Jalbert, who offered many useful suggestions during the development of the assay protocol. Dr. Joanne Curran-Celentano, Professor of Animal and Nutritional Sciences, generously made available for this project the use of the UNH Nutrition and Vision Lab including their High Performance Liquid Chromatograph system, where I was able to develop the method and complete all of the assays in a pleasant and welcoming environment.

I wish to thank Dr. Sterling A. Tomellini, UNH Professor of Chemistry and a member of my committee, who provided critical expertise and direction in the development of the High Performance Liquid Chromatography method. The HPLC method was fine-tuned to minimize the types and quantity of chemicals, the number of single use items as well as processing time and in consideration of health, safety and the environment.

I wish to thank Dr. James E. Pollard, for his continued support, valuable suggestions in the investigations, and critical suggestions in the preparation of my defense seminar, and in writing letters of recommendation which were critical to my obtaining the Teaching Assistantship and TA Summer Fellowship. 
I especially wish to acknowledge and thank my advisor, $\mathrm{Dr}$ Thomas $\mathrm{M}$. Davis, for his support of this project at the outset when my initially appointed advisor left the University. Dr. Davis' assemblage of a most appropriate strawberry germplasm collection, advice and words of encouragement along the way, and immeasurable time and coaching in the preparation of my seminar and this thesis were critical to the success and completion of this project.

I wish to acknowledge the Greenhouse staff, Dave Goudreault and Russell Norton, and the Woodman Horticultural Farm staff, John McLean and Evan Ford, for their support and their maintenance of the germplasm.

In the preparation of my thesis, I wish to acknowledge Dr. Garrett E. Crow, Professor of Botany, for his edit of my thesis for correct plant systematic and plant names and other helpful suggestions. I wish to thank Melanie Shields, Ph.D. student for her thorough proofreading. And finally I wish to thank, Cindy Glidden Graduate School Academic Counselor, for her thorough review of the format.

I wish to thank my family and my friends for their understanding and support. I have really appreciated words of encouragement from my dear friends Bonnie Epstein, Kelly Vining and Melanie Shields.

I wish to acknowledge my husband, Peter Myles Mahoney, who has pitched in a lot at home and without whose support I would not have been able to complete the Master of Science Degree program.

I look forward to continuing and growing relationships at the University of New Hampshire as I embark on a Doctor of Philosophy degree program. 


\section{TABLE OF CONTENTS}

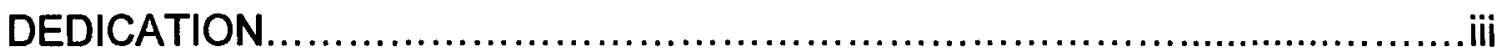

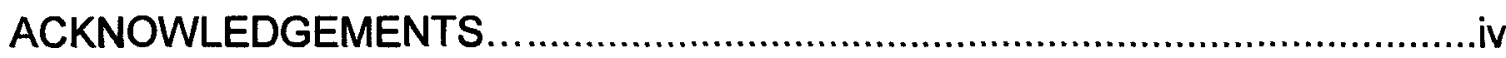

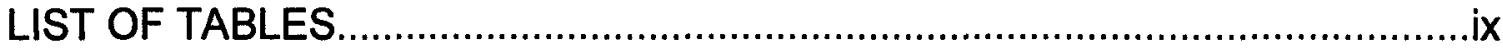

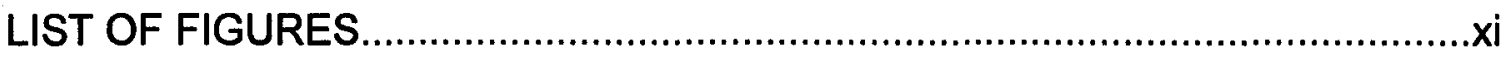

LIST OF ABBREVIATIONS AND UNITS........................................................iii

ABSTRACT

CHAPTER $\quad \underline{\text { Page }}$

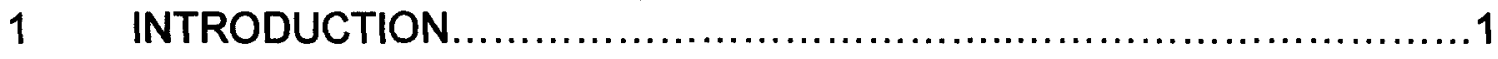

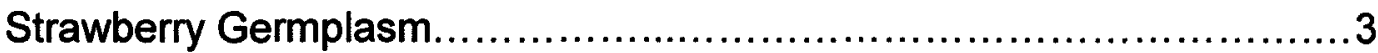

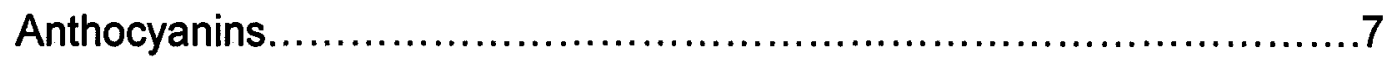

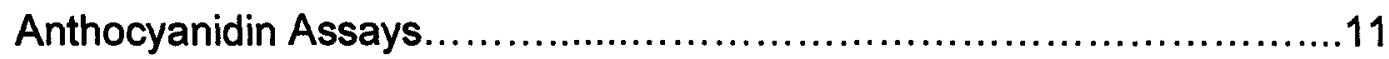

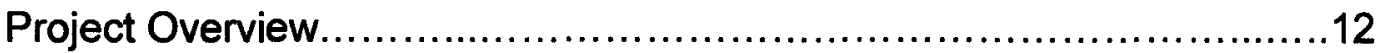

Goals and Objectives..................................................

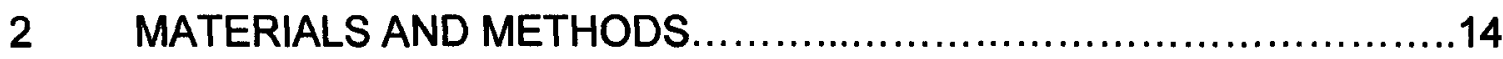

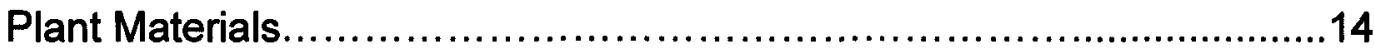

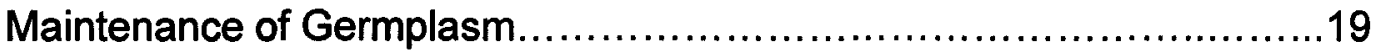

Experimental Design and Statistical Analysis of Data.......................19

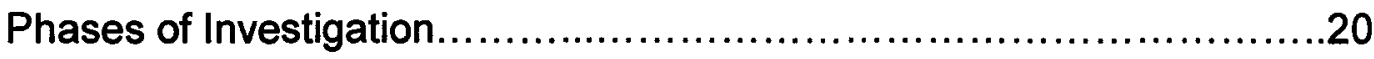

Fruit Sample Collection and Preservation......................................21

vi 
Fruit Sample Preparation for Anthocyanidin Assay........................22

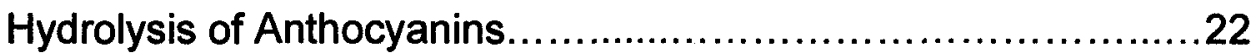

Extraction of Anthocyanidins........................................23

High Performance Liquid Chromatography Method ..........................24

Preparation of Anthocyanidin Standard Solutions...................26

Stability of Anthocyanidin Standards and Mixtures..................28

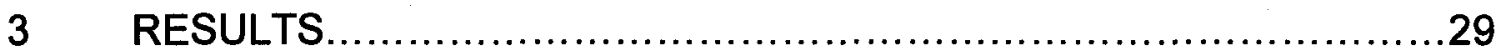

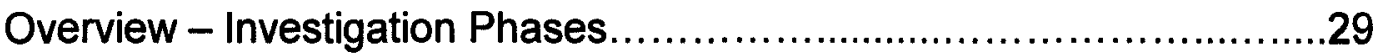

Methods Development.................................................

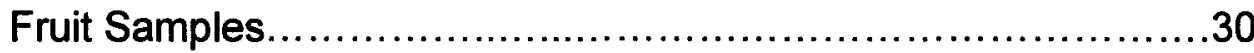

Fruit Sample Preparation for Anthocyanidin Assay....................30

High Performance Liquid Chromatography for Anthocyanidin

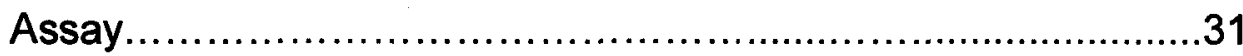

Calibration of HPLC for Anthocyanidin Assay ................33

Stability of Anthocyanidin Standards and Mixtures.............34

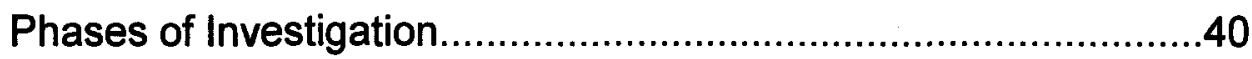

Anthocyanidin Levels in Greenhouse and Field Fruit..........40

HPLC Results with Phase 1 and Phase 2 Methods...........42

HPLC Results with Phase 2 and Phase 3 Methods............43

Application of normalization factors.....................................

Anthocyanidin Content in Fruit at Different Degrees of

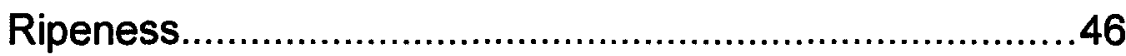

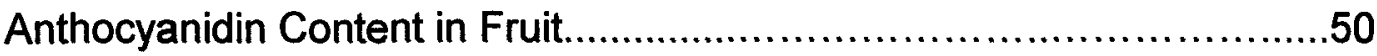

vii 
Fragaria Diploids .50

Octoploid Supercore Collection of Fragaria Wild Species............53

Octoploid Fragaria $\times$ ananassa Cultivars............................59

Octoploid 'Bountiful'(B), 'Pink Panda'(PP) and B-PP Accessions..62

4 DISCUSSION. 66

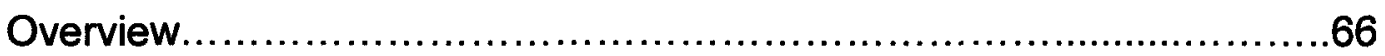

Methods Development..........................................................68

Sample Preparation for Anthocyanidin Assay.......................68

Stability of Anthocyanidin Standard Solutions and Mixtures.........69

Comparison of Greenhouse and Field Fruit............................71

Effect of Degree of Ripeness.............................................

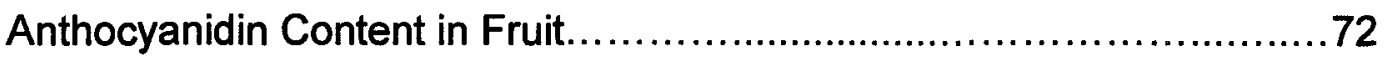

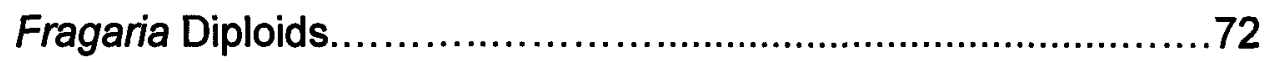

Octoploid Supercore Collection of Fragaria Wild Species............73

Octoploid Fragaria x ananassa Cultivars............................75

Octoploid 'Bountiful', 'Pink Panda', and B-PP Accessions............76

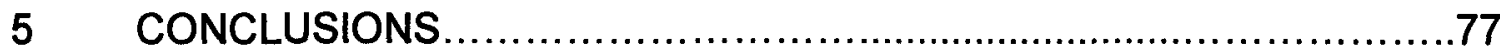

Potential Future Implications of this Work.........................79

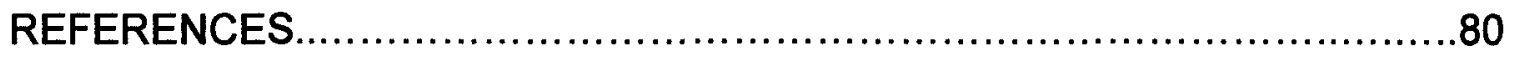

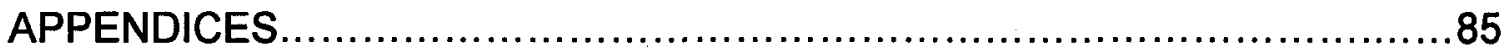

APPENDIX A: GREENHOUSE POT AND FIELD PLOT LAYOUTS........86

APPENDIX B: CHEMICALS AND STOCK SOLUTIONS....................90

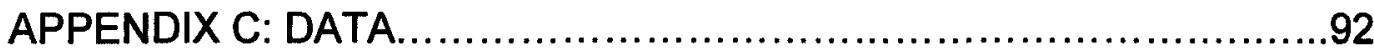

viii 


\section{LIST OF TABLES}

2.1 Diploid accessions surveyed.......................................... 15

2.2 Octoploid Supercore Collection surveyed...................................16

2.3 Octoploid Fragaria $\times$ ananassa cultivars surveyed.............................18

2.4 Octoploid B-PP interspecific hybrids surveyed...............................18

3.1 Anthocyanidin content of mixtures of freshly made standard solutions

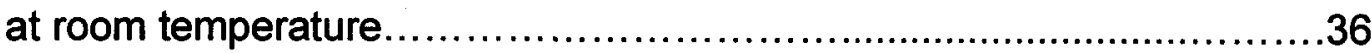

3.2 Anthocyanidin content of standard solutions and mixtures before

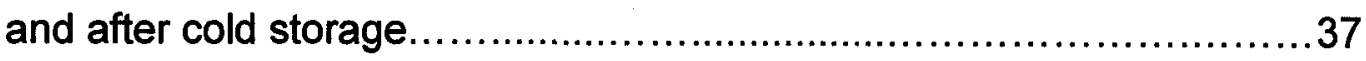

3.3 Anthocyanidin content of cultivar 'Jewel' extract.............................39

3.4 Anthocyanidin content in greenhouse and horticultural field fruit...........41

3.5 Anthocyanidin results with Phase 1 and Phase 2 methods...............44

3.6 Anthocyanidin results with Phase 2 and Phase 3 methods..............45

3.7 Sample data affected by the three different protocols (Phase 1, 2, and 3) and summary of factors applied to the data...............................47

3.8 Anthocyanidin content in fruit with increasing degrees of ripeness........48

3.9 Anthocyanidin content in Fragaria diploids .................................51

3.10 Octoploid species Supercore Collection ripe fruit anthocyanidin content

3.11 Supercore Collection Tukey® multiple subspecies pairwise comparison of cyanidin and pelargonidin contents in ripe fruit. 
3.12a Octoploid Fragaria $\times$ ananassa ripe fruit anthocyanidin content. 60

3.12b Octoploid Fragaria $\times$ ananassa ripe fruit Tukey® pairwise comparison....61

3.13 Octoploid B-PP accessions, ripe fruit anthocyanidin content................63

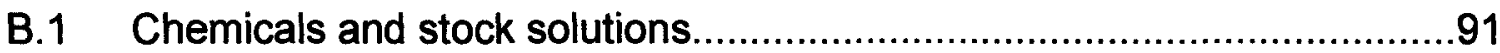

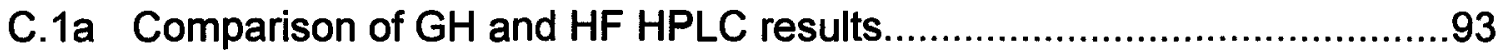

C.1b Comparison of GH and HF accession means .....................................94

C.2a Comparison of Phase 1 and Phase 2 HPLC results...............................95

C.2b Comparison of Phase 1 and Phase 2 accession means.........................97

C.3a Comparison of Phase 2 and Phase 3 HPLC results................................98

C.3b Comparison of Phase 2 and Phase 3 accession means........................99

C.4 Octoploid species Supercore Collection ripe fruit anthocyanidin

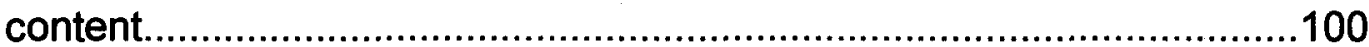

C.5 Octoploid Fragaria $\times$ ananassa ripe fruit anthocyanidin content.............103

C.6 Octoploid cultivars 'Bountiful', and 'Pink Panda' and B-PP accessions

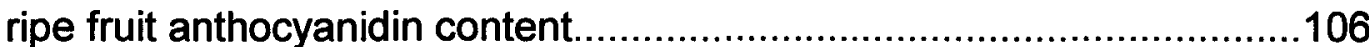




\section{LIST OF FIGURES}

1.1 Chemical structures of anthocyanins in strawberry $\ldots \ldots \ldots \ldots \ldots \ldots \ldots \ldots . . . \ldots \ldots$

1.2 Anthocyanin biosynthetic pathway..................................9

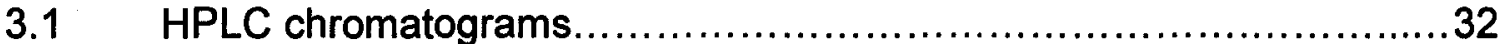

3.2 HPLC calibration with anthocyanidin standard solutions................33

3.3 Stability of freshly made mixed (Cyn and PIr) anthocyanidin mixtures...35

3.4 a-c Stability of anthocyanidin standard solutions and mixtures

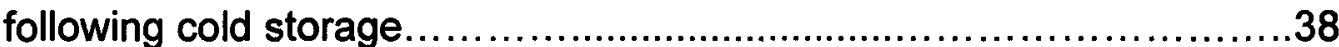

3.5 Stability standard solutions (Cyn and PIr) at room temperature

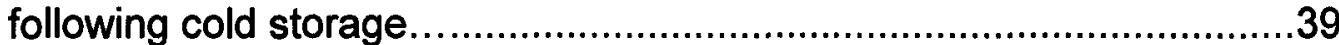

3.6 HPLC 'Jewel' cultivar external standard.................................40

3.7 Comparison of anthocyanidin content in greenhouse and field fruit.....41

3.8 Anthocyanidin results with Phase 1 and Phase 2 methods.............44

3.9 Anthocyanidin results with Phase 2 and Phase 3 methods.............45

3.10 Anthocyanidin content in under-ripe, ripe, and over-ripe fruit...........49

3.11 Anthocyanidin content in ripe fruit of Fragaria diploids ....................52

3.12 Anthocyanidin content in ripe fruit of Supercore Collection Fragaria chiloensis and $F$. virginiana subspecies 
3.13 Supercore Collection flower and fruit variability.........................58

3.14 Anthocyanidin content in ripe fruit of Fragaria $\times$ ananassa cultivars.....61

3.15 Anthocyanidin content in the ripe fruit of octoploid B-PP accessions.....65

A.1 Supercore Collection greenhouse pot and field plot layouts.............87

A.2 Fragaria $\times$ ananassa cultivar field plot layouts............................88

A.3 'Bountiful', 'Pink Panda', and B-PP accessions greenhouse pot

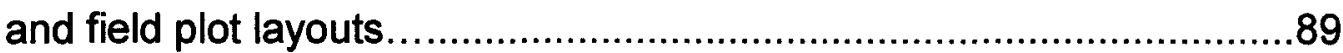




\title{
LIST OF ABBREVIATIONS AND UNITS
}

\author{
UNH University of New Hampshire, Durham NH \\ USDA United States Department of Agriculture \\ NCGR National Clonal Germplasm Repository, Corvallis Oregon \\ NPGS PI National Plant Germplasm System Plant Introduction \\ FRA=CFRA NCGR Inventory ID number prefix \\ HF \\ $\mathrm{GH}$ \\ spp. \\ UNH Woodman Horticultural Farm \\ UNH Greenhouses \\ ssp. \\ f. \\ Species \\ Subspecies \\ forma \\ B Cultivar 'Bountiful' \\ PP Cultivar 'Pink Panda' \\ B-PP \\ HPLC \\ Accessions of an $F_{1}$ population of 'Bountiful' (B) x 'Pink Panda' (PP) \\ FDW \\ aq. \\ $\mathrm{ml}$ \\ High Performance Liquid Chromatography \\ Freeze Dry Weight \\ aqueous \\ $\mu l$ \\ milli $\left(10^{-3}\right)$ liter \\ micro $\left(10^{-6}\right)$ liters \\ $\mu \mathrm{g} \quad$ micro $\left(10^{-6}\right) \mathrm{gram}$ \\ $\mu \mathrm{M} \quad$ micro $\left(10^{-6}\right)$ molar \\ g gram \\ $\mathrm{N} \quad$ Normality, equivalents of solute per liter of solution, ie \\ with $\mathrm{HCl}, 1 \mathrm{~N}=1 \mathrm{M}$. \\ COA Certificate of analysis \\ ORAC Oxygen radical absorbance capacity, $\mu \mathrm{M}$ Trolox equivalent
}

\section{Chemical}

$\begin{array}{ll}\text { [] } & \text { concentration } \\ \text { Cyn } & \text { Cyanidin } \\ \text { PIr } & \text { Pelargonidin } \\ \text { Anth } & \text { Anthocyanidin =Cyn and PIr } \\ \text { CPRatio } & \text { Ratio of [Cyn] to [PIr] } \\ \text { CCPRatio } & \text { Ratio of [Cyn] to [Anth] } \\ \text { HCl } & \text { Hydrochloric Acid } \\ \text { FS } & \text { Flavone synthase } \\ \text { FLS } & \text { Flavonol synthase } \\ \text { F3H } & \text { Flavonone 3-hydroxylase } \\ \text { F3'H } & \text { Flavonoid 3'-hydroxylase } \\ \text { F3'5'H } & \text { Flavonoid 3', 5'-hydroxylase } \\ \text { DFR } & \text { Dihydroflavonol 4-reductase } \\ \text { ANS } & \text { Leucoanthocyanidin oxygenase } \\ \text { 3GT } & \text { anthocyanidin 3-O-glucosyltransferase }\end{array}$

xiii 


\section{Statistical}

\begin{tabular}{|c|c|}
\hline $\begin{array}{l}\text { ANOVA } \\
\text { df } \\
\text { N } \\
\text { SS } \\
\text { MS } \\
\text { ME } \\
\text { F-ratio } \\
\text { P } \\
\text { SE } \\
R^{2}\end{array}$ & $\begin{array}{l}\text { Analysis of Variance } \\
\text { Degrees of Freedom } \\
\text { Number of samples } \\
\text { Sum of the Squares } \\
\text { Mean square } \\
\text { Mean square for error } \\
\text { Fisher test ratio } \\
\text { Probability } \\
\text { Standard Error of Mean } \\
\text { Multiple Rearession Coefficient Squared }\end{array}$ \\
\hline
\end{tabular}




\section{ABSTRACT \\ INVESTIGATION OF CYANIDIN AND PELARGONIDIN CONTENTS IN THE GENUS FRAGARIA L.}

by

Lise Bouchard Mahoney

University of New Hampshire, December 2007

Cultivated strawberry (Fragaria $\times$ ananassa) fruit contain primarily pelargonidin and little cyanidin. The antioxidant potential of cyanidin is reportedly twice that of pelargonidin. A High Performance Liquid Chromatography method was developed to assay fruit anthocyanidin content in 87 Fragaria accessions, including wild diploids and octoploids, cultivars, and two segregating populations. A cyanidin to pelargonidin ratio (CPRatio) greater than one was found only in diploids Fragaria vesca ssp. americana (confirming a previous report), F. viridis, and $F$. iinumae, and in three wild octoploid accessions: all $F$. chiloensis. The highest cyanidin contents were found in diploid $F$. viridis and in $F$. chiloensis ssp. lucida. During fruit ripening, pelargonidin content increased, while cyanidin content held steady. The results hold promise for breeding of cultivars with higher cyanidin content and with potentially higher antioxidant potential. 


\section{CHAPTER 1}

\section{INTRODUCTION}

Strawberries are an economically important and nutritious fruit, with a worldwide annual production of 8 billion pounds (Perez, 2005). The United States accounts for about $29 \%$ of the world's production, or approximately $\mathbf{2 . 3}$ billion pounds (Perez and Toland, 2006), while New Hampshire grows about 1 million pounds of strawberries per year (Keough, 2007). In the United States, the per capita consumption of strawberries has increased by over $50 \%$ in the last ten years to 6.8 pounds, with $5.3 \mathrm{lbs}$ being consumed fresh (Perez, 2005).

The fruit of wild and cultivated strawberry (Fragaria L.) contain anthocyanins, which are important secondary metabolites, are antioxidants, and are regarded as health promoting compounds (Moyer et al., 2002). The level of anthocyanins has been correlated to the total antioxidant activity of strawberry fruit (Wang and Lin, 2000), and the antioxidant activity has also been correlated to the type of anthocyanin (Wang et al., 1997). Strawberry fruit contain two predominant types of anthocyanins: cyanidin 3-glucoside and pelargonidin 3glucoside (Bakker et al., 1994). The antioxidant capacity as measured by oxygen radical absorbance capacity (ORAC, $\mu \mathrm{M}$ Trolox equivalent) of cyanidin 3glucoside is two to three times that of pelargonidin 3-glucoside (Pietta, 2000; Wang et al., 1997). 
Interestingly, cyanidin constitutes only $5 \%$ to $10 \%$ of the total anthocyanins in the octoploid, cultivated strawberry, Fragaria $\times$ ananassa (Weston) Fragaria Duchesne ex Rozier (Kalt et al., 2001; Kikoku et al., 1995; Wang and Zheng, 2001; Wang et al., 2002) and a few cultivars contain no evident cyanidin (Bakker et al., 1994). In contrast, an early study found a 1:1 cyanidin to pelargonidin ratio in the fruit of Fragaria vesca L., a wild diploid species (Sondheimer and Karash, 1956). This early study reported only the ratio of cyanidin to pelargonidin, but did not provide absolute amounts; so it is not known whether the comparatively high cyanidin to pelargonidin ratio reported for Fragaria vesca was due to high cyanidin content, low pelargonidin content, or both.

Growth and cultural practices may also impact the levels of strawberry fruit anthocyanins. Studies have shown that the overall levels of anthocyanins in strawberry fruit are affected by temperature (Wang and Zheng, 2001), compost and fertilizer (Wang and Lin, 2003), matted-row culture versus plasticulture (Wang et al., 2002), and carbon dioxide (Wang et al., 2003), but the anthocyanidin content remained within the ranges observed in cultivated strawberries and the respective ratio of cyanidin to pelargonidin content were unaffected. The results suggest that the reported differences between the cyanidin and pelargonidin contents in $F . \times$ ananassa and in $F$. vesca are likely not the result of environmental effects but rather are due to genetic factors.

Fragaria vesca is considered a likely diploid $(2 n=2 x=14)$ ancestor of the octoploid $(2 n=8 x=56)$ group of strawberry species (Hancock, 1999) the cultivated 
strawberry, $F . \times$ ananassa and its immediate wild progenitors, $F$. chiloensis (L.)

Duchesne and $F$. virginiana Mill. The reported presence of a cyanidin to pelargonidin ratio of 1:1 in $F$. vesca prompted the hypothesis that sources of high cyanidin content may also exist in other wild strawberry species, including the octoploid germplasm pool of the cultivated strawberry. If so, gene introgression from wild octoploid into cultivated varieties could afford an opportunity to increase the cyanidin content in the cultivated strawberry through breeding.

\section{Strawberry Germplasm}

Fragaria is part of the economically important Rosaceae family. Other economically important members of the Rosaceae family include fruit or nut bearing Malus Mill. (apple), Prunus L. (almond, apricot), and Rubus L. (raspberry) and ornamentals such as Potentilla L. (cinquefoil) (Judd et al., 2002).

Fragaria vesca grows across North America from the northern part of British Columbia and south to Central America in San Salvador (Staudt, 1999), on the island of Hawaii (Hancock and Luby, 1993), and in Europe (Hancock and Luby, 1993). Fragaria vesca is represented in the Americas by subspecies americana (Porter) Staudt, bracteata (A. Heller) Staudt, and californica (Chamisso and Schlechtendal) Staudt (Darrow, 1966). From Europe to Siberia, F. vesca is represented by subspecies vesca (Folta and Davis, 2006). The early report of the 1:1 cyanidin to pelargonidin ratio in $F$. vesca concerned plants grown in Geneva, NY, but which originated from one clone from East Malling, England (Sondheimer and Karash, 1956) and therefore were presumably subspecies vesca. In addition to $F$. vesca, many other diploid strawberry species 
have been identified, including $F$. viridis Duchesne, $F$. iinumae Makino, $F$. nilgerrensis Schlecht. ex J.Gay, F. daltoniana J. Gay, F. nubicola (Hook. f.) Lindl. ex Lacaita, F. yezoensis Hara, F. mandshurica Staudt, and F. nipponica Makino (Hancock and Luby, 1993). Along with F. vesca, several of these diploids are considered possible ancestors to the octoploid strawberry species (Davis et al., 2007; Hancock, 1999).

Fragaria chiloensis grows wild along the Pacific coast from the southern coastline of Alaska to the coasts of Oregon and California, in Hawaii, and in South America. In South America, F. chiloensis grows in Ecuador, Peru, and in Chile, but it also occurs at high altitudes where it has escaped from cultivation in areas where it has been under cultivation for many years, as early as 1500 (Darrow, 1966). Fragaria chiloensis is represented by four subspecies and two formae within the subspecies chiloensis (Staudt, 1999), with much fruit color variation including white, yellowish-white, whitish-red and red (Darrow, 1966). The infraspecific taxa in $F$. chiloensis subspecies include ssp. lucida, ssp. pacifica Staudt, ssp. sandwicensis (O. Deg and I. Deg) Staudt, and subspecies chiloensis with f. chiloensis and f. patagonica Staudt (Staudt, 1999).

Fragaria virginiana grows wild throughout North America including Canada and the United States from Alaska to Mississippi (Staudt, 1999). Fragaria virginiana is represented by four subspecies, with red fruit with white to red internal color (Staudt, 1999): ssp. virginiana, ssp. glauca (S. Watson) Staudt, ssp. grayana (E. Vilm. ex J. Gay) Staudt, and ssp. platypetala (Rydb.) Staudt (Staudt, 1999). 
Fragaria $\times$ ananassa, the primary contemporary cultivated strawberry, originated in France from an accidental pollination of $F$. chiloensis by $F$. virginiana, in the mid-1700's. Initially, five female $F$. chiloensis plants were brought from Concepción, Chile to France in 1712 by a French spy with a background in the sciences, who coincidently but most appropriately was named Frézier (meaning strawberry in French). The flowers of these plants were described as having many petals and being as large as $13 / 5^{\prime \prime}$ in diameter, and the fruit was described as 'whitish-red' and as big as a 'walnut' and sometimes a 'hen's egg' (Darrow, 1966). The source of $F$. virginiana and its voyage to France is less clear, but documents indicate that $F$. virginiana came from eastern North America and most likely from the state of Virginia (Darrow, 1966), thereby named virginiana. Fragaria $\times$ ananassa originated, when by chance, by planting alternate rows of $F$. virginiana and $F$. chiloensis, $F$. virginiana donated pollen to F. chiloensis resulting in fruit reported as large as $71 / 2$ " in circumference (Darrow, 1966); approximately $23 / 8$ " in diameter.

Fragaria $\times$ ananassa makes up the largest share of strawberry cultivars on the market. The few exceptions are diploid $F$. vesca 'Alpine' and other varieties such as 'Yellow Wonder' and 'Baron Solemacher' from Europe. Most of the F. $\times$ ananassa cultivars were derived from continual breeding and hybridizations of the original cross of $F$. chiloensis and $F$. virginiana. Fragaria $x$ ananassa cultivars are described as either short-day or day-neutral cultivars. Short-day cultivars form flower buds during photoperiods of short days (long nights), while day-neutral cultivars flower irrespective of the photoperiod. 
More recently, octoploid $F . \times$ ananassa cultivars have been derived through introgression of wild stock originating from different parts of the Americas to introduce new characteristics. For example the day-neutrality of the cultivars 'Seascape' and 'Selva' are the result of introducing $F$. virginiana ssp. glauca into their pedigree (Bringhurst, 1991). In addition, there is growing interest in developing cultivars with increased nutritional value, containing higher amounts of vitamins and minerals, and increased antioxidant potential with identification and focus on secondary metabolites and anthocyanins (Crosby and Jifon, 2007; Just, 2004; Khanizadeh et al., 2007; Scalzo et al., 2007; Yoo et al., 2007). The interest in developing cultivars with increased nutritional content is broad but is not limited to fruits. For example, the carrot traditionally known for its high betacarotene content, has been bred for color and to contain a predominance of secondary metabolites, for example yellow carrots with xanthophylls, red carrots with lycopenes, and purple carrots with anthocyanin compounds (Pike, 2005; Simon, 1997) and all cyanidin derivatives (Kurilich et al., 2005). The purple carrot was derived by interbreeding the cultivated carrot with wild 'Black' carrot germplasm native to Afghanistan, Turkey, and the Middle East (Simon, 2005).

Development of new cultivars is not limited to interspecific breeding. For example, 'Pink Panda' is the result of intergeneric hybridization of Fragaria X ananassa with Potentilla palustris (L.) Scop. (Ellis, 1962; Ellis, 1991). A new combination name Fragaria $\times$ rosea (Mabb.) K. Hammer et Pistrick has been proposed (Hammer and Pistrick, 2003) for this intergeneric hybridization. 'Pink Panda' is considered an ornamental strawberry, because of its pink flowers and 
poor fruit set. Potentilla palustris differs from all the other Potentilla species in that it has "a large fruit with a large but non-succulent spongy receptacle" (Ellis, 1962) and is sometimes segregated as Comarum palustre L. (Crow and Hellquist, 2000). Interestingly, an $F_{1}$ population of a cross between F. $\times$ ananassa 'Bountiful' and 'Pink Panda' initially made by Chad Finn, Oregon State University and repeated by Thomas M. Davis, University of New Hampshire (UNH), segregated for flower color, which elicited the question of whether the population was also segregating for cyanidin content.

\section{Anthocyanins}

Anthocyanins are the most conspicuous of the flavonoids; comprising a large class of plant secondary metabolites (Holton and Cornish, 1995). Cyanidin, the secondary anthocyanin found in the cultivated strawberry, imparts slight reddishblue color as is more typical of raspberry, while pelargonidin imparts the typical orange-red color to the strawberry fruit. Anthocyanins contain a sugar moiety usually at the 3-carbon position. Anthocyanidins do not contain any sugar moiety. The basic chemical structure of anthocyanidins consists of two phenolic rings linked by a three carbon chain (Figure 1.1). Both cyanidin 3-glucoside and
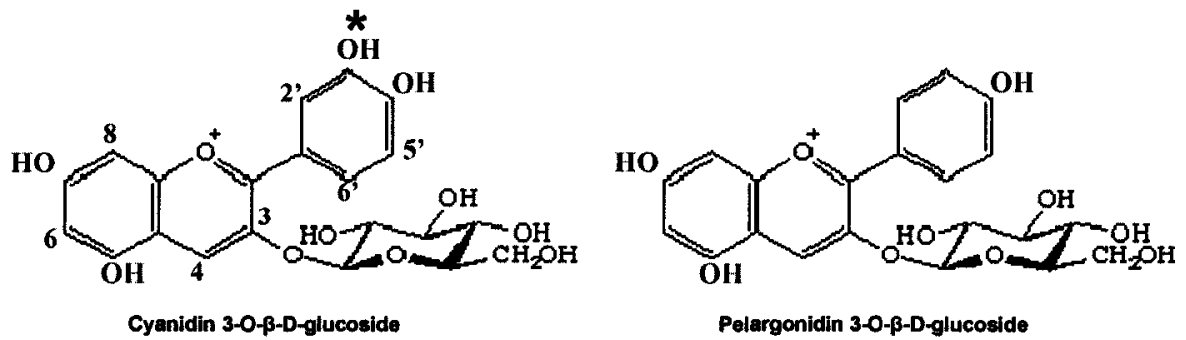

Figure 1.1 Chemical structures of anthocyanins in strawberry. Cyanidin 3-O- $\beta$-D-glucoside and Pelargonidin 3-O- $\beta$-D-glucoside structure and nomenclature differ by only one hydroxyl $\left(\mathrm{OH}^{*}\right)$ group. 
pelargonidin 3-glucoside are very similar in structure, both have an O- $\beta$-Dglucoside at the 3 carbon position, and hydroxyl $(-\mathrm{OH})$ groups at the 5,7 and the 4' carbon positions. Cyanidin 3-glucoside and pelargonidin 3-glucoside differ by only one hydroxyl group, with cyanidin having an additional hydroxyl at the 3' carbon position.

The basic anthocyanin biosynthetic pathway for the synthesis of cyanidin and pelargonidin in plants, as illustrated in Figure 1.2, is well understood (Holton and Cornish, 1995; Moss, 2001). Cyanidin and pelargonidin are both synthesized from dihydrokaempferol. Flavonone 3-hydroxylase $(\mathrm{F} 3 \mathrm{H})$ reduces naringenin and produces dihydrokaempferol. Flavonoid 3'-hydroxylase (F3'H) catalyzes the hydroxylation of the $3^{\prime}$ carbon of dihydrokaempferol to yield dihydroquercetin.

Dihydroflavonol 4-reductase (DFR) reduces dihydrokaempferol to produce leucopelargonidin and reduces dihydroquercetin to produce leucocyanidin. Flavonol synthase (FLS) oxidizes the dihydroflavonols to produce kaempferol and quercetin. The F3'H enzyme competes with DFR and FLS (Holton and Cornish, 1995) for substrates, and kaempferol (a flavonol), naringenin (a flavanone), and epigenin (a flavone) all serve as substrates for F3'H (Moss, 2001), competing with dihydroquercetin. These competing pathways are not shown in Figure 1.2. The lack of specificity for substrates and the competition between the enzymes for common substrates results in the availability of multiple paths for the same intermediate (Holton and Cornish, 1995). 

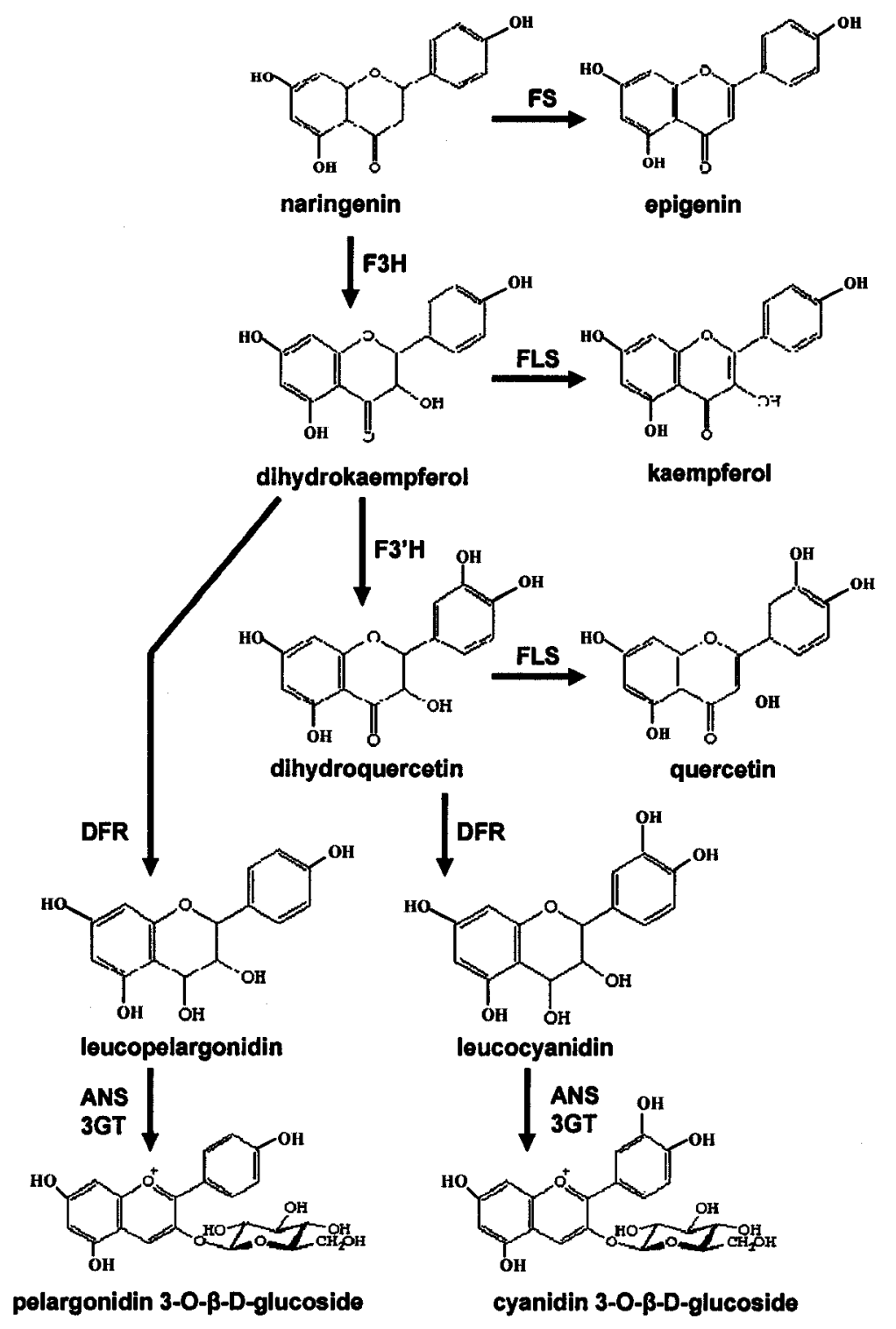

kaempforol

Figure 1.2: Anthocyanin biosynthetic pathway. Enzyme abbreviations: FS (flavone synthase), F3H (flavonone 3-hydroxylase), FLS (flavonol synthase), F3'H (flavonoid 3'-hydroxylase), DFR (dihydroflavonol 4-reductase), ANS (leucoanthocyanidin oxygenase), 3GT (anthocyanidin 3-O-glucosyltransferase).

Low levels of flavonols, quercetin and kaempferol; have been reported in strawberry in a number of studies (Heinonen et al., 1998; Wang and Lin, 2003). The presence of these flavonols at low levels in the cultivated strawberry suggests low activity of the FLS enzyme and that dihydrokaempferol is not being 
consumed for production of these flavonols. In petunia, high levels of cyanidin derivatives accumulate only in accessions that possess $\mathrm{F}^{\prime} \mathrm{H}$ activity but lack flavonoid 3'5'-hydroxylase (F3'5'H) (not shown in Figure 1,2) and FLS activity (Holton and Cornish, 1995). Similarly, FLS activity may also be low in the cultivated strawberry as indicated by the low contents of quercetin and kaempferol. And that, coupled with the lack of $\mathrm{F}^{\prime}{ }^{\prime}{ }^{\prime} \mathrm{H}$, suggest that a possible cause of the low cyanidin content in the cultivated strawberry is a loss of function in the $\mathrm{F}^{\prime} \mathrm{H}$ gene.

Anthocyanin pathway genes for enzymes chalcone synthase (CHS), chalcone hydroxyl isomerase $(\mathrm{CHI})$, flavonone 3-hydroxylase $(\mathrm{F} 3 \mathrm{H})$, dihydroflavonol 4-reductase (DFR), and anthocyanidin synthase (ANS) and one Del-like regulatory gene have been partially cloned and sequenced in strawberry (Deng and Davis, 2001). The complete CHS, CHI, DFR, ANS, and anthocyanidin 3-O-glucosyltransferase (3GT) gene sequences have been determined for maize, snapdragon and petunia (Holton and Cornish, 1995). .The complete sequences of $\mathrm{F} 3 \mathrm{H}$ have been determined for snapdragon and petunia (Holton and Cornish, 1995) and more recently in F. × ananassa (Almeida et al., 2004). An F'H encoding gene has been cloned and sequenced for petunia (Holton and Cornish, 1995). On the basis of research on anthocyanin pathway genes in other species, it is expected that the entire complement of anthocyanin pathway genes will soon be isolated from Fragaria by virtue of homology to the respective genes in other species. Identifying germplasm differing in cyanidin content at the diploid and/or octoploid levels should make it possible to identify 
molecular genetic determinants of cyanidin levels, and to develop molecular tools that breeders could use to select for enhanced cyanidin content.

\section{Anthocyanidin Assays}

For the quantitative determination of anthocyanins and anthocyanidins in fruit, High Performance Liquid Chromatography (HPLC) is the commonly accepted technology (Durst and Wrolstad, 2001; Hong and Wrolstad, 1990; Kikoku et al., 1995; Mazza et al., 2004; Merken and Beecher, 2000; Nyman and Kumpulainen, 2001). Methods of HPLC analysis of strawberry anthocyanidins have been described (Bridle and Garcia-Viguera, 1997; Merken and Beecher, 2000; Nyman and Kumpulainen, 2001). Others have described HPLC procedures for the detection of strawberry anthocyanins (Merken and Beecher, 2000; Wang and Lin, 2003; Wu and Prior, 2005). HPLC methods outlined in the literature differ by column use, temperature control, by wavelength of detection, by use of isocratic or gradient elution, and by type and concentration of chemicals in the mobile phases.

The preparation of the fruit sample for assay of the anthocyanidin content of fruit requires hydrolysis of the anthocyanins (which have an attached sugar) to cleave the sugars, thereby forming the respective anthocyanidins (which do not have an attached sugar). By definition, an anthocyanin has attached sugar(s); once the sugar is removed from an anthocyanin, the pigment is known as an anthocyanidin (Harborne, 1958). Acid treatment in combination with heating of the fruit tissue completes the hydrolysis of the anthocyanins. Acid hydrolysis removes glucosides (sugars) (Durst and Wrolstad, 2001; Merken and Beecher, 
2000; Nyman and Kumpulainen, 2001), thereby reducing the number of possible forms of anthocyanidins in strawberry to two: cyanidin and pelargonidin. The anthocyanidins are then separated from the fruit tissue by centrifugation and purified using selective molecular absorption, in preparation for separation and assay determination of cyanidin and pelargonidin contents by HPLC.

\section{Project Overview}

The focus of this study was to assess cyanidin and pelargonidin contents in a diverse sampling of strawberry diploid and octoploid germplasm (Table 2.12.4). Of particular interest were $F$. vesca, $F$. chiloensis and $F$. virginiana. Included in the study was a sampling of diverse diploid species and hybrids to discover if high cyanidin content was really present in $F$. vesca and/or in other diploid accessions. A United States Department of Agriculture (USDA) Supercore Collection held by National Clonal Germplasm Repository (NCGR) to represent the diversity of wild octoploid species of $F$. chiloensis and $F$. virginiana (Hancock et al., 2001) was surveyed to discover if high cyanidin is present in the wild octoploid germplasm pool of the cultivated strawberry. Among the $F$. $\times$ ananassa cultivars included in the study were day-neutral varieties, to discover if high cyanidin might exist in some of these varieties. Finally, an interspecific hybrid $F_{1}$ population segregating for flower color (pink versus white) was surveyed to determine if the population might also be segregating for cyanidin content. Segregation in the population for cyanidin content would suggest that cyanidin content could be increased in the cultivated strawberry through breeding. 


\section{Goals and Objectives}

The overall goal of the research was to discover sources of high cyanidin content in wild and or cultivated strawberry species and to evaluate the potential for increases in strawberry fruit cyanidin through breeding. The objectives of this project were to:

1) Establish methods and conditions for the assessment of anthocyanidin content in the fruit of strawberry;

2) Assess variation in cyanidin and pelargonidin contents in the fruit of diploid and octoploid germplasm including diploid $F$. vesca, $F$. viridis and some diploid hybrids, and octoploid Supercore Collection, and assorted cultivars; and

3) Assess variation in cyanidin and pelargonidin in an octoploid population segregating for flower color. 


\section{CHAPTER 2}

\section{MATERIALS AND METHODS}

\section{Plant Materials}

A germplasm collection comprised of wild diploid and octoploid species, and an assortment of cultivated diploid and octoploid varieties, was assembled. The word accession (which is widely applied in reference to the members of a germplasm collection) is used generically throughout this thesis to refer to individual wild species, hybrids, cultivated varieties, and to individual members of an $F_{1}$ population. Information about the identification and sites of origin of the species, subspecies, and cultivars used in this study is provided in Tables 2.1 through 2.4. The surveyed diploids included $F$. vesca, $F$. viridis, $F$. iinumae, and an assortment of diploid hybrids (Table 2.1). The wild octoploid species consisted of a Supercore Collection of 43 accessions originally compiled by USDA-sponsored investigators to represent the diversity of wild $F$. chiloensis and F. virginiana in the Americas (Hancock et al., 2000) (Table 2.2). Fragaria $\times$ ananassa cultivars surveyed for the present study comprised an assortment of short-day and day-neutral cultivars (Table 2.3). The further classification within the short-day cultivars indicates when flowers and fruit will develop during the short-day (long night) photoperiod. In addition, an $F_{1}$ population of 43 members resulting from a hybridization of 'Bountiful' (B) and 'Pink Panda' (PP), as well as the two parental cultivars, were surveyed in this investigation (Table 2.4). 


\section{Table 2.1 Diploid accessions surveyed.}

The diploid species, subspecies (ssp.), and hybrids, the name and/or accession number of each plant, the UNH ID, the origin (original collection site of wild species or origin of hybrids), and the sources of seed or plant material with reference information are provided. Hybrids surveyed were originally generated by T.M. Davis. The CFRA ID accessions numbers are the inventory identifications of the National Clonal Germplasm Repository (NCGR) in Corvallis, Oregon. The PI (Plant Introduction) numbers are the National Plant Germplasm System (NPGS) accession designations.

\begin{tabular}{|c|c|c|c|}
\hline Plant_Identity & UNH ID & Origin & Plant or seed source \\
\hline \multicolumn{4}{|l|}{ F. vesca } \\
\hline ssp. americana & WC-8 & $\begin{array}{l}\text { Coos County, } \\
\mathrm{NH}\end{array}$ & UNH (Williamson, 1993) \\
\hline $\begin{array}{l}\text { ssp. vesca 'Baron } \\
\text { Solemacher' }\end{array}$ & BS & $\begin{array}{l}\text { European } \\
\text { origin, 'Alpine' } \\
\text { variety }\end{array}$ & $\begin{array}{l}\text { Seeds obtained from } \\
\text { Johnny's Selected } \\
\text { Seeds (Yu and Davis, } \\
\text { 1995) }\end{array}$ \\
\hline $\begin{array}{l}\text { ssp. vesca 'Yellow } \\
\text { Wonder' }\end{array}$ & YW & $\begin{array}{l}\text { European } \\
\text { origin, 'Alpine' } \\
\text { variety }\end{array}$ & $\begin{array}{l}\text { Seeds obtained from } \\
\text { W. Atlee Burpee and Co } \\
\text { (Yu and Davis, 1995) }\end{array}$ \\
\hline$\frac{\text { F. iinumae }}{\text { CFRA1855 (PI 637969) }}$ & $\mathrm{J}-17$ & $\begin{array}{l}\text { Hokkaido, } \\
\text { Japan }\end{array}$ & $\begin{array}{l}\text { Collected in Japan by } \\
\text { T. M. Davis }\end{array}$ \\
\hline \multicolumn{4}{|l|}{$\mathbf{F}_{1}$ Hybrids } \\
\hline $\begin{array}{l}\text { F. vesca YW } \times F \\
\text { nubicola CFRA520 (PI } \\
\text { 551851) }\end{array}$ & $\mathrm{YW} \times 520 \mathrm{~F}_{1} \mathrm{C}$ & $\begin{array}{l}\text { Europe } x \\
\text { Pakistan }\end{array}$ & (Deng and Davis, 2001) \\
\hline $\begin{array}{l}\text { F. viridis CFRA341(PI } \\
551742) \times F \text {. viridis SIB1 }\end{array}$ & F.vir $F_{1} D$ & $\begin{array}{l}\text { Germany } x \\
\text { Siberia }\end{array}$ & $\begin{array}{l}\text { SIB1 seeds collected by } \\
\text { G. E. Crow (UNH) in } \\
\text { Siberia. }\end{array}$ \\
\hline $\begin{array}{l}\text { F. vesca } \mathrm{YW} \times(F \text {. viridis } \\
\times F . \text { vesca ssp. bracteata } \\
\text { (CFRA364) }\end{array}$ & $\begin{array}{l}\text { BQS } \\
\text { prefixes }\end{array}$ & $F_{1}$ population & $\begin{array}{l}\text { Progeny derived from a } \\
\text { complex and partially } \\
\text { undefined pedigree. } \\
\text { CFRA364 initially listed } \\
\text { by USDA as } F \text {. vesca, } \\
\text { but later determined to } \\
\text { be an interspecific hybrid } \\
\text { of } F \text {. viridis } \times F \text {. vesca } \\
\text { spp. bracteata (Yu and } \\
\text { Davis, 1995) }\end{array}$ \\
\hline $\begin{array}{l}\text { Potentilla nepalensis } \\
\text { Hook. } \\
\text { (PI 436993) }\end{array}$ & & Himalayas & $\begin{array}{l}\text { Clone obtained from } \\
\text { North Central Regional } \\
\text { Station: Ames, lowa }\end{array}$ \\
\hline
\end{tabular}


Table 2.2 Octoploid Supercore Collection surveyed.

A diverse collection of $F$. chiloensis and $F$. virginiana from the Americas (Hancock et al., 2000). Accessions were collected in the wild, unless otherwise indicated. The National Clonal Germplasm Repository (NCGR) in Corvallis, Oregon provided these accessions as runners. The suffix in the Taxon nomenclature for $F$. virginiana ssp. virginiana refers to the latitudinal origin of the plant material in the United States; $(\mathrm{N})$ for northern and $(\mathrm{S})$ for southern. NPGS PI \# refers to the National Plant Germplasm System Plant Introduction number. The NCGR Inventory CFRA ID numbers of the accessions that produced enough fruit for sampling are underlined and in bold.

\begin{tabular}{lrrll}
\hline Taxon & $\begin{array}{c}\text { NPGS } \\
\text { PI \# }\end{array}$ & $\begin{array}{l}\text { NCGR } \\
\text { CFRA ID }\end{array}$ & Plant Origin \\
\hline F. chiloensis ssp. chiloensis f. chiloensis & 551736 & $\underline{372.002}$ & $\begin{array}{l}\text { Previously } \\
\text { cultivated in }\end{array}$ \\
& 552038 & 743.001 & Chile \\
& 616544 & 1104.002 & Chile \\
& 602570 & 1108.002 & Chile \\
& 612318 & 1480.001 & Ecuador \\
F. chiloensis ssp. chiloensis f. patagonica & 552091 & 796.001 & Chile \\
& 612316 & 1088.002 & Chile \\
& 612317 & 1092.002 & Chile \\
& 602568 & $\underline{1100.002}$ & Chile \\
& 236579 & 24.001 & Chile, Garden \\
& 551445 & 34.002 & California \\
F. chiloensis ssp. Iucida & 551453 & $\underline{\mathbf{4 2 . 0 0 1}}$ & Washington \\
& 612489 & $\underline{\mathbf{1 6 9 1 . 0 0 1}}$ & Oregon \\
& 551459 & $\mathbf{4 8 . 0 0 1}$ & Oregon \\
& 551728 & 357.002 & California \\
& 551735 & $\underline{368.002}$ & Alaska \\
& 551735 & $\underline{368.005}$ & Alaska \\
& 612487 & 1689.001 & B.C., Canada \\
& 612488 & 1690.001 & B.C., Canada \\
& 612490 & 1692.001 & California \\
\hline & & &
\end{tabular}


Table 2.2 continued.

\begin{tabular}{|c|c|c|c|}
\hline Taxon & $\begin{array}{c}\text { NPGS } \\
\text { PI \# }\end{array}$ & $\begin{array}{c}\text { NCGR } \\
\text { CFRA ID }\end{array}$ & Plant Origin \\
\hline \multirow[t]{2}{*}{ F. virginiana ssp. glauca } & 612496 & 1698.001 & Alaska \\
\hline & 612501 & 1703.001 & Montana \\
\hline \multirow[t]{3}{*}{ F. virginiana ssp. grayana } & 612486 & 1408.001 & Mississippi \\
\hline & 612486 & 1408.002 & Mississippi \\
\hline & 612569 & 1414.001 & Mississippi \\
\hline \multirow[t]{3}{*}{ F. virginiana ssp. glauca $\times$ ssp. virginiana } & 612494 & 1696.001 & S. Dakota \\
\hline & 612495 & 1697.001 & Montana \\
\hline & 612495 & 1697.002 & Montana \\
\hline \multirow[t]{2}{*}{ F. virginiana ssp. platypetala } & 551471 & 58.002 & California \\
\hline & 551527 & 110.001 & Oregon \\
\hline \multirow[t]{7}{*}{ F. virginiana ssp. virginiana $(N)$} & 612492 & $\underline{1694.001}$ & Ont., Canada \\
\hline & 612493 & 1695.001 & Ont., Canada \\
\hline & 612493 & 1695.002 & Ont., Canada \\
\hline & 612497 & 1699.001 & Ont., Canada \\
\hline & 612498 & 1700.001 & Minnesota \\
\hline & 612499 & 1701.001 & Minnesota \\
\hline & 612499 & 1701.002 & Minnesota \\
\hline \multirow[t]{7}{*}{ F. virginiana ssp. virginiana (S) } & 612570 & 1435.001 & Florida \\
\hline & 612570 & 1435.002 & Florida \\
\hline & 612320 & 1455.001 & Georgia \\
\hline & 612320 & 1455.002 & Georgia \\
\hline & 612323 & 1557.001 & Alabama \\
\hline & 612324 & $\underline{1580.001}$ & S. Carolina \\
\hline & 612325 & 1620.001 & S. Carolina \\
\hline
\end{tabular}


Table 2.3: Octoploid Fragaria $\times$ ananassa cultivars surveyed. Cultivars were donated as crowns by Nourse Farms, Deerfield, Massachusetts, with the exception of cultivars 'Delmarvel' and 'Selva' which were obtained from *NCGR (National Clonal Germplasm Repository: Corvallis, Oregon). ${ }^{* *}$ Information on these cultivars can be found on NPGS PI\# entries or at the alternate sources listed.

\begin{tabular}{lllc}
\hline Day-length Preference & \multicolumn{1}{c}{ Variety } & Information $^{* *}$ \\
\hline Short-day & Early & Earliglow & 551394 \\
& Early & Northeaster & 616918 \\
& Mid-Season & Delmarvel & 616589 \\
& & Honeoye & 551588 \\
& Raritan & 551595 \\
& \multirow{2}{*}{ Mid-Late } & Jewel & 551927 \\
& & Seneca & 616559 \\
Day-neutral & Sparkle & 551559 \\
& \multirow{4}{*}{ Late } & Winona & U of M Extension \\
& & Seascape & Patent \#PP7,614 \\
& & Tribute & 551953 \\
& & Tristar & 551954 \\
& & Selva* & 551814 \\
\hline
\end{tabular}

Table 2.4: Octoploid B-PP interspecific hybrids surveyed. Chad Finn Oregon State University donated parents and first 40 of $F_{1}$ numbered progeny as runners.

\begin{tabular}{lcl}
\hline \multicolumn{1}{c}{ Variety } & Accession PI\# & \multicolumn{1}{c}{ Pedigree Description } \\
\hline Bountiful & 551855 & F. $\times$ ananassa \\
Pink Panda & 616586 & $\begin{array}{l}\text { F. } \times \text { ananassa } \times \text { Potentilla palustris. } \\
\text { Fragaria 'Frel' US Patent Plant } \\
\text { \#7598(Ellis, 1991) }\end{array}$ \\
B-PP\# & $\begin{array}{c}\text { Numbered F } 1 \\
\text { population }\end{array}$ & $\begin{array}{l}\text { 'Bountiful' } \times \text { 'Pink Panda' hybrid crosses } \\
\text { made by Chad Finn (progeny \#1-\#40) and } \\
\text { by T. M. Davis (progeny \#41-201) }\end{array}$ \\
\hline
\end{tabular}




\section{Maintenance of Germplasm}

All of the germplasm was maintained in the UNH greenhouses. In addition, the octoploids were planted at the UNH Woodman Horticultural Farm.

\section{Experimental Design and Statistical Analysis of Data}

An observational unit (replicate) consisted of a sample of fruit from a single pot (in the greenhouse), or a single plot (in the field), containing one or more plants that had been clonally propagated from an original source plant. For each replicate sample, one to five berries were harvested and pooled. The replicates were collected over one to three seasons. In addition to the individual accessions maintained in pots in the greenhouse, field plots (Appendix A) were established, one plot for each of the Supercore Collection accessions (Figure A.1), four plots for each cultivar (Figure A.2), and one plot for each of the B-PP accessions as well as for Bountiful (B) and Pink Panda (PP) (Figure A.3).

A field plot consisted of a section of row where a clone was allowed to propagate itself by runners. Plots were spaced 4' on center within the row. Replication consisted of repeat sampling (on the same or different dates) of the same plot, or pot, and/or sampling of different plots of the same variety (on the same or different dates). Each plot of the Supercore Collection initially consisted of five crowns. Each plot of the cultivars initially consisted of one crown. Each plot of $B \times P P F_{1}$ progeny and associated parents initially consisted of a division of crowns from one 12" pot. In the context of data analysis by ANOVA (analysis of variance), individual accessions were considered treatments. The plant germplasm collections; Fragaria diploids, octoploids $(F . \times$ ananassa) cultivars, 
octoploid 'Supercores', and the B-PP accessions including 'Bountiful' and 'Pink Panda', were considered as separate treatment groups in the statistical analysis of the data.

Anthocyanidin content in the fruit of each accession was calculated as the average of assay results of two or more replicate samples, unless otherwise noted. Systat $\otimes 10$ (SPSS Inc) was used to analyze the data. For each plant accession, the Standard Error of the Mean (SE) was taken as the square root of the Mean Square for Error (ME) of the respective treatment group divided by the number of replicate samples of the particular accession. Analysis of variance with Fisher test (F-ratio) and probability $(\mathrm{P})$ were used to test hypotheses, and Tukey® tests were used to check within-group pairwise differences. In addition, ANOVA using SYSTAT@ 10 was employed to test results for similarity between harvest locations (greenhouse versus field), and to test for similarity between analytical methods used in investigation Phases 1, 2, and 3 (see below).

\section{Phases of Investigation}

The methodology for extracting and analyzing the anthocyanidins was developed incrementally as real samples were assayed. The data obtained during the initial methods development Phase of the study are referred to as "Phase 1 and Phase 2" data. Data obtained after the final methodology had been

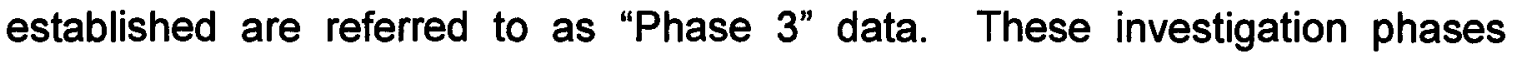
differed with respect to HPLC sample injection volume and/or to centrifuge speed, as detailed subsequently. The ANOVA results on comparison of methods were used to determine whether normalization factors would be required to 
enable the combining of Phase 1, Phase 2, and Phase 3 data in the same statistical analysis.

\section{Fruit Sample Collection and Preservation}

The fruit was harvested at 'peak' ripeness firm-ripe stage (Wang and Camp, 2000) or 'commercially ripe stage' (Wang et al., 2003), with the exception of fruit harvested earlier for the degree of ripeness study. Harvested fruit were carefully handled in preparation for the HPLC analysis. Fruit samples of strawberry fruit were harvested into labeled zip-lock bags and placed on ice in a cooler. Subsequently, within 1 to 2 hours, each zip-lock bag was individually removed from the cooler, the sample was removed from the bag and weighed in a labeled weigh boat, and the fruit-containing weigh boat was re-inserted into the original zip-lock bag. The fruit was then squashed by pressing the fruit into the weigh boat from outside of the zip-lock bag, in order to expose more tissue surface area so as to facilitate the subsequent freeze drying process. Each ziplock bag containing squashed fruit in a weigh boat was then placed on ice in a cooler. Once all of the collected fruit in the zip-lock bags had been weighed and squashed, the samples were transferred from the cooler to a $-80^{\circ} \mathrm{C}$ freezer.

The frozen fruit was lyophilized (Nyman and Kumpulainen, 2001; Wang et al., 2003) to minimize the water content, and then stored at $-80^{\circ} \mathrm{C}$ (Wang et al., 2003), as opposed to the $-18^{\circ} \mathrm{C}$ temperature used by Nyman and Kumpulainen (2001). Just prior to freeze drying, fruit samples were taken out of the $-80^{\circ} \mathrm{C}$ freezer and pre-conditioned at $-20^{\circ} \mathrm{C}$ for 1 to 2 hours. The samples were then freeze dried under vacuum at 0.20 to 0.25 mbars with a condenser temperature 
of $-60^{\circ} \mathrm{C}$ to $-80^{\circ} \mathrm{C}$ for 48 hours and without the use of a heat plate, so as to minimize any loss of quality as studied by Shishehgarha et al.(2002). The lyophilized samples were weighed to provide dry weight values and returned to storage at $-80^{\circ} \mathrm{C}$. The lyophilized samples were stored at $-80^{\circ} \mathrm{C}$ for an indefinite amount of time ranging from a day to months.

\section{Fruit Sample Preparation for Anthocyanidin Assay}

\section{Hydrolysis of Anthocyanins}

The lyophilized fruit was pulverized (Wang et al., 2003) to achieve a uniform composite sample (Phases 2 and 3). The acid hydrolysis process was performed using aqueous $2 \mathrm{~N} \mathrm{HCl}$ (Durst and Wrolstad, 2001), as opposed to the use of $2 \mathrm{~N} \mathrm{HCl}$ in methanol (Nyman and Kumpulainen, 2001), to avoid use of highly hazardous methanol at elevated temperatures and in proximity to nonexplosion proof electrical devices. Each $0.5 \mathrm{~g}$ sample of lyophilized strawberry fruit was mixed with $7 \mathrm{ml}$ of $2 \mathrm{~N} \mathrm{HCl}$ in a $12 \mathrm{ml}$ glass tube (Phases 1 and 2), or in a $15 \mathrm{ml}$ polypropylene centrifuge tube (Phase 3) (WWR SuperClear ${ }^{\mathrm{TM}}$ Catalog \#21008), hydrolyzed at $90^{\circ} \mathrm{C}$ for 50 minutes (Nyman and Kumpulainen, 2001) using a Fisher Scientific Dry Bath Incubator (Phases 1 and 2), or in a Nitrogen Evaporator ${ }^{\mathrm{TM}} 111$ (Organomation Associates, Inc) used as a hot water bath (Phase 3), and then cooled in a separate cold tap-water bath for 5 minutes. The hydrolyzed samples were spun for 20 minutes in a Damon IEC HN-3 centrifuge at $1200 \times \mathrm{xg}$ and room temperature (Phases 1 and 2), or in an Eppendorf 5804R centrifuge at $15,500 \mathrm{xg}$ and $4^{\circ} \mathrm{C}$ (Phase 3). The centrifuged samples were 
filtered, using syringe-adapted filter housings with F6801 Sigma-Aldrich $100 \mu \mathrm{m}$ mesh nylon fabric, to recover the liquid extract containing the anthocyanidins.

\section{Extraction of Anthocyanidins}

The procedure used to extract the anthocyanidins was patterned after those previously described (Rodriguez-Saona and Wrolstad, 2001; Wang and Lin, 2003; Wang et al., 2003), with modifications as indicated below. Sep-Pak ${ }^{\circledR}$ C18 cartridges (Waters Corp, Ireland) were activated with $2 \mathrm{ml}$ of $0.01 \% \mathrm{HCl}$ in methanol, but the additional rinses of deionized water (Rodriguez-Saona and Wrolstad, 2001; Wang et al., 2003) or formic acid (aqueous) (Wang et al., 2003) were not employed. Each supernatant sample was poured into a Sep-Pak ${ }^{\circledR} \mathrm{C} 18$ cartridge to bind the anthocyanidins, then the sugars and starches were eluted with $10 \mathrm{ml}$ of $3 \%$ formic acid (aqueous). The anthocyanidins and other phenolic compounds were recovered from the C18 Sep-Pak ${ }^{\circledR}$ cartridges with $2.5 \mathrm{ml}$ acidified methanol containing $0.01 \% \mathrm{HCl}$ (Rodriguez-Saona and Wrolstad, 2001), rather than 3\% formic acid in methanol (Wang et al., 2003), to minimize the handling of formic acid and the required number of stock solutions (Table B.1).

The recovered anthocyanidins were then filtered with a $0.2 \mu \mathrm{m}$ syringe filter, in lieu of the $0.45 \mu \mathrm{m}$ filter (Wang et al., 2003), to prolong the life of the HPLC separation column. Sample aliquot volumes of $750 \mu \mathrm{l}$ were transferred to $1.5 \mathrm{ml} \mathrm{HPLC}$ vials for analysis. In order to minimize decomposition of the anthocyanidins, the processed samples were immediately analyzed by HPLC, or held in a $-20^{\circ} \mathrm{C}$ freezer for up to 2 hours before warming to room temperature for 15 to 20 minutes before analysis by HPLC. The purified samples were stored at 
$-80^{\circ} \mathrm{C}$ according to Rodriguez-Saona and Wrolstad (2001), who recommended storage of purified samples at less than $-15^{\circ} \mathrm{C}$, preferably less at $-70^{\circ} \mathrm{C}$.

\section{High Performance Liquid Chromatography Method}

The separation and quantification of anthocyanidins were conducted following a modified protocol (Miyazawa et al., 1999) with a Hewlett Packard Series 1100 HPLC equipped with a Diode Array Detector. A reverse-phase Nova-Pak ${ }^{\boxplus}$ C18 column $150 \times 3.9 \mathrm{~mm}$ with $4 \mu \mathrm{m}$ particle size equipped with a Nova-Pak ${ }^{\circledR} \mathrm{C} 1820 \times 3.9 \mathrm{~mm}$ guard column (Waters Corp, Ireland) (Wang et al., 2003) was used for the separation of cyanidin and pelargonidin. Due to its smaller size (lower cost) and corresponding lower chemical and sample volume requirements, this configuration was preferred to a commonly used reversephase C18 $250 \times 4.6 \mathrm{~mm}$ ODS (Durst and Wrolstad, 2001; Miyazawa et al., 1999).

The photodiode array was set to scan the range of 240 to $570 \mathrm{~nm}$ with detection at 320, 350 and $528 \mathrm{~nm}$, similar to Wang et al. (2003), whose scan was set at 240 to $550 \mathrm{~nm}$ with detection at 320,350 and $510 \mathrm{~nm}$, as compared with single point detection at $520 \mathrm{~nm}$ (Durst and Wrolstad, 2001), or $532 \mathrm{~nm}$ (Miyazawa et al., 1999)

The temperature of the columns was maintained at $30^{\circ} \mathrm{C}$ to operate above fluctuations in the room temperature which might impact results, in contrast to the use of ambient temperature (Durst and Wrolstad, 2001), $20^{\circ} \mathrm{C}$ (Wang et al., 2003), or $40^{\circ} \mathrm{C}$ (Miyazawa et al., 1999). Cooling the column was not an option with the utilized HPLC system. 
The solvents chosen for mobile phases A and B were formic acid (aqueous) and 100\% methanol, respectively, (Miyazawa et al., 1999), in contrast to Wang et al.(2003) mobile phases A $2.5 \%$ formic acid (aq) and B (acetonitrile) or mobile phases $A$ (acetonitrile) and $B$ (10\% acetic acid, $5 \%$ acetonitrile, and $1 \%$ phosphoric acid) (Durst and Wrolstad, 2001) to coincide with the chemicals used in the sample preparation and thus minimize the variety of chemicals required.

The mobile phase $A$ concentration of formic acid was reduced to $0.3 \% \mathrm{v} / \mathrm{v}$ from 6.9\% v/v (1.5 molar )(Miyazawa et al., 1999) or from 2.5\% v/v (Wang et al., 2003) in order to minimize corrosion of the HPLC plumbing system and to extend the life of the column, as well as to minimize use of chemicals, while maintaining an acidic pH for pigment stability and maximum absorption (Cabrita et al., 2000). The mobile phase B methanol was diluted to $95 \% \mathrm{v} / \mathrm{v}$ to reduce gas bubbles in the column at the point of mixing of the two mobile phases.

Isocratic elution as opposed to gradient elution was chosen to maintain steady state and thus minimize the run cycle time to 15 minutes. The mobile phases were optimized to $52 \%$ as mobile phase $A$ ( $0.3 \%$ formic acid) and $48 \%$ as mobile phase B (95\% methanol) in contrast to (Miyazawa et al., 1999) compositions of $14 \%$ A containing $1.5 \mathrm{~mol} / / \mathrm{l}(6.9 \%)$ formic acid and $86 \%$ B (100\% methanol) and in contrast to gradient elution and alternative mobile phase solvents as described above (Wang et al., 2003). The mobile phase total flow was reduced to 0.7 from $1.5 \mathrm{ml} / \mathrm{min}$ (Miyazawa et al., 1999) based on the smaller column size and from $1.0 \mathrm{ml} / \mathrm{min}$ (Wang et al., 2003) based on sample peak shape. The initial volume of the sample injection was $20 \mu \mathrm{l}$ (Phase 1) in 
accordance with Wang et al.(2003) much less than the $50 \mu$ used by Durst and Wrolstad (2001) or $100 \mu$ by Miyazawa et al.(1999). The volume of the sample injections was later optimized to $5 \mu$ l (Phases 2 and 3) to reduce the load on the columns, with the intent of reducing the potential for overload and improve peak shape.

The prepared anthocyanidin samples, $20 \mu$ (Phase 1) or $5 \mu l$ (Phases 2 and 3), were auto-injected into an isocratic $0.7 \mathrm{ml} / \mathrm{min}$ elution stream containing $52 \%$ mobile phase A $(0.3 \%$ formic acid) and $48 \%$ mobile phase B $(95 \%$ methanol).

\section{Preparation of Anthocyanidin Standard Solutions}

Standard solutions needed for calibration of the HPLC for assays were prepared from concentrated master stock solutions. The master solutions were prepared by dissolving certified HPLC grade powder standards (Indofine Chemicals, Hillsborough NJ) of pelargonidin chloride and cyanidin chloride in acidified methanol $(0.01 \% \mathrm{HCl})$ to make master solutions. The master solutions were made at a concentration of $1000 \mu \mathrm{g} / \mathrm{g}$ in acidified methanol as follows: the powder standards were weighed (scale accuracy of four decimal places) and then the required amount of acidified methanol was used to police the powder standard into a dark colored vial. The required amount of acidified methanol was determined as follows:

$Y$ mls of methanol $=\underline{X}$ gms of powder standard $\times$ purity of standard (density of methanol $\times 1000 \mu \mathrm{g} / \mathrm{g}$ )

The purity of the powder standards was obtained from the certificates of analysis (COA).

- Pelargonidin $\mathrm{COA}=0.998$ 
- Cyanidin $\mathrm{COA}=0.972$

The density of methanol was obtained from the manufacturer's technical data sheet.

- Density of the methanol $=0.7875 \mathrm{~g} / \mathrm{ml}$

Standard solutions with concentrations of $10,50,90,100$, and $150 \mu \mathrm{g} / \mathrm{g}$ of cyanidin and pelargonidin chloride were each made directly from the master solutions For instance, to make a standard solution concentration of $10 \mu \mathrm{g} / \mathrm{g}$ of acidified methanol, $10 \mu \mathrm{l}$ of the master batch was added to $990 \mu \mathrm{l}$ of acidified methanol. Aliquots of the standard solutions were stored at $-20^{\circ} \mathrm{C}$.

Using freshly made standards, the HPLC was calibrated once during the course of Phase 1 data collection with $20 \mu \mathrm{l}$ sample injections. At the onset of Phase 2, the standard solutions previously used in the Phase 1 calibration and stored at $-20^{\circ} \mathrm{C}$ were assayed with $20 \mu \mathrm{l}$ and $5 \mu \mathrm{l}$ sample injections to develop a calibration curve for $5 \mu$ sample injections (Phases 2 and 3). The integrated HPLC absorbance areas at $5 \mu \mathrm{l}$ were correlated to concentrations determined from the $20 \mu$ injections. Aliquots of anthocyanidin extract of cultivar 'Jewel' fruit, prepared as described earlier and stored at $-80^{\circ} \mathrm{C}$, were used as an external standard for most of the assays in Phases 1 and 2, and for all assays in Phase 3, to assure run-to-run repeatability. Cyanidin and pelargonidin were identified by comparing the retention times of the standards with those of the strawberry fruit extract. 


\section{Stability of Anthocyanidin Standards and Mixtures}

The studies of the stability of anthocyanidin standard solutions at room temperature were conducted on freshly prepared and on cold stored standards and mixtures of standards to 1 ) determine if freshly prepared standard solutions could be preserved in cold storage and reused at a later time, and 2) to guide the establishment of time constraints for the HPLC analyses. Initially, freshly made standard solutions were used to prepare a set of mixtures containing varying concentrations and proportions of cyanidin chloride to pelargonidin chloride. Aliquots of each mixture were put into cold storage at $-80^{\circ} \mathrm{C}$, while samples of the freshly made mixtures were immediately assayed over a twenty-two hour period. In parallel, aliquots of the original cyanidin or pelargonidin standards were stored at $-20^{\circ} \mathrm{C}$. After one week in cold storage, these standard solutions were warmed to room temperature for one hour in preparation for analyses and then were repeatedly analyzed by HPLC over a twenty-four hour period. 


\section{CHAPTER 3}

\section{RESULTS}

Note: Anthocyanidin (anthocyanidin=anth, cyanidin=cyn, and pelargonidin=plr) content of fruits is reported as micrograms of pigment/gram freeze dry weight of fruit tissue $(\mu \mathrm{g} / \mathrm{g} F D W) \pm \mathrm{SE}$ (where SE = Standard Error of the Mean).

\section{Overview - Investigation Phases}

The methodology was developed in phases as real samples were assayed. In Phase 1,20 $\mu$ prepared samples were assayed by the HPLC. Beginning with Phase 2 and continuing thereafter, the volume of prepared samples assayed in the HPLC was reduced from 20 to $5 \mu$. In Phases 1 and 2, a centrifuge with a maximum speed of $1200 \mathrm{xg}$ was used to extract the pigments from the hydrolyzed samples. The solids were amorphous in the liquid extract and only about half of the supernatant was recovered. In Phases 2 and 3, the lypholized fruit tissue was pulverized with a mortar and pestle before hydrolysis to expose more anthocyanidin for hydrolysis and extraction. In Phase 3, a new centrifuge permitted spinning samples at $15500 \mathrm{xg}$, thus improving the recovery of the anthocyanidins. The solids were more clearly separated from the supernatant and were filtered out improving the recovery of the anthocyanidins. Accessions that were sampled during at least two of the three phases were compared in order to develop normalization factors to pool and compare the data 
from different phases for ANOVA of the treatment groups, as subsequently described.

\section{Methods Development}

\section{Fruit Samples}

Initially, none of the germplasm was planted at the horticultural farm, and so only fruit from accessions maintained in the greenhouse could be sampled. The Fragaria diploids were primarily maintained in the greenhouse, with only a few planted in the field during the first season. The Supercore Collection was obtained in mid-June of the second season and the runners were immediately rooted in pots in the greenhouse and then planted in the field in late July, and therefore fruit was not available until the third season. The cultivars were obtained and planted early in the second season and so fruit was available from these in both the second and third season. The greenhouse maintained B-PP accessions were divided and planted in the field during the first season and so

fruit obtained from these in the first and second season was available for sampling. In the third season, the B-PP field plants were less productive and fruit was more limited.

\section{Fruit Sample Preparation for Anthocyanidin Assay}

During the procedures of fruit harvesting, storage, lyophilizing, and freezing, all procedures went smoothly, and no noteworthy problems were encountered. There was no visible evidence of sample degradation during cold storage. 
When the anthocyanins in the lyophilized fruit were hydrolyzed and the anthocyanidins extracted, the only difficulty encountered was in the use of the Sep-Pak ${ }^{\circledR}$ C18 cartridges. A thorough activation of the cartridges, as evidenced by an almost translucent appearance of the $\mathrm{C} 18$ cartridge, was required, without which the anthocyanidins plugged the cartridge. An incompletely activated cartridge appeared opaque. In addition, the solids had to be filtered out of the hydrolyzed extract following the centrifugation step, to prevent plugging the Sep$\mathrm{Pak}^{\circledR} \mathrm{C} 18$ cartridges with solids. Filtering out the solids using a syringe-adapted filter housings with F6801 Sigma-Aldrich $100 \mu \mathrm{m}$ mesh nylon fabric provided the added benefit of a more complete recovery of the anthocyanidins; only solids with no visible liquid remained in the centrifuge tubes.

The extraction of the filtered anthocyanidin sample was successfully accomplished using Sep-Pak ${ }^{\circledast} \mathrm{C} 18$ cartridges that were activated with $2 \mathrm{ml}$ of $0.01 \% \mathrm{HCl}$ in methanol. There was no evidence of anthocyanidin loss in the liquid effluent, which was colorless.

\section{High Performance Liquid Chromatography for Anthocyanidin Assay}

The HPLC calibration was based on detection at the $528 \mathrm{~nm}$ wavelength, which was found to maximize the absorption of both cyanidin and pelargonidin (data not shown).

The laboratory room temperature varied considerably from about $18^{\circ} \mathrm{C}$ to $27^{\circ} \mathrm{C}$ over the 2 year period of the investigation. Therefore, with the temperature of the columns set at $30^{\circ} \mathrm{C}$, conservatively above the upper limit of room temperature range, possible variations in the results due to temperature 
fluctuation were avoided. Although a cooler temperature may have been better in terms of the impact on the stability of the anthocyanidins, heating was the only option with the available HPLC equipment

Using the chosen HPLC conditions, cycle time was 15 minutes (Figure 3.1), as compared to prior studies: 45 minutes (Miyazawa et al., 1999), or 32 minutes (Wang et al., 2003), or 25 minutes (Durst and Wrolstad, 2001). The chosen conditions also favored preservation of the initially purchased reverse column, which remained functional throughout the investigation and was used for all the assays.

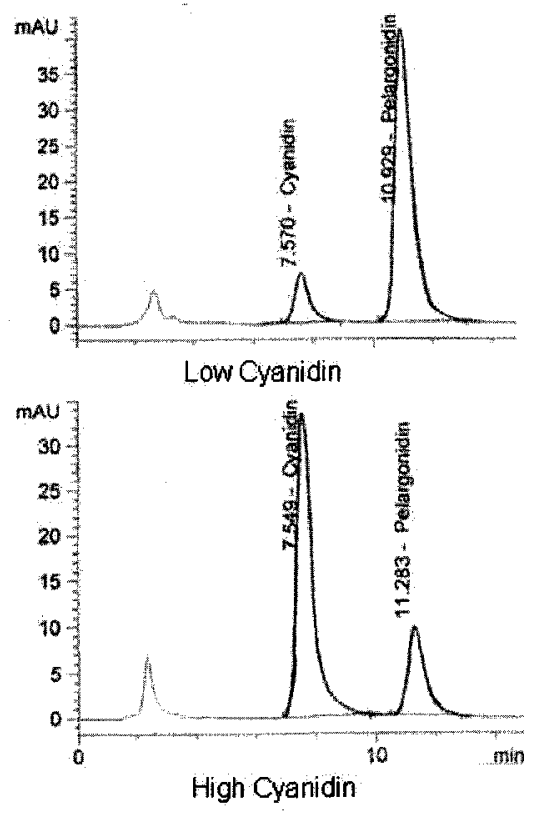

Figure 3.1 HPLC chromatograms.

Examples of typical chromatograms using 15 minute cycle time. Chromatograms of anthocyanidin extracts of fruit samples with absorption peak heights (mAU) and retention time (minutes) with high cyanidin and low pelargonidin (lower figure) and with low cyanidin and high pelargonidin contents (top figure). Cyanidin and pelargonidin contents are determined by comparing the integration of the area under the respective peaks to the calibration curve. 
Calibration of HPLC for Anthocyanidin Assay. An appropriate concentration range for the standards was selected by measuring absorption with a spectrophotometer and diluting the standards until the highest concentration had an Absorbance of less than 1 using a stand-alone spectrophotometer (Spectronic Genesys 5, Milton Roy).

The HPLC integrated absorption peak areas of cyanidin and pelargonidin standard solutions correlated linearly with concentration, with $R^{2}$ (multiple regression coefficient squared) of greater than 0.994 with both $20 \mu l$ sample injections (Phase 1), and $5 \mu$ l sample injections (Phases 2 and 3) (Figure 3.2).

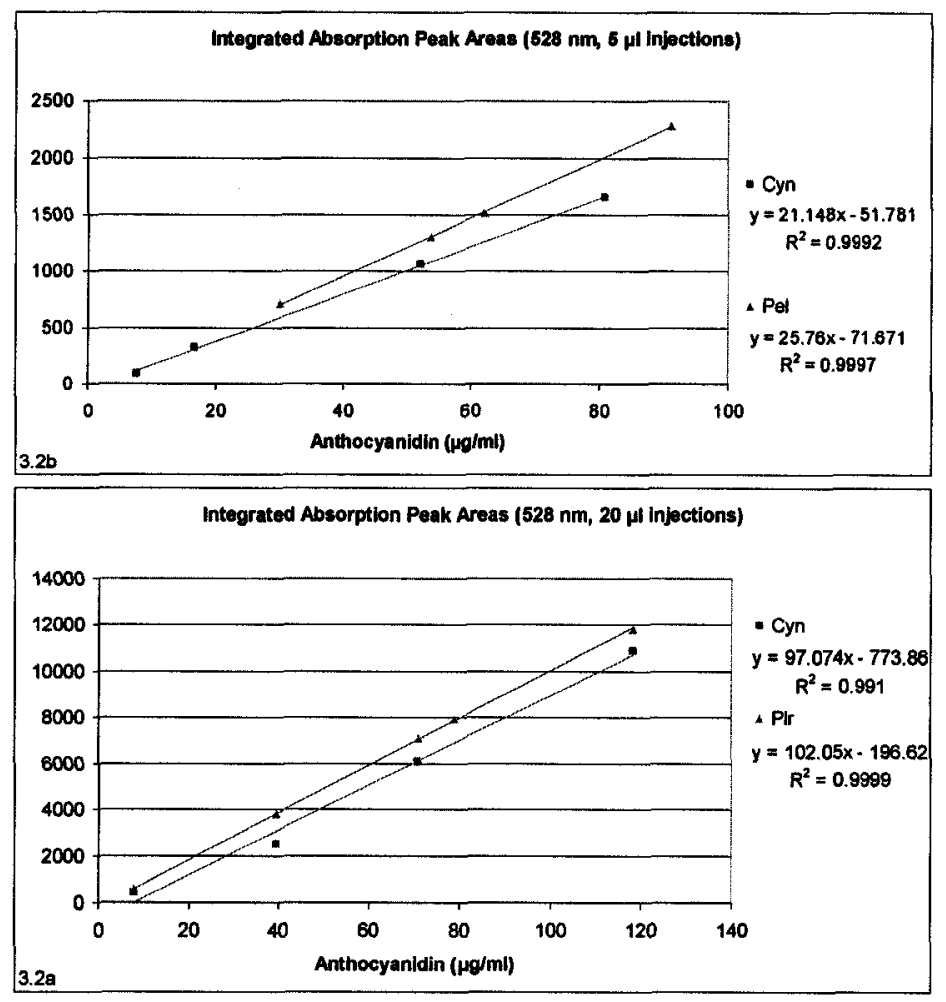

Figure 3.2: HPLC calibration with anthocyanidin standard solutions.

HPLC integrated peak absorption areas, at $528 \mathrm{~nm}$, with $20 \mu \mathrm{l}$ (Phase 1) and $5 \mu \mathrm{l}$ injections (Phases 2 and 3 ) of cyanidin chloride and pelargonidin chloride standard solutions $(\mu \mathrm{g} / \mathrm{ml}$ powder standard dissolved in acidified methanol, $0.01 \% \mathrm{HCl}$ ). Linear calibration equations have correlation coefficients of $\mathrm{R}^{2}$ $>0.99$. 
Stability of Anthocyanidin Standards and Mixtures. The stability of freshly made mixtures of pelargonidin and cyanidin standard solutions was tested at room temperature over time. Slight increases in concentration were observed for each component, with the exception of the cyanidin content in the $[C y n]_{0}=51.9$ $:[P e \mid]_{0}=9.0$ mixture, which decreased slightly in the first eleven hours of the twenty-two hour test (Figure 3.3a and 3.3b). An ANOVA (Table 3.1) of the data from the first eleven hours indicated that at the higher and lower ranges of concentration, [Cyn] and [PIr] responded similarly to time and that neither [Cyn] nor [PIr] changed significantly over this time period. However, a linear regression of concentration with time indicated that concentrations were increasing slightly over time at the lower concentration range, but with low $R^{2}=0.286$ and $R^{2}=0.434$ for cyanidin and pelargonidin, respectively. In contrast, at the higher range, cyanidin and pelargonidin concentrations were not changing significantly over time, with even lower respective $R^{2}=0.004$ and $R^{2}=0.022$. Following one week of cold storage, the concentrations of the standard solutions and mixtures were initially equivalent to their respective original, pre-storage concentrations, as shown in a t-test pairwise comparison of the data (Table 3.2). However, over the subsequent twenty-four hour period at room temperature, the concentrations of both [Cyn] and [PIr] of the previously cold stored standard solutions and mixtures declined, and the rate of decline increased with the concentration of the starting solution and with time (Figure 3.4a-c). In another comparison of freshly made standards containing comparable concentrations (Figure 3.5), but made at 
different times, with one set stored at $-20^{\circ} \mathrm{C}$ and the other set stored at $-80^{\circ} \mathrm{C}$, the rate of loss at room temperature over twenty-four hours was higher with the standards stored for one week at $-80^{\circ} \mathrm{C}$ as compared to six weeks at $-20^{\circ} \mathrm{C}$.

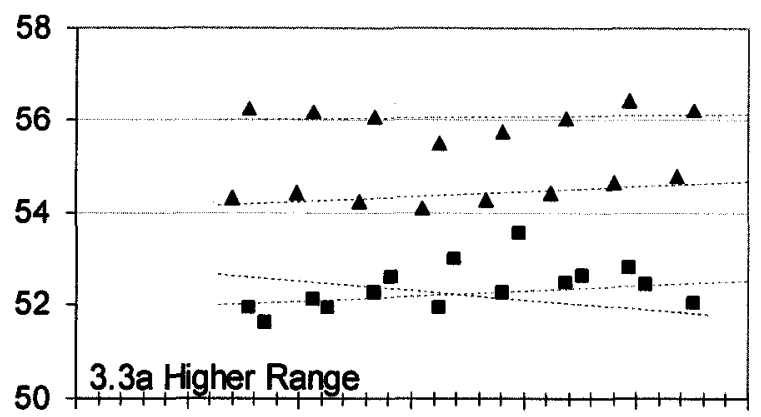

Anthocyanidin $(\mu \mathrm{g} / \mathrm{ml})$

- .... [Cyn] in [Cyn]o=51.6:[PIr]o=9.0

- $[$ Cyn $]$ in $[$ Cyn $] 0=51.9:[P I r] 0=56.2$

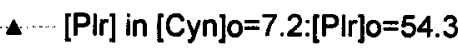

A. $[\mathrm{PIr}]$ in $[$ Cyn $] 0=51.9:[\mathrm{PIr}] \mathrm{o}=56.2$

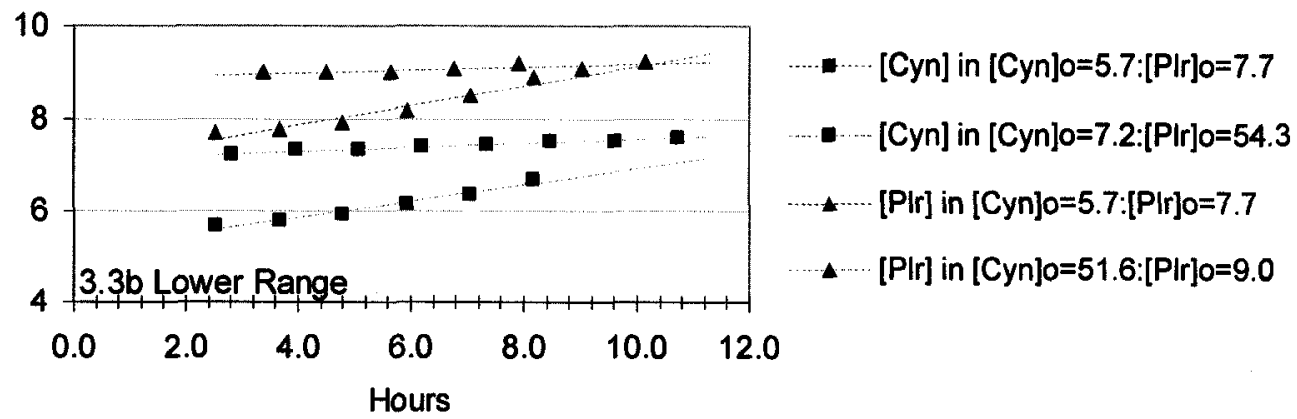

Figure 3.3 Stability of freshly made mixed (Cyn and PIr) anthocyanidin mixtures.

Mixtures containing standard solutions were prepared at two levels of concentration $(\mu \mathrm{g} / \mathrm{ml})$ of cyanidin (Cyn) and pelargonidin (PIr) in four combinations. Initial concentrations are indicated as cyanidin [Cyn], pelargonidin [PIr]o. figure legend. Concentrations were measured at the indicated time points in a period of 11 hours. 
Table 3.1 Anthocyanidin content of mixtures of freshly made standard solutions at room temperature.

Mixtures containing standard solutions were prepared at two levels of concentration of pelargonidin [PIr] and cyanidin [Cyn] in four combinations of lower [Cyn $]_{L}$ and $[\mathrm{PIr}]_{L}$ range and higher $[\mathrm{Cyn}]_{H}$ and $[\mathrm{PIr}]_{H}$ ranges. Provided are initial values for concentrations of Cyn, PIr, and Anth (Cyn + PIr), along with means over a period of 11 hours and SE, followed by ANOVAs and linear regressions on the data set.

\begin{tabular}{|c|c|c|c|c|c|c|c|c|c|c|c|}
\hline \multirow{3}{*}{$\begin{array}{l}\text { Mixtures } \\
\text { Ranges }\end{array}$} & \multirow{3}{*}{$\mathbf{N}$} & \multicolumn{10}{|c|}{ Anthocyanins ( $\mu \mathrm{g} / \mathrm{ml})$} \\
\hline & & \multirow{2}{*}{\multicolumn{3}{|c|}{$\begin{array}{l}\text { Initial } \\
\text { [PIr] [Anth] }\end{array}$}} & \multicolumn{4}{|c|}{ Mean } & \\
\hline & & & & & & [Cyn] & [PIr] & [Anth] & [Cyn] & $\begin{array}{l}\text { SE } \\
{[\mathrm{P} \mid \mathrm{r}]}\end{array}$ & [Anth] \\
\hline$[\mathrm{Cyn}]_{L} /[\mathrm{PIr}]_{L}$ & 6 & 5.7 & 7.7 & 13. & & 6.10 & 8.17 & 14.27 & 0.157 & 0.189 & 0.349 \\
\hline$\left.[\text { Cyn }]_{H} / \mathrm{P} / r\right]_{L}$ & 8 & 51.6 & 9.0 & 60. & & 52.19 & 9.10 & 61.31 & 0.405 & 0.033 & 0.396 \\
\hline$[\text { Cyn }]_{L} /[\mathrm{PIr}]_{H}$ & 8 & 7.2 & 54.3 & 61. & & 7.42 & 54.40 & & 0.045 & 0.076 & 0.112 \\
\hline $\begin{array}{l}\left.[\text { Cyn }]_{H} / \mathrm{PIr}\right]_{H} \\
\text { Combined }\end{array}$ & 8 & 51.9 & 56.2 & 107 & & 52.24 & 56.04 & 108.28 & 0.108 & 0.105 & 0.177 \\
\hline$\left.\overline{[C y n]_{L} \&[P \mid r}\right]_{L}$ & 14 & & & & & 6.86 & 8.70 & 15.56 & 0.194 & 0.150 & 0.280 \\
\hline$[\mathrm{Cyn}]_{\mathrm{H}} \&[\mathrm{Plr}]_{\mathrm{H}}$ & 16 & & & & & 52.21 & 55.22 & 107.43 & 0.202 & 0.220 & 0.262 \\
\hline \multicolumn{12}{|c|}{ ANOVA $(\mathrm{N}=30)$ Low and High Range } \\
\hline $\begin{array}{l}\text { Dependent } \\
\text { Variable }\end{array}$ & \multicolumn{4}{|c|}{ Source } & \multicolumn{2}{|r|}{ df } & SS & \multicolumn{2}{|l|}{ MS } & F-ratio & $\mathbf{P}$ \\
\hline [Cyn] & \multicolumn{4}{|c|}{ Hours } & 1 & & 0.85 & 0.85 & & 1.5 & 0.231 \\
\hline $\mathrm{R}^{2}=0.999$ & & yn leve & & & 1 & & 2008 & 2008 & & 549 & 0.000 \\
\hline & & yn leve & $\mathrm{el} \times \mathrm{Ho}$ & ours & 1 & & 1.41 & 1.41 & & 2.5 & 0.127 \\
\hline & & rror & & & 2 & & 14.7 & 0.6 & & & \\
\hline [PIr] & & ours & & & 1 & & 1.76 & 1.76 & & 3.3 & 0.080 \\
\hline & & r level & & & 1 & & 2115 & 2115 & & 001 & 0.000 \\
\hline & & r level & $\times$ Hou & & 1 & & 0.4 & 0.4 & & 0.8 & 0.381 \\
\hline & & ror & & & 2 & & 13.7 & 0.5 & & & \\
\hline & & ear I & es & ion & & f prob & bility th & at slope 0 & of line $b=$ & & \\
\hline Mixture & $s(u$ & $\mathrm{a} / \mathrm{ml})$ & & $N$ & & & Syn & & Plr & Cyn & $1+P I r$ \\
\hline & & & & & & $\mathrm{R}^{2}$ & $P$ & $\mathrm{R}^{2}$ & $P$ & $\mathrm{R}^{2}$ & $P$ \\
\hline $\begin{array}{c}{[\text { Cyn] }} \\
{[\text { Cyn }} \\
{[\text { Cyn }]} \\
{[\text { Cyn] }} \\
\text { Combin }\end{array}$ & $\begin{array}{l}/[\mathrm{F} \\
/ \mathrm{F} \\
/[\mathrm{F} \\
/ \mathrm{F}\end{array}$ & $\begin{array}{l}\mathrm{Plr}]_{\mathrm{L}} \\
\mathrm{PIr}]_{\mathrm{L}} \\
\mathrm{P} \mathrm{Ir}]_{\mathrm{H}} \\
\mathrm{PIr}]_{\mathrm{H}} \\
\text { Ranges }\end{array}$ & & $\begin{array}{l}6 \\
8 \\
8 \\
8\end{array}$ & & $\begin{array}{l}0.946 \\
0.059 \\
0.913 \\
0.319\end{array}$ & $\begin{array}{l}0.001 \\
0.562 \\
0.000 \\
0.145\end{array}$ & $\begin{array}{l}0.938 \\
0.783 \\
0.466 \\
0.008\end{array}$ & $\begin{array}{l}0.001 \\
0.004 \\
0.062 \\
0.835\end{array}$ & $\begin{array}{ll} & 0.950 \\
& 0.021 \\
2 & 0.647 \\
2 & 0.140\end{array}$ & $\begin{array}{l}0.001 \\
0.734 \\
0.016 \\
0.360\end{array}$ \\
\hline $\begin{array}{l}{[\text { Cyn }]_{L}} \\
{[\text { Cyn }]_{H}}\end{array}$ & & $\begin{array}{l}{[\mathrm{Plr}]_{\mathrm{L}}} \\
{[\mathrm{PIr}]_{\mathrm{H}}}\end{array}$ & & $\begin{array}{l}14 \\
16\end{array}$ & & $\begin{array}{l}0.286 \\
0.00\end{array}$ & $\begin{array}{l}0.049 \\
0.813\end{array}$ & $\begin{array}{l}.434 \\
0.022 \\
\end{array}$ & $\begin{array}{r}0.010 \\
2 \quad 0.586 \\
\end{array}$ & & \\
\hline
\end{tabular}


Table 3.2 Anthocyanidin content of standard solutions and mixtures before and after cold storage.

Components consisted of standard solutions of cyanidin (Cyn) and pelargonidin (PIr) and mixtures of cyanidin and pelargonidin. HPLC results of concentration of fresh solutions $\left(\right.$ Conc $_{0}$ ) and of solutions following one week of cold storage $\left(\right.$ Conc $_{\mathrm{a}}$ ). HPLC results represented as concentration of $\mu \mathrm{g}$ anthocyanidin per $\mathrm{ml}$ acidified methanol $(0.01 \% \mathrm{HCl})$.

\begin{tabular}{|c|c|c|}
\hline \multicolumn{3}{|c|}{ Data used in $t$ test } \\
\hline Standard Solutions or Mixtures & Conc $_{o}(\mu \mathrm{g} / \mathrm{ml})$ & $\mathrm{Conc}_{\mathrm{a}}(\mu \mathrm{g} / \mathrm{ml})$ \\
\hline \multicolumn{3}{|l|}{ Cold Storage at $-20^{\circ} \mathrm{C}$} \\
\hline [Cyn] & 5.5 & 6.7 \\
\hline [Cyn] & 23.9 & 27.6 \\
\hline [Cyn] & 48.8 & 57.3 \\
\hline [Cyn] & 76.7 & 85.7 \\
\hline [PIr] & 8.7 & 9.6 \\
\hline [Plr] & 26.5 & 30.2 \\
\hline [PIr] & 63.3 & 72.8 \\
\hline [PIr] & 97.7 & 103.6 \\
\hline \multicolumn{3}{|l|}{ Cold Storage at $-80^{\circ} \mathrm{C}$} \\
\hline$[$ Cyn] in [Cyn]o=5.7:[PIr]o=7.7 & 5.7 & 5.8 \\
\hline$[$ Cyn] in $[$ Cyn $] 0=51.6:[P \mid r] 0=9.0$ & 51.6 & 49.5 \\
\hline$[$ Cyn] in $[$ Cyn $] o=7.2:[P \mid r] 0=54.3$ & 7.2 & 7.6 \\
\hline$[$ Cyn $]$ in $[$ Cyn $] 0=51.9:[P \mid r] 0=56.2$ & 51.9 & 51.3 \\
\hline$[\mathrm{PIr}]$ in $[\mathrm{Cyn}] \mathrm{o}=5.7:[\mathrm{PIr}] \mathrm{o}=7.7$ & 7.7 & 7.4 \\
\hline$[P \mid r]$ in $[$ Cyn]o $=51.6:[P I r] 0=9.0$ & 9.0 & 8.0 \\
\hline$[\mathrm{PIr}]$ in $[\mathrm{Cyn}] \mathrm{o}=7.2:[\mathrm{PIr}] \mathrm{o}=54.3$ & 54.3 & 51.8 \\
\hline$[P I r]$ in $[$ Cyn $] 0=51.9:[P I r] o=56.2$ & 56.3 & 50.4 \\
\hline
\end{tabular}




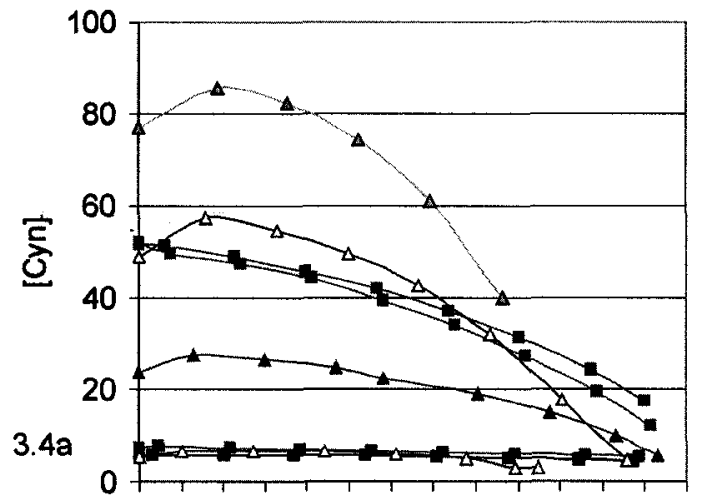

$\rightarrow-[$ Cyn] in [Cyn]o=5.7:[PIr]o=7.7

- $[$ Cyn] in [Cyn]o=51.6:[PIr]o=9.0

$\rightarrow-[$ Cyn] in [Cyn]o=7.2:[PIr]o=54.3

$-[$ [Cyn] in [Cyn]o=51.9:[PIr]o=56.2

$\triangle-[$ Cyn] in [Cyn]o=5.5

$\rightarrow[$ Cyn] in [Cyn]o=23.9

$\rightarrow-[$ Cyn $]$ in $[$ Cyn]o=48.8

$\triangle \quad[$ Cyn] in [Cyn]o=76.7

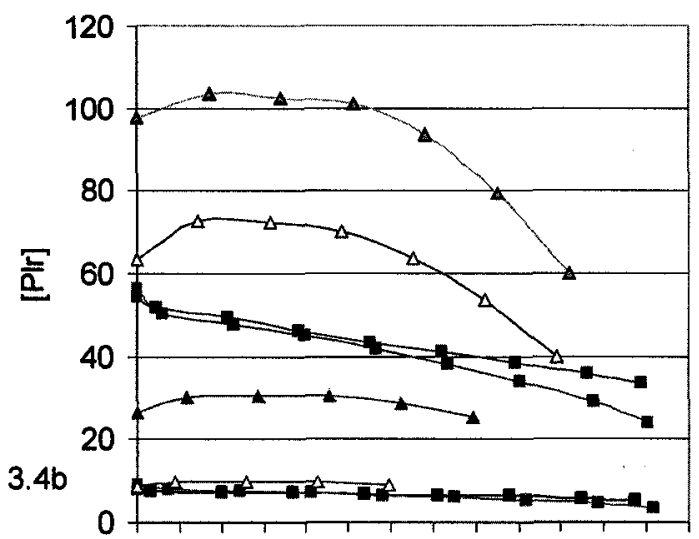

- $[\mathrm{PIr}]$ in [Cyn]o=5.7:[PIr $] 0=7.7$

$\rightarrow-[P I r]$ in $[$ Cyn $] 0=51.6:[P \mid r] 0=9.0$

$\rightarrow-[\mathrm{PIr}]$ in $[$ Cyn] $0=7.2:[\mathrm{PIr}] 0=54.3$

$\rightarrow-[P I r]$ in $[C y n] 0=51.9:[P \mid r] 0=56.2$

$\triangle-[\mathrm{PIr}]$ in $[\mathrm{PIr}] \mathrm{O}=8.7$

$-\downarrow[\mathrm{PIr}]$ in $[\mathrm{PIr}] \mathrm{O}=26.5$

$\triangle-[\mathrm{PIr}]$ in $[\mathrm{PIr}] 0=63.4$

4 [PIr] in [PIr]o=97.7

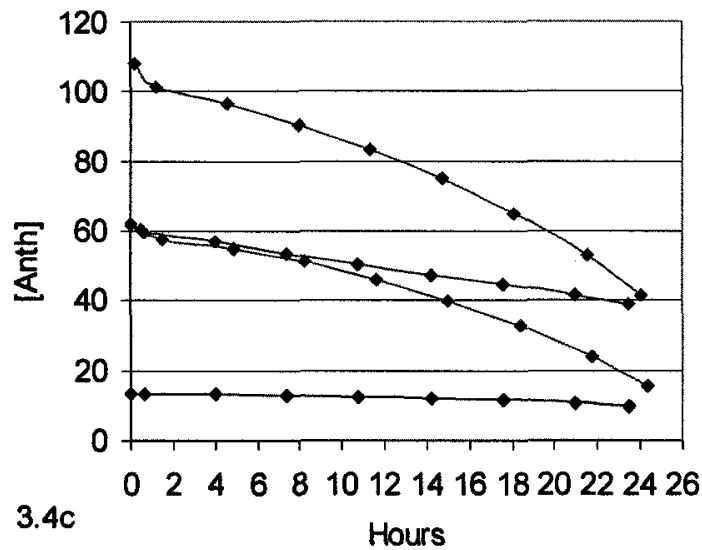

$\rightarrow$ [Anth] in [Antho]o=13.4 with $[$ Cyn]0 $=5.7:[\mathrm{PIr}] 0=7.7$

$\leftarrow$ [Anth] in [Antho]0 $=60.6$ with $[$ Cyn]0 $=51.6:[P \mid r] 0=9.0$

$\rightarrow[$ Antho] in [Antho]o=61.6 with $[$ Cyn $] 0=7.2:[P I r] 0=54.3$

$\rightarrow[$ Antho] in [Antho]o=108.2 with $[$ Cyn]0 $=51.9:[P \mid r] 0=56.2$

Figure 3.4a-c Stability of anthocyanidin standard solutions and mixtures following cold storage.

Concentrations $(\mu \mathrm{g} / \mathrm{ml})$ were measured at the indicated time points over a 26 hour period. Initial concentrations are indicated as cyanidin [Cyn], pelargonidin $[\mathrm{PIr}]_{0}$, and anthocyanins [Anth]o. The freshly made standard solutions were and mixtures were cold stored and then assayed at room temperature. Both solutions and mixtures were stored for one week prior to analysis; standard solutions of cyanidin or pelargonidin were stored at $-80^{\circ} \mathrm{C}$, while mixtures containing both cyanidin and pelargonidin were stored at $-20^{\circ} \mathrm{C}$. 


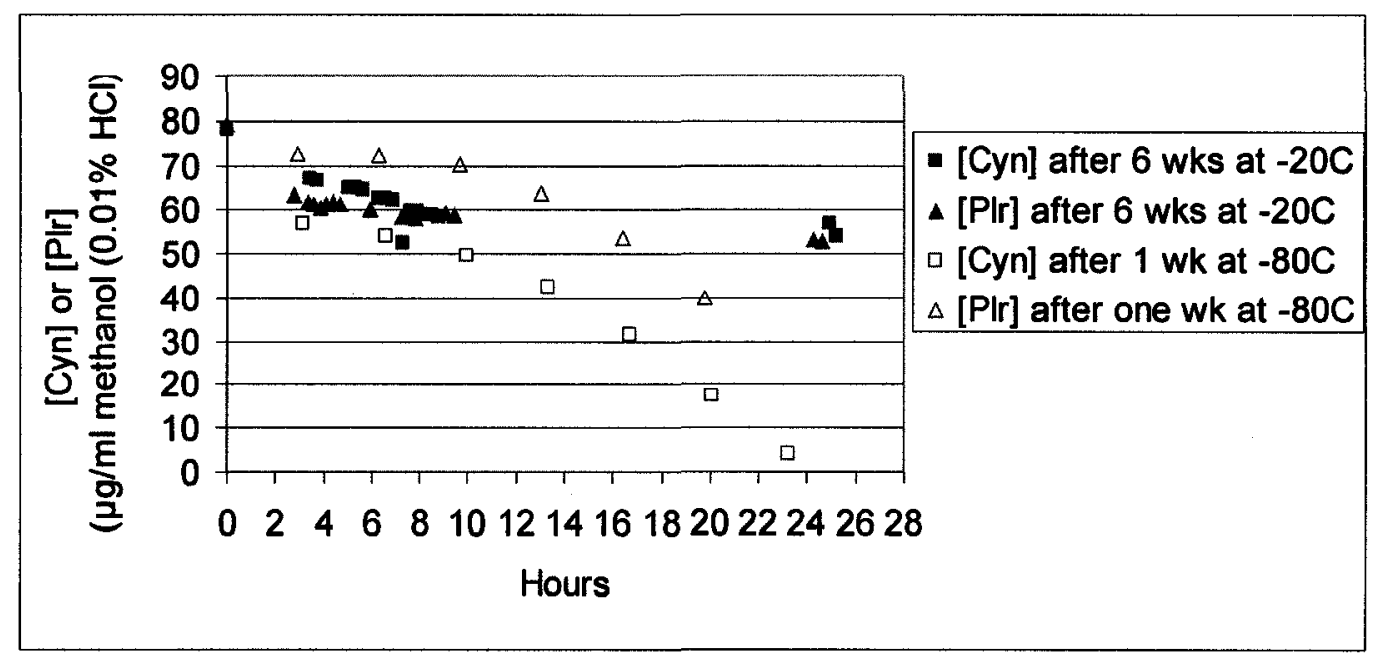

Figure 3.5 Stability standard solutions (Cyn and PIr) at room temperature following cold storage.

Two freshly made standard solutions were stored 1) at $-20^{\circ} \mathrm{C}$ for six weeks or 2) at $-80^{\circ} \mathrm{C}$ for one week, and then compared at room temperature over twenty-four hours.

Cultivar 'Jewel' fruit anthocyanidin extract was stable in storage at $-80^{\circ} \mathrm{C}$ over a three month test period, with respective average cyanidin and pelargonidin contents of 33.6 and $683.0 \mu \mathrm{g} / \mathrm{g}$ including two outliers (Table 3.3 and Figure 3.6), and was used for all Phase 3 assays as the external standard.

Table 3.3 Anthocyanidin content of cultivar 'Jewel' extract. Extract used as an external standard for three months.

\begin{tabular}{|c|c|c|c|c|c|c|}
\hline \multirow{3}{*}{\multicolumn{2}{|c|}{ 'Jewel' Extract }} & \multirow{3}{*}{$\begin{array}{c}\text { Number of } \\
\text { Analyses }\end{array}$} & \multicolumn{4}{|c|}{ Anthocyanidin $(\mu \mathrm{g} / \mathrm{g}$ FDW } \\
\hline & & & \multicolumn{2}{|c|}{ Means } & \multicolumn{2}{|c|}{ SE } \\
\hline & & & Cyn & PIr & Cyn & Plr \\
\hline Overall & & 15 & 33.6 & 683 & 0.5 & 12.5 \\
\hline \multicolumn{7}{|c|}{ ANOVA } \\
\hline $\begin{array}{l}\text { Dependent } \\
\text { Variable }\end{array}$ & Source & df & SS & MS & F-ratio & $\mathbf{P}$ \\
\hline Cyn & $\begin{array}{l}\text { Date } \\
\text { Error }\end{array}$ & $\begin{array}{c}12 \\
2\end{array}$ & $\begin{array}{c}39.1 \\
4.5\end{array}$ & $\begin{array}{l}3.26 \\
2.25\end{array}$ & 1.45 & 0.480 \\
\hline Plr & $\begin{array}{l}\text { Date } \\
\text { Error }\end{array}$ & $\begin{array}{c}12 \\
2\end{array}$ & $\begin{array}{c}31460 \\
1250\end{array}$ & $\begin{array}{c}2622 \\
625\end{array}$ & 4.2 & 0.208 \\
\hline
\end{tabular}




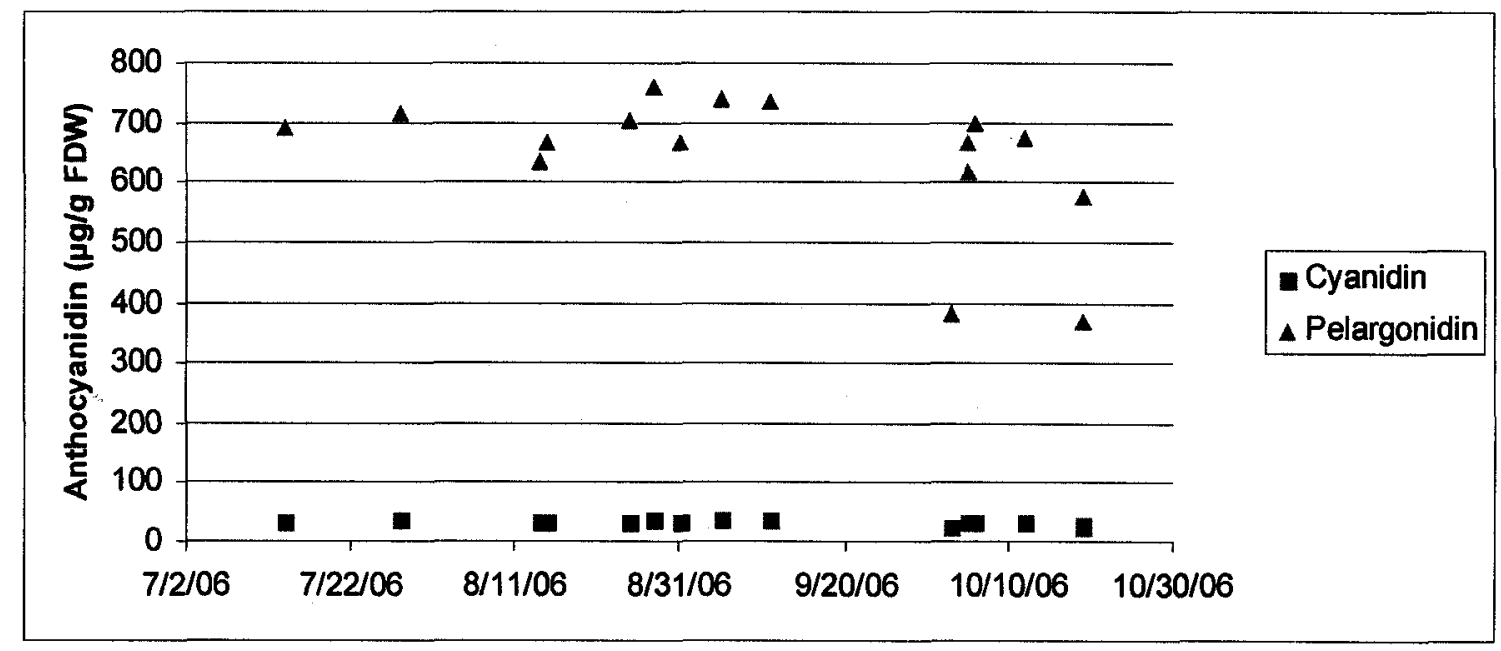

Figure 3.6: HPLC 'Jewel' cultivar external standard.

HPLC results $(\mu \mathrm{g} / \mathrm{g}$ FDW) of anthocyanidins extract of fruit from 'Jewel' cultivar used as an external standard. The external standard consisted of $100 \mu \mathrm{l}$ samples taken from extract aliquots stored at $-80^{\circ} \mathrm{C}$ for three months.

\section{Phases of Investigation}

Anthocyanidin Levels in Greenhouse and Field Fruit. In order to validate pooling of greenhouse $(\mathrm{GH})$ and field (HF) fruit in the comparison of data obtained using the different Phase protocols, fruit from nine accessions (Table C.1a and C.1b) obtained from both the $\mathrm{GH}$ and $\mathrm{HF}$ and analyzed using Phase 3 protocol were compared retrospectively. The average cyanidin content in the (GH) fruit was higher than in the (HF) fruit, $115 \mu \mathrm{g} / \mathrm{g}$ compared to $107 \mu \mathrm{g} / \mathrm{g}$ respectively, but the difference was not significant, $\mathrm{P}=0.545$ (Table 3.4 and Figure 3.7). The average pelargonidin content in fruit collected from the GH (559 $\mu \mathrm{g} / \mathrm{g})$ were also higher when compared to fruit collected from the HF $(371 \mu \mathrm{g} / \mathrm{g})$, and the difference was significant, $\mathrm{P}=0.004^{* *}$. The data consisted of thirty-four data points, twelve from the GH and twenty-two from the HF. From each environment, four B-PP accessions, four Supercore Collection accessions, and 
Table 3.4 Anthocyanidin content in greenhouse and horticultural field fruit. The same protocol was used on ripe fruit accessions from both the greenhouse (GH) and the horticultural field (HF). The mean represents the mean of the means of each accession and the SE $=\sqrt{ }(\mathrm{ME} /$ Number of Samples $)$. The accession sample data used in the statistical analysis is provided in Table C.1.

\begin{tabular}{|c|c|c|c|c|c|c|c|}
\hline \multirow{3}{*}{ Location } & \multirow{2}{*}{\multicolumn{3}{|c|}{ Number of }} & \multicolumn{4}{|c|}{ Anthocyanin ( $\mu \mathrm{g} / \mathrm{g}$ FDW) } \\
\hline & & & & \multirow{2}{*}{ Mean } & \multicolumn{3}{|c|}{ SE } \\
\hline & Samples & \multicolumn{2}{|c|}{ Accessions } & & {$[\mathrm{PIr}]$} & [Cyn] & [PIr] \\
\hline$\overline{\mathrm{GH}}$ & 12 & 9 & & 115 & 559 & & \\
\hline HF & 22 & 9 & & 107 & 371 & & \\
\hline Overall & 34 & 18 & & 111 & 465 & & \\
\hline \multicolumn{8}{|c|}{ Greenhouse versus Field Fruit ANOVA } \\
\hline \multirow[t]{9}{*}{$\begin{array}{l}\text { Dependen } \\
\text { Variable } \\
\end{array}$} & Sour & & df & SS & MS & F-ratio & $\mathbf{P}$ \\
\hline & [Cyn] & Location & 1 & 363 & 363 & 0.382 & 0.545 \\
\hline & & Accession & 8 & 108305 & 13538 & 14.234 & 0.000 \\
\hline & Loc & Accession & 8 & 3816 & 477 & 0.501 & 0.838 \\
\hline & & Error & 16 & 15218 & 951 & & \\
\hline & [PIr] & Location & 1 & 221816 & 221816 & 11.141 & $0.004^{\star \star}$ \\
\hline & & Accession & 9 & 789171 & 98646 & 4.954 & 0.003 \\
\hline & Loc & Accession & 9 & 258363 & 32295 & 1.622 & 0.195 \\
\hline & & Error & 16 & 318570 & 19911 & & \\
\hline \multirow[t]{4}{*}{ [Cyn]/([Cy } & $\pm[P \mid r])$ & Location & 1 & 0.004 & 0.004 & 1.799 & 0.199 \\
\hline & & Accession & 9 & 0.696 & 0.087 & 41.771 & 0.000 \\
\hline & LoC & Accession & 9 & 0.064 & 0.008 & 3.843 & 0.011 \\
\hline & & Error & 16 & 0.033 & 0.002 & & \\
\hline
\end{tabular}

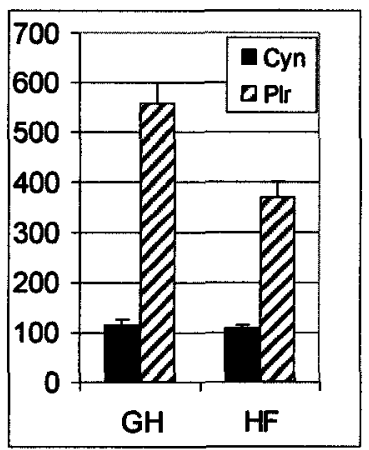

Figure 3.7 Comparison of anthocyanidin content in greenhouse and field fruit.

Mean values $\mu \mathrm{g} / \mathrm{g} F D W \pm S E(N=10)$ of fruit harvested from the two cultural methods. The differences between fruit harvested from the $\mathrm{GH}$ and $\mathrm{HF}$ were not significant for $(P=0.509)$ cyanidin, and significant $P=0.004^{* *}$ for pelargonidin). 
one cultivar accession, were tested under the Phase 3 conditions. The individual accessions responded similarly to the cultural method, $\mathrm{GH}$ or $\mathrm{HF}$, in both cyanidin $(P=0.838)$ and pelargonidin content $(P=0.195)$. Retrospectively, the data from the GH and HF data were pooled in the ANOVAs of fruit anthocyanidin content, notwithstanding the significant difference in pelargonidin content between the two cultural methods. The rationale for pooling the data was that 1 ) the difference in cyanidin content between $\mathrm{GH}$ and HF collected fruit samples were not significant, 2) the variability in the cyanidin content were much less than that of the pelargonidin content, and 3) the large variability in pelargonidin may be typical as found in the degree of ripeness study to be described following this Phases of Investigation section.

HPLC Results with Phase 1 and Phase 2 Methods. Anthocyanidin results using sample volumes of $20 \mu \mathrm{ll}$ (Phase 1) compared to $5 \mu l$ (Phase 2) injections differed significantly $\left(P=0.000^{\star *}\right.$ and $\left.P=0.002^{* *}\right)$ for both cyanidin and pelargonidin contents respectively (Table 3.5 and Figure 3.8). In Phase 2, with the $5 \mu$ injections, cyanidin and pelargonidin contents ( $\mu \mathrm{g} / \mathrm{g}$ FDW) averaged, respectively 44 and $250 \mu \mathrm{g} / \mathrm{g}$ FDW compared to 16 and $100 \mu \mathrm{g} / \mathrm{g}$ FDW (Table 3.5), with the $20 \mu$ injections (Phase 1). The data consisted of sixty data points, sixteen from the Phase 1 and forty-four from Phase 2 (Table C.2). From each phase, thirteen B-PP accessions were tested. All Phase 1 replicates were greenhouse fruit and all Phase 2 replicates were field fruit. In addition to the specific injection volume change in going from Phase 1 to Phase 2 protocol, during Phase 2 the fruit was ground using a mortar and pestle to expose more 
tissue to the anthocyanidin extraction and the time required to complete the samples was reduced by about one-half thus reducing the time and temperature exposure of the samples and resultant decomposition. These factors are more difficult to quantify, but combine to improve the effectiveness of the Phase 2 protocol.

HPLC Results with Phase 2 and Phase 3 Methods. A new centrifuge obtained during this study permitted the extraction of pigments from hydrolyzed fruit at 15,500 xg (Phase 3) versus the original 1,200 $\mathrm{xg}$ force (Phase 1 and Phase 2), which resulted in significantly different cyanidin and pelargonidin $\left(P=000^{* *}\right)$ contents (Table 3.6 and Figure 3.9). The data consisted of thirty-five data points, twenty-three from the Phase 2 and twelve from Phase 3 (Table C.3). From each phase, five B-PP and two cultivar accessions were tested. All of the samples were horticultural farm fruit. Of the replicated samples, five were B-PP, and two were cultivars. In addition to a new centrifuge obtained in Phase 3, the hydrolyzed samples were filtered to recover about twice the amount of pigment and the duration of sample preparation protocol was reduced by about an additional $25 \%$, thus reducing again the time temperature exposure of the samples.

Application of normalization factors. In the assay of cyanidin and pelargonidin contents respectively, the Phase 2 protocol was 2.75 and 2.50 times more effective than the Phase 1 protocol (Table 3.7). Phase 3 was 1.95 and 2.08 times (Table 3.7) more effective in the extraction of cyanidin and 
Table 3.5 Anthocyanidin results with Phase 1 and Phase 2 methods.

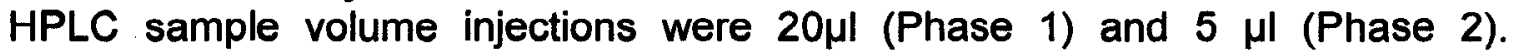
Samples were centrifuged at 1,200 $\mathrm{xg}$ in both Phase 1 and Phase 2. The mean is the mean of the means of each accession. SE $=\sqrt{ }(\mathrm{ME} /$ Number of Samples $)$. The accession sample data used in the statistical analysis is provided in Appendix C, Table C.2.

\begin{tabular}{|c|c|c|c|c|c|c|}
\hline \multirow{3}{*}{$\begin{array}{c}\text { Phase } \\
\text { (Injection Volume) } \\
(\mu \mathrm{l})\end{array}$} & \multirow{3}{*}{\multicolumn{2}{|c|}{ Number of }} & \multicolumn{4}{|c|}{ Anthocyanin $(\mu \mathrm{g} / \mathrm{g}$ FDW) } \\
\hline & & & \multicolumn{2}{|c|}{ Mean } & \multicolumn{2}{|c|}{ SE } \\
\hline & & & Cyn & Plr & Cyn & Plr \\
\hline & Samples & Accessions & & & & \\
\hline Phase $1(20)$ & 16 & 16 & 16 & 100 & 4.1 & 37 \\
\hline Phase $2(5)$ & 44 & 16 & 44 & 250 & 2.5 & 22 \\
\hline Overall & 60 & 32 & 30 & 175 & 2.1 & 19 \\
\hline \multicolumn{7}{|c|}{ Phase 1 and Phase 2 ANOVA } \\
\hline $\begin{array}{l}\text { Dependent } \\
\text { Variable }\end{array}$ & Source & df & SS & MS & F-ratio & $P$ \\
\hline \multirow[t]{4}{*}{ [Cyn] } & Phase & 1 & 8983 & 8983 & 32.989 & $0.000^{\star *}$ \\
\hline & Accession & 15 & 5233 & 349 & 1.281 & 0.277 \\
\hline & Phase $\times$ Accession & 15 & 1812 & 121 & 1.281 & 0.950 \\
\hline & Error & 28 & 7625 & 272 & 0.443 & \\
\hline \multirow[t]{4}{*}{ [Plr] } & Phase & 1 & 248716 & & 11.303 & $0.002^{* *}$ \\
\hline & Accession & 15 & 744277 & 49618 & 2.255 & $0.031^{*}$ \\
\hline & Phase $\times$ Accession & 15 & 120573 & 8038 & 0.365 & 0.978 \\
\hline & Error & 28 & 616178 & 22006 & & \\
\hline \multirow[t]{4}{*}{ Cyn]/[([Cyn]+[PIr]) } & Phase & 1 & 0.001 & 0.001 & 0.523 & 0.476 \\
\hline & Accession & 15 & 0.181 & 0.012 & 4.243 & 0.001 \\
\hline & Phase $\times$ Accession & 15 & 0.122 & 0.008 & 2.853 & 0.009 \\
\hline & Error & 28 & 0.077 & 0.003 & & \\
\hline
\end{tabular}

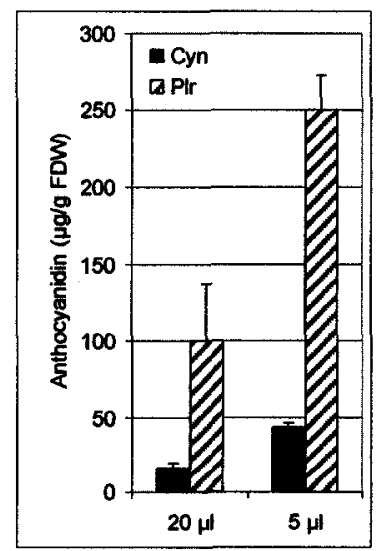

Figure 3.8 Anthocyanidin results with Phase 1 and Phase 2 methods. Cyanidin and pelargonidin ( $\mu \mathrm{g} / \mathrm{g}$ FDW $\pm \mathrm{SE}$ ) results were significantly different $\left(P=0.000^{* \star}\right.$ and $P=0.002^{* \star}$ respectively) with $20 \mu \mathrm{l}$ (Phase 1) and $5 \mu \mathrm{l}$ (Phase 2 injections. 
Table 3.6 Anthocyanidin results with Phase 2 and Phase 3 methods.

HPLC results of ripe fruit accessions using Phase 2 protocol $(1,200 \mathrm{xg})$ were compared to ripe fruit of the same accessions using Phase $3(15,500 \mathrm{xg})$. The represents the mean of the means of each accession and the $\mathrm{SE}=\sqrt{ }(\mathrm{ME} /$ Number of Samples). The accession sample data used in the statistical analysis is provided in Appendix C, Table C.3.

\begin{tabular}{|c|c|c|c|c|c|c|c|}
\hline \multirow{3}{*}{$\begin{array}{c}\text { Phase (Centrifuge) } \\
(\mathrm{xg})\end{array}$} & \multirow{2}{*}{\multicolumn{3}{|c|}{ Number of }} & \multicolumn{4}{|c|}{ Anthocyanin $(\mu \mathrm{g} / \mathrm{g}$ FDW $)$} \\
\hline & & & & \multicolumn{2}{|c|}{ Mean } & \multicolumn{2}{|c|}{$\overline{S E}$} \\
\hline & Samples & \multicolumn{2}{|c|}{ Accessions } & Cyn & PIr & Cyn & PIr \\
\hline Phase 2 & 23 & & 7 & 56 & 289 & 4 & 37 \\
\hline Phase 3 & 12 & & 7 & 109 & 600 & 6 & 51 \\
\hline Overall & 35 & & 7 & 76 & 426 & 3 & 30 \\
\hline \multicolumn{8}{|c|}{ Phase 2 and Phase 3 ANOVA } \\
\hline \multirow{5}{*}{$\begin{array}{l}\text { Dependent } \\
\text { Variable } \\
\text { [Cyn] }\end{array}$} & Source & $d f$ & SS & \multicolumn{2}{|c|}{ MS } & F-ratio & $P$ \\
\hline & Phase & 1 & 18312 & \multicolumn{2}{|c|}{18312} & 46.316 & $0.000^{* *}$ \\
\hline & Accession & 6 & 17265 & \multicolumn{2}{|c|}{2878} & 7.278 & $0.000^{\star *}$ \\
\hline & Phase $\times$ Accession & 6 & 4249 & \multicolumn{2}{|c|}{708} & 1.791 & 0.150 \\
\hline & Error & 21 & 8303 & \multicolumn{2}{|c|}{395} & & \\
\hline \multirow[t]{4}{*}{ [PIr] } & Phase & 1 & 628055 & \multicolumn{2}{|c|}{628055} & 20.459 & $0.000^{* *}$ \\
\hline & Accession & 6 & 88293 & \multicolumn{2}{|c|}{147132} & 4.793 & $0.003^{\star \star}$ \\
\hline & Phase $\times$ Accession & 6 & 320920 & \multicolumn{2}{|c|}{53487} & 1.742 & 0.160 \\
\hline & Error & 21 & 644652 & \multicolumn{2}{|c|}{30698} & & \\
\hline \multirow[t]{4}{*}[\text{Cyn]/[([Cyn]+[P|r]}]{)} & Phase & 1 & 0.002 & \multicolumn{2}{|c|}{0.002} & 0.552 & 0.466 \\
\hline & Accession & 6 & 0.068 & \multicolumn{2}{|c|}{0.011} & 3.658 & $0.012^{*}$ \\
\hline & Phase $\times$ Accession & 6 & 0.021 & \multicolumn{2}{|c|}{0.003} & 1.110 & 0.390 \\
\hline & Error & 21 & 0.065 & \multicolumn{2}{|c|}{0.003} & & \\
\hline
\end{tabular}

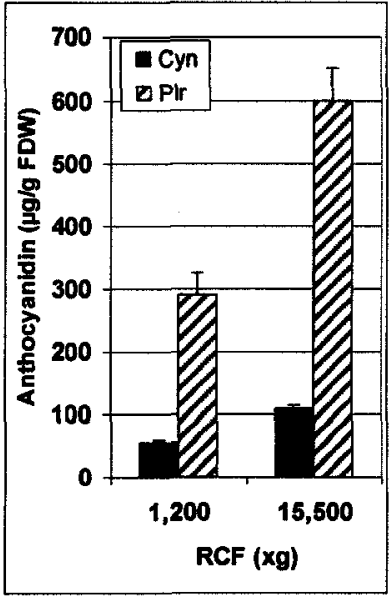

Figure 3.9 Anthocyanidin results with Phase 2 and Phase 3 methods.

Cyanidin and pelargonidin ( $\mu \mathrm{g} / \mathrm{g} \mathrm{FDW} \pm \mathrm{SE}$ ) results were significantly different for sample preparations made with centrifugal forces, at 1,200 $\mathrm{xg}$ (Phase 2) and $15,500 \times g$ (Phase 3), $\left(P=0.000^{* *}\right)$. 
pelargonidin respectively from the fruit compared to Phase 2. A conservative normalization factor of 1.90 was applied to both the cyanidin and pelargonidin results from Phase 2 to allow pooling of the Phase 2 and Phase 3 data. In order to pool the Phase 1 and Phase 3 data in the ANOVAs, an overall factor of 5.1 [(the application of the 2.7 factor (Phase 1 to Phase 2) multiplied by the1.9 normalization factor (Phase 2 to Phase 3)] was applied. Data affected by the normalization factors (Table 3.7) included sixteen out of the eighteen diploid samples (12 from Phase 1 and 4 from Phase 2), none of the Supercore Collection samples, ten out of the seventy-nine octoploid cultivars samples (none from Phase 1 and 10 from Phase 2), and ninety-one of the one hundred and fifty B-PP samples (34 from Phase 1 and 71 from Phase 2).

Anthocyanidin Content in Fruit at Different Degrees of Ripeness. In a pattern that applied across the germplasm (Table 3.8 and Figure 3.10), the cyanidin content was relatively constant $(P=0.971)$ and independent of degree of ripeness, while pelargonidin content continued to increase with increasing degree of ripeness treatment $\left(P=0.023^{*}\right)$. Each treatment included replicates of accessions including three accessions from the Supercore Collection (one $F$. chiloensis, and two F. virginiana), four cultivars, and one B-PP accession. Because the cyanidin and pelargonidin did not respond in the same manner to increasing ripeness, and because the pelargonidin varied in the $\mathrm{GH}$ and $\mathrm{HF}$ comparison, the absolute contents of cyanidin and pelargonidin were used in the ANOVA instead of a calculated ratio of cyanidin to pelargonidin as used in the early literature (Sondheimer and Karash, 1956). 
Table 3.7 Sample data affected by the three different protocols (Phases 1, 2 and 3) and summary of factors applied to the data.

Cyanidin and pelargonidin contents of Phase 1 and Phase 2 data normalized to Phase 3 data, in order to pool data in the ANOVAs. The number of accessions represented in each Phase is indicated in (parenthesis) following the number, $\mathbf{N}$, of fruit samples. The mean represents the mean of the means of each accession and the $S E=\sqrt{ }(M E /$ Number of Samples $)$.

\begin{tabular}{|c|c|c|c|c|c|c|}
\hline \multirow{2}{*}{\multicolumn{2}{|c|}{$\begin{array}{l}\text { Sample data distribution: } \\
\text {-Centrifuge force, } \mathrm{xg} \\
\text {-Sample injection volume, } \mu \mathrm{l}\end{array}$}} & \multicolumn{3}{|c|}{ Phase } & \multirow{2}{*}{\multicolumn{2}{|c|}{ Total }} \\
\hline & & $\begin{array}{c}1 \\
1,200 \\
20 \\
\end{array}$ & $\begin{array}{c}2 \\
1,200 \\
5 \\
\end{array}$ & $\begin{array}{c}3 \\
15,500 \\
5 \\
\end{array}$ & & \\
\hline \multicolumn{2}{|c|}{$\begin{array}{l}\text { Number of Samples: N } \\
\text {-Diploids } \\
\text {-Supercore Collection } \\
\text { - Octoploid Cultivars } \\
\text { - B-PP including B and PP }\end{array}$} & $34(32)$ & $\begin{array}{l}4(4) \\
10(4) \\
57(22) \\
\end{array}$ & $\begin{array}{r}2(2) \\
53(16) \\
69(12) \\
59(27) \\
\end{array}$ & \multicolumn{2}{|c|}{$\begin{array}{r}18(14) \\
53(16) \\
79(12) \\
150(45) \\
\end{array}$} \\
\hline \multicolumn{2}{|c|}{ Total number of samples } & $46(42)$ & $71(30)$ & $183(57)$ & \multicolumn{2}{|c|}{$300(87)$} \\
\hline \multicolumn{2}{|l|}{-Ripening Study } & & & $67(19)$ & \multicolumn{2}{|c|}{$67(19)$} \\
\hline \multirow{3}{*}{$\begin{array}{l}\text { Comparison of data } \\
\text { with method }\end{array}$} & \multirow{2}{*}{\multicolumn{2}{|c|}{ Number of }} & \multicolumn{4}{|c|}{ Anthocyanin ( $\mu \mathrm{g} / \mathrm{g}$ FDW) } \\
\hline & & & \multicolumn{2}{|c|}{ Mean } & \multicolumn{2}{|c|}{ SE } \\
\hline & Samples & Accessions & Cyn & Plr & Cyn & Plr \\
\hline Phase 1 & 16 & 16 & 16 & 100 & 4.1 & 37 \\
\hline $\begin{array}{c}\text { Phase } 2 \\
\text { Phase } 2 / \text { Phase } 1 \text { ratio } \\
\text { Phase } 1 \text { and } 2, P= \\
\end{array}$ & 46 & 16 & $\begin{array}{r}44 \\
2.75 \\
0.000^{\star \star} \\
\end{array}$ & $\begin{array}{c}250 \\
2.50 \\
0.002^{\star \star} \\
\end{array}$ & $\begin{array}{r}2.5 \\
\text { signific } \\
\end{array}$ & 22 \\
\hline $\begin{array}{l}\text { Phase 3/Phase } 2 \text { ratio } \\
\text { Phase } 2 \text { and } 3, P=\end{array}$ & $\begin{array}{l}23 \\
12\end{array}$ & $\begin{array}{l}7 \\
7\end{array}$ & $\begin{array}{c}56 \\
109 \\
1.95 \\
0.000^{\star \star} \\
\end{array}$ & $\begin{array}{c}289 \\
600 \\
2.08 \\
0.000^{\star \star} \\
\end{array}$ & $\begin{array}{r}4 \\
6 \\
\text { signific } \\
\end{array}$ & $\begin{array}{l}37 \\
51\end{array}$ \\
\hline $\begin{array}{l}\text { Summary of ratios }= \\
\text { normalization factors }\end{array}$ & Cyn & PIr & \multicolumn{2}{|c|}{$\begin{array}{c}\text { Applied } \\
\text { Cyn \& Plr factor }\end{array}$} & \multicolumn{2}{|c|}{$\begin{array}{c}\text { Normalization } \\
\text { Factor } \\
\text { to Phase } 3\end{array}$} \\
\hline Phase 2/Phase 1 ratio & 2.75 & 2.50 & \multicolumn{2}{|l|}{2.70} & \multicolumn{2}{|c|}{5.1} \\
\hline Phase 3/Phase 2 ratio & 1.95 & 2.08 & \multicolumn{2}{|l|}{1.90} & \multicolumn{2}{|c|}{1.9} \\
\hline \multicolumn{7}{|c|}{$\begin{array}{l}\text { Normalization factor: Normalization factor } x \text { data at Phase } 1 \text { or Phase } 2 \text { conditions }= \\
\text { Results normalized to Phase } 3 \text { conditions }\end{array}$} \\
\hline
\end{tabular}


Table 3.8 Anthocyanidin content in fruit with increasing degrees of ripeness.

Germplasm included three groups: Supercores (FRA372.002, 1408.001, and 1695.002), cultivars (Delmarvel, Jewel, Seneca, and Sparkle), and only one B-PP (B-PP-59). The three degrees of ripeness were under-ripe (UR), ripe (R), and over-ripe (OR). Anthocyanidin reported as mean values \pm SE $(\mu \mathrm{g} / \mathrm{g} F D W)$, where $S E=\sqrt{ }(M E / N), M E=$ Mean square for error of data set, and $N=$ number of samples at each level of ripeness of each group.

\begin{tabular}{|c|c|c|c|c|c|c|}
\hline \multirow{3}{*}{ Group } & \multirow{3}{*}{$\begin{array}{l}\text { Degree of } \\
\text { Ripeness }\end{array}$} & \multirow{3}{*}{$\mathrm{N}$} & \multicolumn{4}{|c|}{ Anthocyanin $(\mu \mathrm{g} / \mathrm{g}$ FDW $)$} \\
\hline & & & \multicolumn{2}{|c|}{ Means } & \multicolumn{2}{|c|}{$\mathrm{SE}$} \\
\hline & & & Cyn & PIr & Cyn & Plr \\
\hline \multirow[t]{3}{*}{ Supercores } & UR & 4 & 330 & 224 & 62 & 137 \\
\hline & $\mathrm{R}$ & 4 & 296 & 445 & 62 & 137 \\
\hline & OR & 3 & 199 & 444 & 72 & 158 \\
\hline \multirow[t]{3}{*}{ Cultivars } & UR & 6 & 46 & 164 & 51 & 112 \\
\hline & $\mathbf{R}$ & 7 & 54 & 538 & 47 & 103 \\
\hline & OR & 8 & 67 & 843 & 44 & 97 \\
\hline \multirow[t]{3}{*}{ B-PP } & UR & 1 & 101 & 212 & 124 & 273 \\
\hline & $\mathbf{R}$ & 1 & 111 & 373 & 124 & 273 \\
\hline & OR & 1 & 161 & 680 & 124 & 273 \\
\hline \multirow[t]{3}{*}{ Overall } & UR & 11 & 155 & 190 & 37 & 82 \\
\hline & $\mathbf{R}$ & 12 & 139 & 494 & 36 & 79 \\
\hline & OR & 12 & 108 & 730 & 36 & 79 \\
\hline \multicolumn{7}{|c|}{ Degree of Ripeness ANOVA $(N=35)$} \\
\hline $\begin{array}{l}\text { Dependent } \\
\text { Variable }\end{array}$ & Source & df & SS & MS & F-ratio & $\mathrm{p}$ \\
\hline \multirow[t]{4}{*}{ Cyn } & Ripeness & 2 & 916 & 458 & 0.03 & 0.971 \\
\hline & Group & 2 & 341610 & 170805 & 11.06 & 0.000 \\
\hline & Ripeness×Group & 4 & 31564 & 7891 & 0.51 & 0.728 \\
\hline & Error & 26 & 401523 & 15443 & & \\
\hline \multirow[t]{4}{*}{ PIr } & Ripeness & 2 & 653202 & 326601 & 4.38 & 0.023 \\
\hline & Group & 2 & 152693 & 76347 & 1.02 & 0.374 \\
\hline & Ripeness $\times$ Group & 4 & 258045 & 64511 & 0.86 & 0.498 \\
\hline & Error & 26 & 1941127 & 74659 & & \\
\hline
\end{tabular}




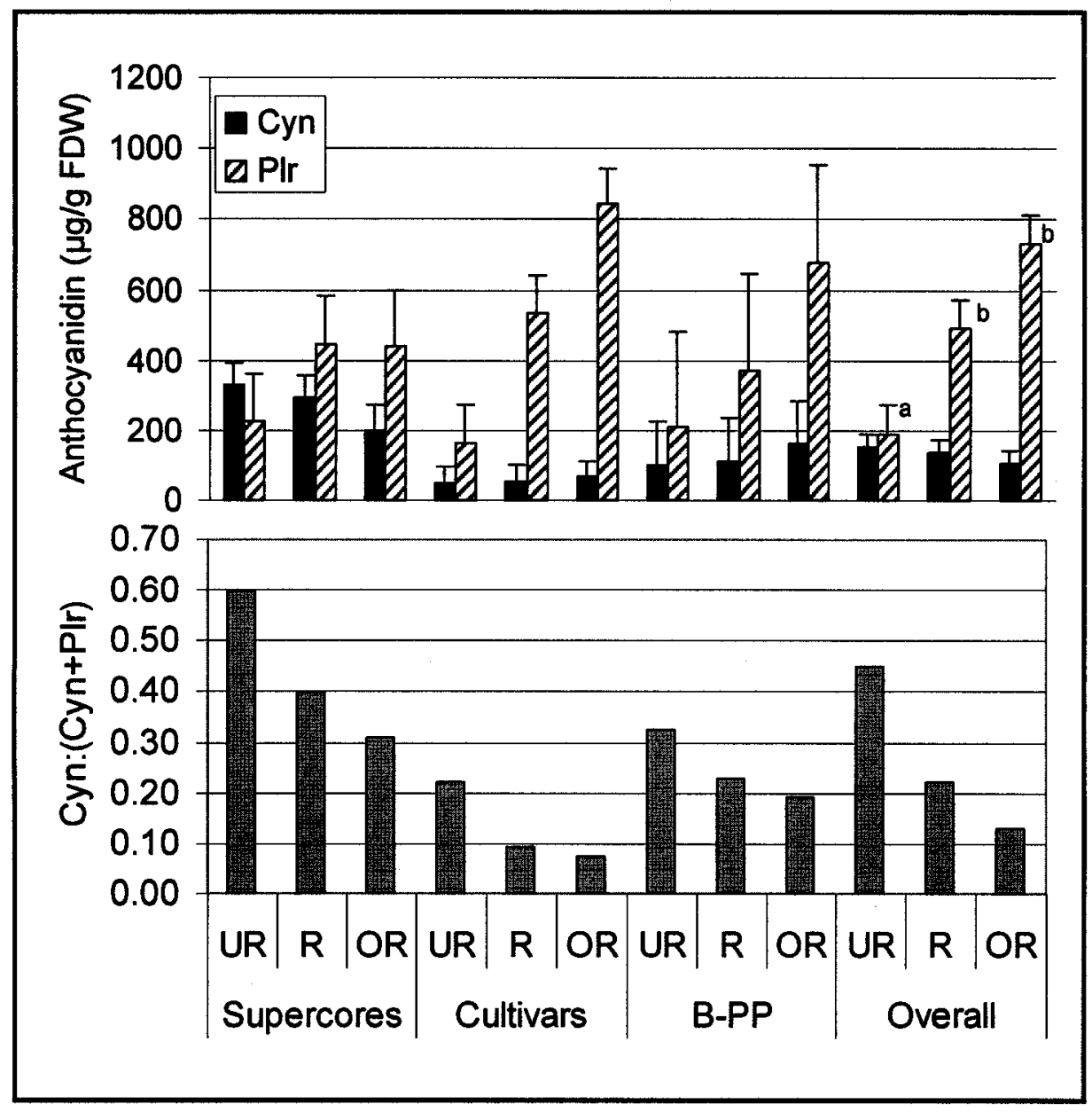

Figure 3.10 Anthocyanidin content in under-ripe, ripe, and over-ripe fruit. Cyanidin and pelargonidin expressed as mean values \pm SE ( $\mu \mathrm{g} / \mathrm{g} \mathrm{FDW})$, and the ratio of cyanidin to total anthocyanidins in under-ripe (UR), ripe (R), and over-ripe (OR) fruit. Accessions include: Supercore Collection FRA372.002, 1408.001, and 1695.002, Cultivars (Delmarvel, Jewel, Seneca, and Sparkle), and one B-PP (B-PP-59). The $S E=\sqrt{ }(M E / N)$ and $N=$ number of samples at each level of ripeness of each group. The three germplasm groups responded similarly to increasing ripeness $(P=0.728$ for cyanidin, $P=0.498$ for pelargonidin). Cyanidin content in under-ripe, ripe and over-ripe fruit do not differ $(P=0.971)$. Overall pelargonidin content in ripe and over-ripe fruit differ from under-ripe fruit (means without a common letter ( $a$ and $b$ ) differ significantly at $P=0.05$ ). The ratio of [Cyn] to [Cyn] and [PIr] show a decrease in the ratio with increasing degree of ripeness. 


\section{Anthocyanidin Content in Fruit}

\section{Fragaria Diploids}

Most of the diploid fruit samples (12 of the 18 samples) were assayed using the Phase 1 protocol (Table 3.9). The cyanidin and pelargonidin values in the accessions are provided with the normalization factors (Figure 3.11a) and without the normalization factors (Figure 3.11b). The ANOVA was completed with the data normalized to Phase 3 according to Table 3.7. The ANOVA of the diploid accession data showed significant variability in cyanidin values $\left(P=0.014^{*}\right)$, but the variability in pelargonidin values $(P=0.258)$ was not statistically significant (Table 3.9 and Figure 3.11). Replicate sampling was lacking with eight of the thirteen accessions and limited to two samples for the five remaining accessions. A wide range of ratios of cyanidin to total anthocyanidin and of anthocyanidin values ( $\mu \mathrm{g} / \mathrm{g} \mathrm{FDW} \pm \mathrm{SE}$ ) was observed among the Fragaria diploids. The [Cyn] to [PIr] ratio varied from 0.56 to 19.28 and the [Cyn] to [Anth] ratio varied from 0.359 to 0.951 . A reported [Cyn]:([Cyn]+[PIr]) ratio $\geq 0.5$ is equivalent to a ratio of $[\mathrm{Cyn}]:[\mathrm{PIr}] \geq 1.0$. The ratio of [Cyn] to [Anth] exceeded 0.5 for most accessions (10 out of 12 red fruited accessions). No anthocyanidins were detected in the yellow-fruited ' $\mathrm{YW}$ ' accession samples. In the red-fruited accessions, the cyanidin content values ranged from $122 \mu \mathrm{g} / \mathrm{g}$ in F. vesca 'BS' to $2805 \mu \mathrm{g} / \mathrm{g}$ in $F$. viridis $F_{1} D$, with an overall average of $792 \pm 86$ $\mu \mathrm{g} / \mathrm{g}$. The pelargonidin content values ranged from $109 \mu \mathrm{g} / \mathrm{g}$ in $F$. vesca $\times F$. viridis 'BQS37' to $912 \mu \mathrm{g} / \mathrm{g}$ in F. vesca spp. americana WC8 with an average of $425 \pm 72 \mu \mathrm{g} / \mathrm{g}$. 
Table 3.9 Anthocyanidin content in Fragaria diploids.

The [Cyn] and [PIr] and ratio of [Cyn] to [Cyn] and [PIr] along with the number of samples $(\mathrm{N})$ for each accession is provided. The accession mean represents the mean of the accession means including BQS Yellow. The data is shown with Phase normalization factors applied and Phase 1 data is highlighted in bold and underlined.

\begin{tabular}{|c|c|c|c|c|c|c|c|c|}
\hline & & & & & Anth & tocyani & $\operatorname{din}(\mu g / g F$ & $=\mathrm{DW}$ ) \\
\hline & Acces & sions & & $\mathbf{N}$ & [Cyn] & [PIr] & $\begin{array}{l}{[\text { Cyn]/ }} \\
{[\mathrm{Plr}]}\end{array}$ & $\begin{array}{l}\text { [Cyn]' } \\
\text { [Anth] }\end{array}$ \\
\hline F. vesca & & & & & & & & \\
\hline & BS & & & 2 & $\underline{328}$ & 447 & 0.73 & 0.423 \\
\hline & & & & & $\overline{122}$ & 195 & 0.62 & 0.384 \\
\hline & WC & & & 1 & 2111 & 912 & 2.31 & 0.698 \\
\hline & YW & $\times 520 \mathrm{~F} 1 \mathrm{C}$ & & 1 & $\underline{222}$ & 158 & 1.40 & 0.583 \\
\hline F. vesca $\times F$ & iridis ( & $\mathrm{W} \times \mathrm{CFRA3}$ & & & & & & \\
\hline & $B Q S$ & & & 1 & 147 & 109 & 1.35 & 0.574 \\
\hline & BQS & & & 1 & 211 & 378 & 0.56 & 0.359 \\
\hline & BQS & & & 1 & 325 & 242 & 1.34 & 0.573 \\
\hline & BQS & & & 2 & 423 & $\underline{274}$ & 1.18 & 0.607 \\
\hline & & & & & $1 \overline{132}$ & 960 & 1.54 & 0.541 \\
\hline & BQS & & & 2 & $\underline{769}$ & 447 & 1.72 & 0.632 \\
\hline & & & & & $1 \overline{1398}$ & 785 & 1.78 & 0.640 \\
\hline & BQS & & & 2 & $\overline{1093}$ & 961 & 1.53 & 0.532 \\
\hline & & & & & $\underline{1231}$ & $\underline{806}$ & 1.14 & 0.605 \\
\hline & $B Q S$ & & & 1 & 1335 & $\underline{509}$ & 2.62 & 0.724 \\
\hline & $B Q \$$ & Yellow & & 2 & $\underline{0}$ & $\underline{0}$ & NA & \\
\hline & & & & & $\underline{\mathbf{0}}$ & $\underline{0}$ & NA & \\
\hline E. viridis & & & & & & & & \\
\hline & $F_{1} D$ & & & 1 & 2805 & 146 & 19.28 & 0.951 \\
\hline F. iinum & & & & & & & & \\
\hline & $J-17$ & & & 1 & $\underline{599}$ & $\underline{320}$ & 1.87 & 0.652 \\
\hline Overall Acc & sion 1 & lean & & & 792 & 425 & & 0.591 \\
\hline Overall Sta & $\operatorname{ard} \mathrm{Er}$ & & & & 73 & 61 & & 0.007 \\
\hline & & & 10 & $(N=18)$ & & & & \\
\hline Dependent V & able & Source & df & SS & & MS & F-ratio & $\mathbf{P}$ \\
\hline [Cyn] & & $\begin{array}{l}\text { Accessions } \\
\text { Error }\end{array}$ & $\begin{array}{c}12 \\
5\end{array}$ & $\begin{array}{l}9762273 \\
479901\end{array}$ & & $\begin{array}{l}313523 \\
95980\end{array}$ & 8.48 & 0.014 \\
\hline [PIr] & & Accessions & 12 & 1489950 & & 124162 & 1.85 & 0.258 \\
\hline & & Error & 5 & 336184 & & 67237 & & \\
\hline [Cyn]/[Anth] & & Accessions & 11 & 0.294 & & 0.027 & 18.59 & 0.006 \\
\hline & & Error & 4 & 0.006 & & 0.001 & & \\
\hline
\end{tabular}




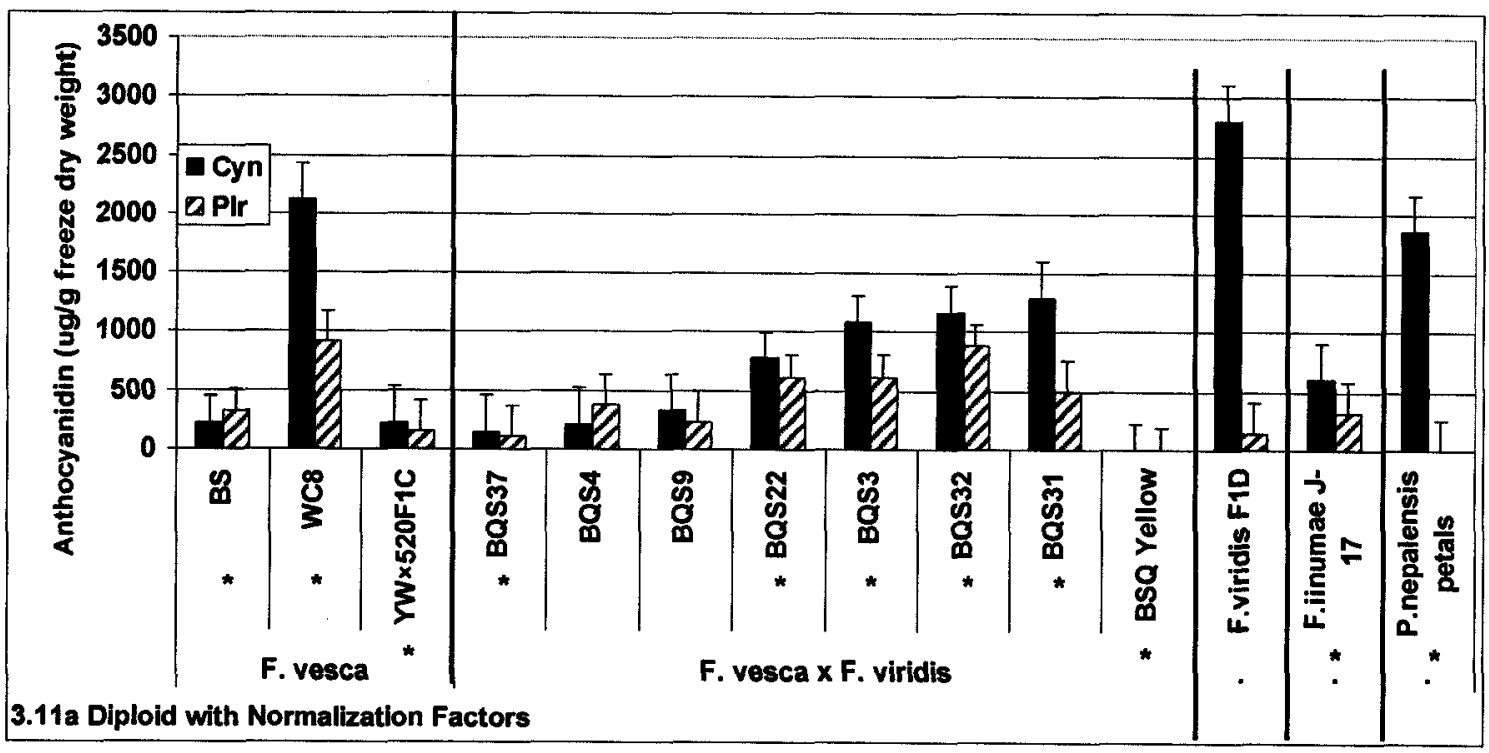

3.11a Diploid with Normalization Factors

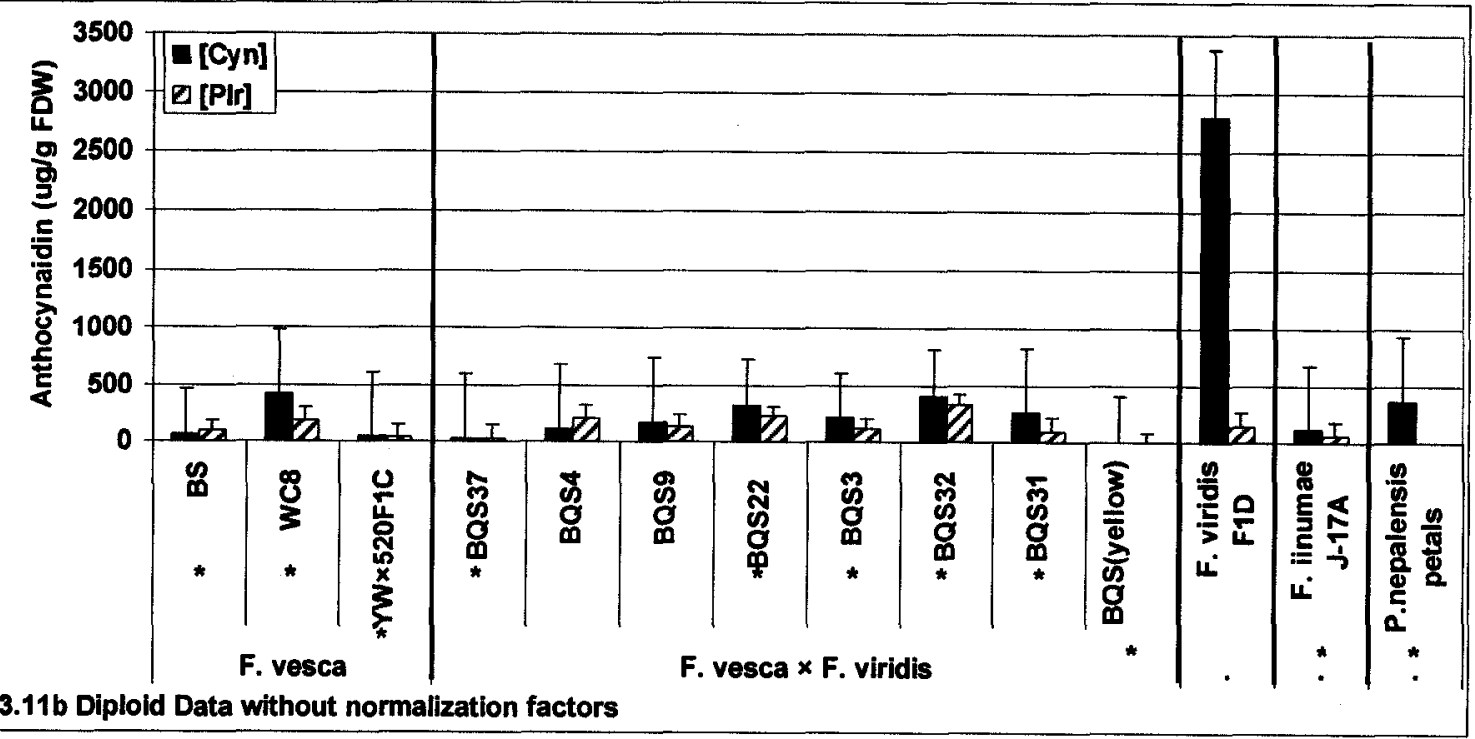

Figure 3.11 Anthocyanidin content in ripe fruit of Fragaria diploids.

Cyanidin and pelargonidin values $(\mu \mathrm{g} / \mathrm{g}$ FDW) show variability in cyanidin and insignificant variability in pelargonidin. Diploid Potentilla nepalensis flower petals contained only cyanidin, and were included for comparison. The accession data which include Phase 1 results are prefaced with an asterisk (*). Normalization factors that were applied to Phase 1 and Phase 2 data in Figure 3.11a were not applied to Figure 3.11b.

In the accessions of the BQS progeny population with red fruit, the cyanidin values ranged from 147 to $1290 \mu \mathrm{g} / \mathrm{g}$, and pelargonidin values ranged from 109 to $884 \mu \mathrm{g} / \mathrm{g}$. When the statistical analysis was limited to the BQS 
progeny population, the differences between the accessions in both cyanidin and pelargonidin values were not significant $(P>>0.05)$, while in a Tukey $($ multiple pairwise comparison (not shown), the difference in ratio of cyanidin to total anthocyanins was only significant $\left(P=0.044^{*}\right)$ between accessions $B Q S 4$ and BQS31.

\section{Octoploid Supercore Collection of Fragaria Wild Species}

Fruit was produced and harvested from at least one accession each of the four $F$. chiloensis subspecies, and three of the five $F$. virginiana subspecies groups. Neither of the two $F$. virginiana ssp. platypetala accessions or the two ssp. glauca accessions produced any fruit. F. virginiana are subdivided as groups rather than subspecies because one of the groups consists of three accessions which are putative hybrids of $F$. virginiana of ssp. glauca $\times$ ssp. virginiana. The inventory ID numbers of the accessions that produced fruit suitable for analyses are underlined and highlighted in bold (Table 2.2). Although inconsistent fruit production resulted in uneven replication, there were at least two replicates for twelve of the sixteen fruiting accessions.

The analysis of the Supercore Collection anthocyanidin content $(\mu \mathrm{g} / \mathrm{g} \mathrm{FDW} \pm \mathrm{SE})$ indicated significant variability in both cyanidin and pelargonidin contents (Table 3.10 and Figure 3.12). At the level of species, cyanidin content was significantly higher in $F$. chiloensis $(270 \mu \mathrm{g} / \mathrm{g})$ than in $F$. virginiana $(146 \mu \mathrm{g} / \mathrm{g})$, whereas pelargonidin content was significantly lower in $F$. chiloensis (189 $\mu \mathrm{g} / \mathrm{g})$ than in $F$. virginiana $(485 \mu \mathrm{g} / \mathrm{g})$ (Table 3.10). However, total anthocyanidins was not significantly different between the two species. In a 
Tukey pairwise comparison (Table 3.11) $F$. chiloensis ssp. lucida, had a significantly higher average cyanidin content $(592 \mu \mathrm{g} / \mathrm{g})$, when compared with any of the other subspecies groups. The $F$. chiloensis ssp. lucida, FRA1691 accession from Oregon, contained the most cyanidin, with an average content of $707 \mu \mathrm{g} / \mathrm{g}$.

In comparisons among groups, $F$. virginiana ssp. virginiana (North) had the highest pelargonidin value $(671 \mu \mathrm{g} / \mathrm{g})$, but in pairwise comparisons was only significantly higher than $F$. virginiana ssp. virginiana grayana $(339 \mu \mathrm{g} / \mathrm{g})$, and $F$. chiloensis ssp chiloensis f. chiloensis $(133 \mu \mathrm{g} / \mathrm{g})$ and $F$. chiloensis ssp. lucida $(151 \mu \mathrm{g} / \mathrm{g})$ (Table 3.11). F. chiloensis ssp. lucida from Oregon and $F$. virginiana ssp. virginiana (North) contained equivalent amounts of total anthocyanins due to inversely high and low cyanidin and pelargonidin contents.

The variability in cyanidin and pelargonidin contents in the Supercore Collection was to an extent observable in the fruit color. The red color of the fruit of Fragaria chiloensis ssp. lucida from Oregon (Figure 3.13) was particularly distinct with noticeable bluish/purplish hue and contained the most cyanidin (Figure 3.12). 


\section{Table 3.10 Octoploid species Supercore Collection ripe fruit anthocyanidin}

content.

Germplasm collection includes USDA selected subspecies of $F$. chiloensis and $F$. virginiana. "Origin" refers to original accession collection site. The shaded or boxed data are $\mathrm{N}$ totals and means for grouped species or subspecies. Separate ANOVAs were conducted on the individual accessions and on the species and subspecies groups. All Supercore samples were assayed in Phase 3. Individual sample data is provided in Table C.4.

\begin{tabular}{|c|c|c|c|c|c|c|c|}
\hline \multirow{3}{*}{$\begin{array}{c}\text { Species and subspecies } \\
\text { groups }\end{array}$} & \multirow[b]{3}{*}{ ORIGIN } & \multirow[b]{3}{*}{ FRA\# } & \multirow[b]{3}{*}{$\mathbf{N}$} & \multicolumn{4}{|c|}{$\begin{array}{c}\text { Anthocyanidin } \\
\text { ( } \mu \mathrm{g} / \mathrm{g} \text { FDW })\end{array}$} \\
\hline & & & & \multicolumn{2}{|c|}{ Mean } & \multicolumn{2}{|c|}{ SE } \\
\hline & & & & Cyn & PIr & Cyn & $\mathrm{Plr}$ \\
\hline F. chiloensis ssp. & & & 11 & 270 & 189 & 27 & 70 \\
\hline pacifica & Arkansas & 368 & 4 & 91 & 249 & 45 & 115 \\
\hline \multirow[t]{3}{*}{ lucida } & & & 3 & 592 & 151 & 52 & 133 \\
\hline & Washington & 42 & 1 & 362 & 52 & 91 & 231 \\
\hline & Oregon & 1691 & 2 & 707 & 201 & 64 & 163 \\
\hline chiloensis f. chiloensis & Peru & 372 & 3 & 220 & 133 & 52 & 133 \\
\hline chiloensis f. patagonica & Chile & 1100 & 1 & 167 & 233 & 91 & 231 \\
\hline \multirow{7}{*}{$\frac{\text { E. virginiana ssp. }}{\text { virginiana (North) }}$} & & & 42 & 146 & 485 & 14 & 36 \\
\hline & & & 17 & 189 & 671 & 22 & 56 \\
\hline & Ontario & 1694 & 1 & 165 & 749 & 91 & 231 \\
\hline & Ontario & 1699 & 4 & 189 & 835 & 45 & 115 \\
\hline & Ontario & 1695 & 5 & 293 & 661 & 41 & 103 \\
\hline & Minnesota & 1701 & 5 & 68 & 454 & 41 & 103 \\
\hline & Minnesota & 1700 & 2 & 245 & 871 & 64 & 163 \\
\hline \multirow[t]{4}{*}{ virginiana (South) } & & & 8 & 122 & 365 & 32 & 82 \\
\hline & South Carolina & 1580 & 5 & 106 & 252 & 41 & 103 \\
\hline & Georgia & 1455 & 2 & 112 & 550 & 64 & 163 \\
\hline & Florida & 1435 & 1 & 222 & 561 & 91 & 231 \\
\hline glauca $\times$ virginiana & Montana & 1697 & 7 & 115 & 379 & 34 & 87 \\
\hline \multirow[t]{3}{*}{ grayana } & & & 10 & 112 & 339 & 29 & 73 \\
\hline & Mississippi & 1414 & 3 & 77 & 227 & 52 & 133 \\
\hline & Mississippi & 1408 & 7 & 128 & 387 & 34 & 87 \\
\hline Overall & & & 53 & 172 & 424 & 12 & 32 \\
\hline
\end{tabular}


Table 3.10 continued.

\begin{tabular}{|c|c|c|c|c|c|c|}
\hline \multicolumn{7}{|c|}{ All Supercore Accessions ANOVA $(\mathrm{N}=53)$} \\
\hline $\begin{array}{l}\text { Dependent } \\
\text { Variable }\end{array}$ & Source & df & SS & MS & F-ratio & $\mathbf{P}$ \\
\hline Cyn & $\begin{array}{l}\text { Accessions } \\
\text { Error }\end{array}$ & $\begin{array}{l}19 \\
33\end{array}$ & $\begin{array}{l}909362 \\
271344\end{array}$ & $\begin{array}{r}47861 \\
8223\end{array}$ & 5.82 & $0.000^{\star *}$ \\
\hline Plr & $\begin{array}{l}\text { Accessions } \\
\text { Error }\end{array}$ & $\begin{array}{l}19 \\
33\end{array}$ & $\begin{array}{l}2905912 \\
1757137\end{array}$ & $\begin{array}{r}152943 \\
53247\end{array}$ & 2.87 & $0.004^{\star *}$ \\
\hline Anth & $\begin{array}{l}\text { Accessions } \\
\text { Error }\end{array}$ & $\begin{array}{l}19 \\
33 \\
\end{array}$ & $\begin{array}{l}4158830 \\
2826726 \\
\end{array}$ & $\begin{array}{r}218886 \\
85658 \\
\end{array}$ & 2.56 & $0.009^{* *}$ \\
\hline \multicolumn{7}{|c|}{ Species and Subspecies (SSP) Groups ANOVA $(\mathrm{N}=53)$} \\
\hline $\begin{array}{l}\text { Dependent } \\
\text { Variable }\end{array}$ & Source & df & SS & MS & F-ratio & $\mathbf{P}$ \\
\hline Cyn & Species & 1 & 120193 & 120193 & 10.09 & $0.003^{\star \star}$ \\
\hline & $\begin{array}{l}\text { SSP (Species) } \\
\text { Error }\end{array}$ & $\begin{array}{c}6 \\
45\end{array}$ & $\begin{array}{l}511025 \\
536073\end{array}$ & $\begin{array}{l}85171 \\
11913\end{array}$ & 7.15 & $0.000^{\star *}$ \\
\hline$\underline{\text { PIr }}$ & $\begin{array}{l}\text { Species } \\
\text { SSP (Species) } \\
\text { Error }\end{array}$ & $\begin{array}{c}1 \\
6 \\
45\end{array}$ & $\begin{array}{r}416921 \\
1023900 \\
2875525\end{array}$ & $\begin{array}{r}416921 \\
170650 \\
63901\end{array}$ & $\begin{array}{l}6.525 \\
2.671\end{array}$ & $\begin{array}{l}0.014^{*} \\
0.027^{\star}\end{array}$ \\
\hline Anth & $\begin{array}{l}\text { Species } \\
\text { SSP (Species) }\end{array}$ & $\begin{array}{l}1 \\
6\end{array}$ & $\begin{array}{r}89388 \\
1846570\end{array}$ & $\begin{array}{r}89388 \\
307762\end{array}$ & $\begin{array}{l}0.824 \\
2.838\end{array}$ & $\begin{array}{l}0.369 \\
0.020^{\star}\end{array}$ \\
\hline & Error & 45 & 4880714 & 108460 & & \\
\hline
\end{tabular}

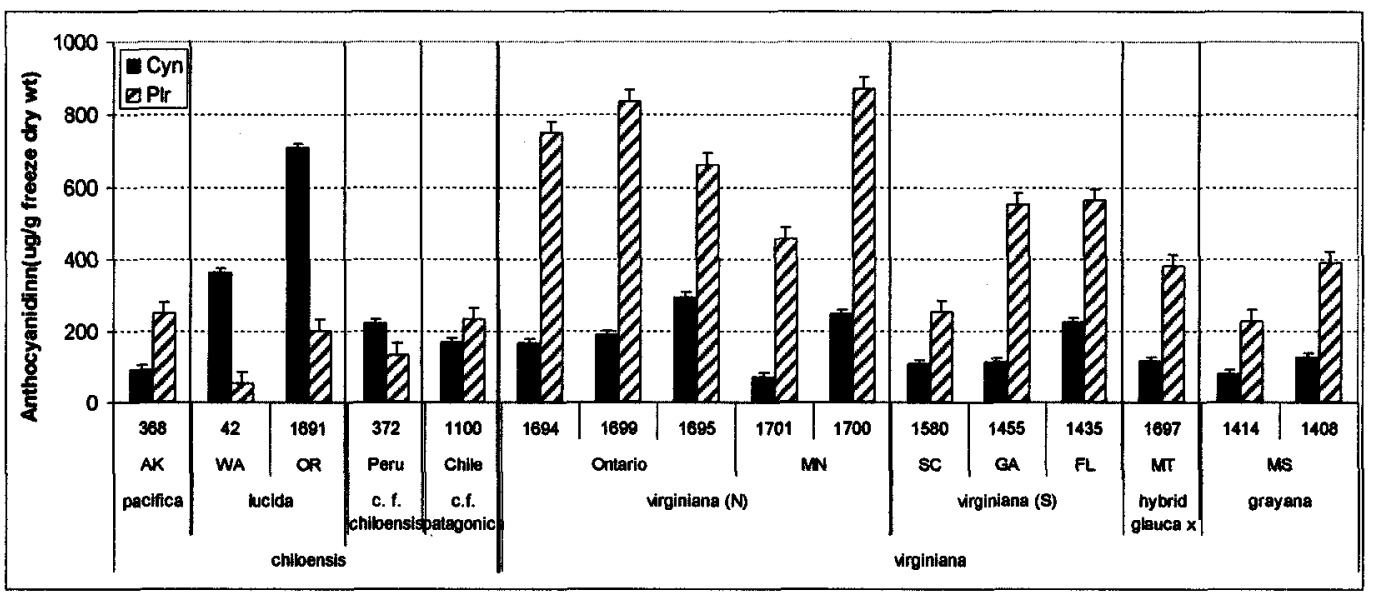

Figure 3.12 Anthocyanidin content in ripe fruit of Supercore Collection Fragaria chiloensis and $F$. virginiana subspecies.

Cyanidin and pelargonidin contents reported ( $\mu \mathrm{g} / \mathrm{g}$ FDW $\pm \mathrm{SE}$ ) in fruit collected from plants at UNH horticultural farm and greenhouses. At the subspecies level in terms of cyanidin content, $F$. chiloensis ssp. lucida significantly different $\left(P=0.000^{* *}\right.$ to $\left.0.031^{*}\right)$ from any of the other subspecies with exception of $F$. chiloensis ssp. pacifica. In terms of pelargonidin content, $F$. virginiana ssp. virginiana $(\mathrm{N})$ differed significantly when compared to $F$. chiloensis ssp. lucida $\left(P=0.038^{*}\right)$ and ssp. chiloensis f. chiloensis $\left(P=0.028^{*}\right)$ and also with F. virginiana ssp. grayana $\left(P=0.037^{\star}\right)$. 
Table 3.11 Supercore Collection Tukey® multiple subspecies pairwise comparison of cyanidin and pelargonidin contents in ripe fruit.

The number in the column headings refer to the same species and subspecies as numbered in the rows. Significant differences are underlined and bold. The mean cyanidin and pelargonidin contents for each subspecies are given for ease of comparison. $P$ values are provided in the main body of the table.

\begin{tabular}{l|r|rrrrrrrr}
\hline Cyanidin & Mean & 1 & 2 & 3 & 4 & 5 & 6 & 7 & 8 \\
\hline F. chiloensis subspecies & & & & & & & & \\
\hline 1. chiloensis f. chiloensis & 220 & 1.000 & & & & & & \\
2. chiloensis f. patagonica & 167 & 1.000 & 1.000 & & & & & \\
3. lucida & 592 & $\underline{0.003}$ & $\underline{0.031}$ & 1.000 & & & & \\
4. pacifica & 91 & 0.778 & 0.998 & $\underline{0.000}$ & 1.000 & & & & \\
F. virginiana subspecies & & & & & & & & & \\
\hline 5. glauca x virginiana & 115 & 0.857 & 1.000 & $\underline{0.000}$ & 1.000 & 1.000 & & & \\
6. virginiana (S) & 122 & 0.883 & 1.000 & $\underline{0.000}$ & 1.000 & 1.000 & 1.000 & & \\
7. virginiana (N) & 189 & 1.000 & 1.000 & $\underline{0.000}$ & 0.736 & 0.798 & 0.833 & 1.000 & \\
8. grayana & 112 & 0.805 & 1.000 & $\underline{0.000}$ & 1.000 & 1.000 & 1.000 & 0.646 & 1.000 \\
\hline Pelargonidin & Mean & 1 & 2 & 3 & 4 & 5 & 6 & 7 & $\mathbf{8}$ \\
\hline F. chiloensis subspecies & & & & & & & & & \\
\hline 1. chiloensis f. chiloensis & 133 & 1.000 & & & & & & & \\
2. chiloensis f. patagonica & 233 & 1.000 & 1.000 & & & & & & \\
3. lucida & 151 & 1.000 & 1.000 & 1.000 & & & & & \\
4. pacifica & 249 & 0.999 & 1.000 & 1.000 & 1.000 & & & & \\
F. virginiana subspecies & & & & & & & & & \\
\hline 5. glauca x virginiana & 379 & 0.848 & 0.999 & 0.893 & 0.991 & 1.000 & & & \\
6. virginiana (S) & 365 & 0.870 & 1.000 & 0.912 & 0.995 & 1.000 & 1.000 & & \\
7. virginiana (N) & 671 & 0.028 & 0.697 & $\underline{0.038}$ & 0.076 & 0.192 & 0.116 & 1.000 & \\
8. grayana & 339 & 0.915 & 1.000 & 0.947 & 0.999 & 1.000 & 1.000 & $\underline{0.037}$ & 1.000 \\
\hline
\end{tabular}




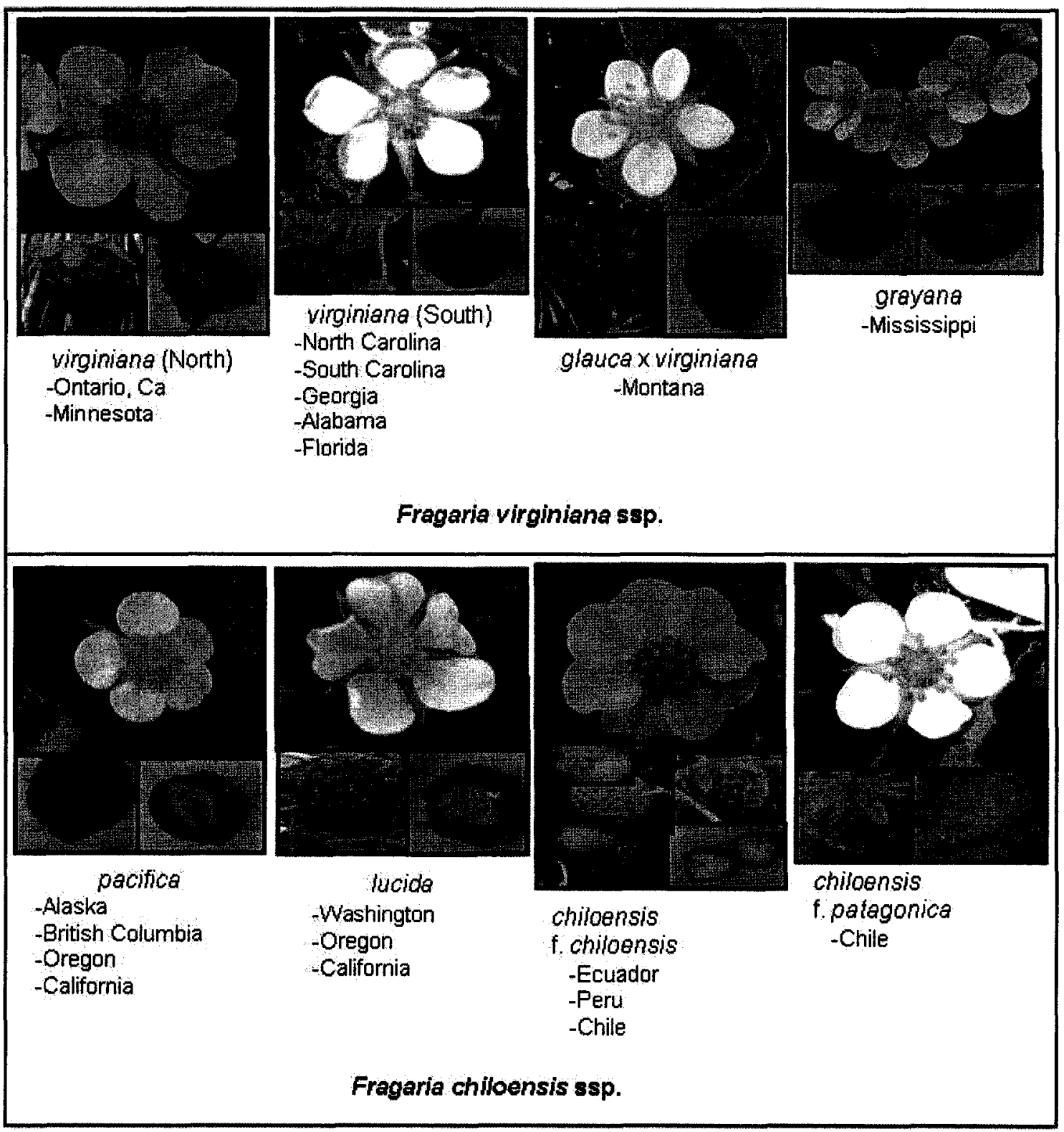

Figure 3.13 Supercore Collection flower and fruit variability. 


\section{Octoploid Fragaria $\times$ ananassa Cultivars}

Fragaria $\times$ ananassa cultivars included nine short-day and four day-neutral varieties. Fruit set in these cultivars was sufficient to allow at least three replications per accession. The anthocyanidin ( $\mu \mathrm{g} / \mathrm{g}$ FDW) content found in the fruit from the cultivars harvested at peak ripeness varied significantly for cyanidin, but not for pelargonidin (Table 3.12a and Figure 3.14). Overall, the content of cyanidin in the cultivars averaged $60 \mu \mathrm{g} / \mathrm{g}$, with 'Raritan' having the lowest (27 $\mu \mathrm{g} / \mathrm{g})$ and 'Seascape' having the highest $(120 \mu \mathrm{g} / \mathrm{g})$ cyanidin content. The cultivar 'Seascape' also had the highest cyanidin to total anthocyanidin ratio of 0.19 , compared to an overall average ratio of 0.10 in the cultivars. Overall, the content of pelargonidin averaged $597 \mu \mathrm{g} / \mathrm{g}$, and ranged from a low of $402 \mu \mathrm{g} / \mathrm{g}$ in 'Tribute' to a high of $761 \mu \mathrm{g} / \mathrm{g}$ in 'Tristar'. Day-neutral cultivars, as a group, contained significantly more cyanidin than the short-day cultivars (only because of 'Seascape'), while the pelargonidin contents were not significantly different. In

a Tukey pairwise comparison 'Seascape' was significantly different from the other cultivars in both cyanidin and ratio of cyanidin to total anthocyanidins (Table 3.12b). 
Table 3.12a Octoploid Fragaria $\times$ ananassa ripe fruit anthocyanidin content. Varieties are organized by production day-length. Ripe fruit were harvested from plants maintained at UNH. Individual sample data along with Phase protocol in use is provided in Table C.5.

\begin{tabular}{|c|c|c|c|c|c|c|c|c|}
\hline \multirow{3}{*}{$\begin{array}{l}\text { Day-length } \\
\text { Preference }\end{array}$} & \multirow{3}{*}{\multicolumn{2}{|c|}{ Variety }} & \multirow[b]{3}{*}{$\mathrm{N}$} & \multicolumn{5}{|c|}{$\begin{array}{c}\text { Anthocyanidin } \\
(\mu \mathrm{g} / \mathrm{g} \mathrm{FDW})\end{array}$} \\
\hline & & & & \multirow[b]{2}{*}{$\begin{array}{c}\text { Cyn/ } \\
\text { (Cyn+PIr) }\end{array}$} & \multicolumn{2}{|c|}{ Mean } & \multicolumn{2}{|c|}{ SE } \\
\hline & & & & & Cyn & Plr & Cyn & Pir \\
\hline Short-day & & & 55 & 0.08 & 52 & 589 & 4 & 33 \\
\hline \multirow[t]{2}{*}{ Early } & \multicolumn{2}{|c|}{ Northeaster } & 4 & 0.09 & 47 & 499 & 14 & 125 \\
\hline & \multicolumn{2}{|l|}{ Earliglow } & 5 & 0.09 & 62 & 588 & 13 & 112 \\
\hline \multirow[t]{3}{*}{ Mid-Season } & \multicolumn{2}{|l|}{ Raritan } & 5 & 0.05 & 27 & 532 & 13 & 112 \\
\hline & \multicolumn{2}{|c|}{ Delmarvel } & 3 & 0.06 & 43 & 727 & 16 & 144 \\
\hline & \multicolumn{2}{|l|}{ Honeoye } & 8 & 0.07 & 50 & 697 & 10 & 88 \\
\hline \multirow[t]{3}{*}{ Mid-Late } & \multicolumn{2}{|l|}{ Jewel } & 9 & 0.07 & 48 & 671 & 9 & 83 \\
\hline & \multicolumn{2}{|l|}{ Seneca } & 7 & 0.10 & 53 & 484 & 11 & 94 \\
\hline & \multicolumn{2}{|l|}{ Sparkle } & 9 & 0.13 & 74 & 512 & 9 & 83 \\
\hline Late & \multicolumn{2}{|l|}{ Winona } & 5 & 0.08 & 50 & 598 & 13 & 112 \\
\hline \multirow[t]{5}{*}{ Day Neutral } & & & 24 & 0.11 & 77 & 617 & 7 & 50 \\
\hline & \multicolumn{2}{|l|}{ Tribute } & 7 & 0.10 & 45 & 402 & 11 & 94 \\
\hline & \multicolumn{2}{|l|}{ Tristar } & 13 & 0.10 & 81 & 761 & 8 & 69 \\
\hline & \multicolumn{2}{|c|}{ Seascape } & 4 & 0.19 & 120 & 524 & 14 & 125 \\
\hline & \multicolumn{2}{|l|}{ Overall } & 79 & 0.10 & 60 & 597 & 3 & 28 \\
\hline \multicolumn{9}{|c|}{ F. xananassa ANOVA $(\mathrm{N}=79)$} \\
\hline $\begin{array}{l}\text { Dependent } \\
\text { Variable } \\
\end{array}$ & Source & $\mathrm{df}$ & & s & MS & \multicolumn{2}{|c|}{ F-ratio } & $\mathbf{P}$ \\
\hline \multirow[t]{2}{*}{ Cyn } & Variety & 11 & \multicolumn{2}{|c|}{33228} & 3021 & 3.86 & & 0.00 \\
\hline & Error & 67 & & 396 & 782 & & & \\
\hline Plr & Variety & 11 & & 4694 & 94063 & 1.51 & & 0.15 \\
\hline & Error & 67 & & 3658 & 62487 & & & \\
\hline Cyn:(Cyn+PIr) & Variety & 11 & & 66 & 0.006 & 5.92 & & 0.00 \\
\hline & Error & 67 & & 68 & 0.001 & & & \\
\hline Cyn & Day & 1 & & 098 & 10098 & 10.296 & & 0.002 \\
\hline & Error & 77 & & 526 & 981 & & & \\
\hline$\underline{P l r}$ & Day & 1 & & 263 & 132263 & 0.19 & & 0.65 \\
\hline & Error & 77 & & 3089 & 67638 & & & \\
\hline
\end{tabular}


Table 3.12b Octoploid Fragaria $\times$ ananassa ripe fruit Tukey® pairwise comparison.

A comparison between cultivars of the cyanidin content and of the CCPRatio (ratio of cyanidin to total anthocyanidins) highlighting significant differences in bold and underlined. The column headings refer to the same cultivars as numbered in the rows.

\begin{tabular}{|c|c|c|c|c|c|c|c|c|c|c|c|c|}
\hline Cyanidin & 1 & 2 & 3 & 4 & 5 & 6 & 7 & 8 & 9 & 10 & 11 & 12 \\
\hline $\begin{array}{l}1 \text { Delmarvel } \\
2 \text { Earliglow } \\
3 \text { Honeoye } \\
4 \text { Jewel } \\
5 \text { Northeaster } \\
6 \text { Raritan } \\
7 \text { Seascape } \\
8 \text { Seneca } \\
9 \text { Sparkle } \\
10 \text { Tribute } \\
11 \text { Tristar } \\
12 \text { Winona }\end{array}$ & $\begin{array}{l}1.000 \\
0.999 \\
1.000 \\
1.000 \\
1.000 \\
1.000 \\
0.027 \\
1.000 \\
0.883 \\
1.000 \\
0.622 \\
1.000\end{array}$ & $\begin{array}{l}1.000 \\
1.000 \\
0.999 \\
1.000 \\
0.713 \\
0.101 \\
1.000 \\
1.000 \\
0.997 \\
0.977 \\
1.000\end{array}$ & $\begin{array}{l}1.000 \\
1.000 \\
1.000 \\
0.951 \\
0.006 \\
1.000 \\
0.829 \\
1.000 \\
0.381 \\
1.000\end{array}$ & $\begin{array}{l}1.000 \\
1.000 \\
0.965 \\
0.003 \\
1.000 \\
0.731 \\
1.000 \\
0.260 \\
1.000 \\
\end{array}$ & $\begin{array}{l}1.000 \\
0.996 \\
0.020 \\
1.000 \\
0.894 \\
1.000 \\
0.598 \\
1.000\end{array}$ & $\begin{array}{l}1.000 \\
0.000 \\
0.903 \\
0.128 \\
0.993 \\
0.023 \\
0.971\end{array}$ & $\begin{array}{l}1.000 \\
0.014 \\
0.225 \\
0.003 \\
0.383 \\
0.020 \\
\end{array}$ & $\begin{array}{l}1.000 \\
0.942 \\
1.000 \\
0.616 \\
1.000\end{array}$ & $\begin{array}{l}1.000 \\
0.671 \\
1.000 \\
0.936\end{array}$ & $\begin{array}{l}1.000 \\
0.244 \\
1.000\end{array}$ & $\begin{array}{l}1.000 \\
0.653\end{array}$ & 1.000 \\
\hline CCPRatio & 1 & 2 & 3 & 4 & 5 & 6 & 7 & 8 & 9 & 10 & 11 & 12 \\
\hline $\begin{array}{l}1 \text { Delmarvel } \\
2 \text { Earliglow } \\
3 \text { Honeoye } \\
4 \text { Jewel } \\
5 \text { Northeaster } \\
6 \text { Raritan } \\
7 \text { Seascape } \\
8 \text { Seneca } \\
9 \text { Sparkle } \\
10 \text { Tribute } \\
11 \text { Tristar } \\
12 \text { Winona } \\
\end{array}$ & $\begin{array}{l}1.000 \\
0.982 \\
1.000 \\
1.000 \\
0.999 \\
1.000 \\
0.000 \\
0.883 \\
0.195 \\
0.969 \\
0.590 \\
1.000 \\
\end{array}$ & $\begin{array}{l}1.000 \\
0.976 \\
0.929 \\
1.000 \\
0.671 \\
0.003 \\
1.000 \\
0.846 \\
1.000 \\
0.999 \\
0.999 \\
\end{array}$ & $\begin{array}{l}1.000 \\
1.000 \\
0.999 \\
0.998 \\
0.000 \\
0.771 \\
0.034 \\
0.943 \\
0.256 \\
1.000 \\
\end{array}$ & $\begin{array}{l}1.000 \\
0.997 \\
1.000 \\
0.000 \\
0.602 \\
0.013 \\
0.853 \\
0.124 \\
1.000 \\
\end{array}$ & $\begin{array}{l}1.000 \\
0.915 \\
0.002 \\
1.000 \\
0.694 \\
1.000 \\
0.986 \\
1.000 \\
\end{array}$ & $\begin{array}{l}1.000 \\
0.000 \\
0.313 \\
0.007 \\
0.540 \\
0.060 \\
0.987 \\
\end{array}$ & $\begin{array}{l}1.000 \\
0.003 \\
0.076 \\
\frac{0.001}{0.003} \\
0.000 \\
\end{array}$ & $\begin{array}{l}1.000 \\
0.943 \\
1.000 \\
1.000 \\
0.979 \\
\end{array}$ & $\begin{array}{l}1.000 \\
0.764 \\
0.990 \\
0.262 \\
\end{array}$ & $\begin{array}{l}1.000 \\
0.998 \\
0.999 \\
\end{array}$ & $\begin{array}{l}1.000 \\
0.768\end{array}$ & \\
\hline
\end{tabular}

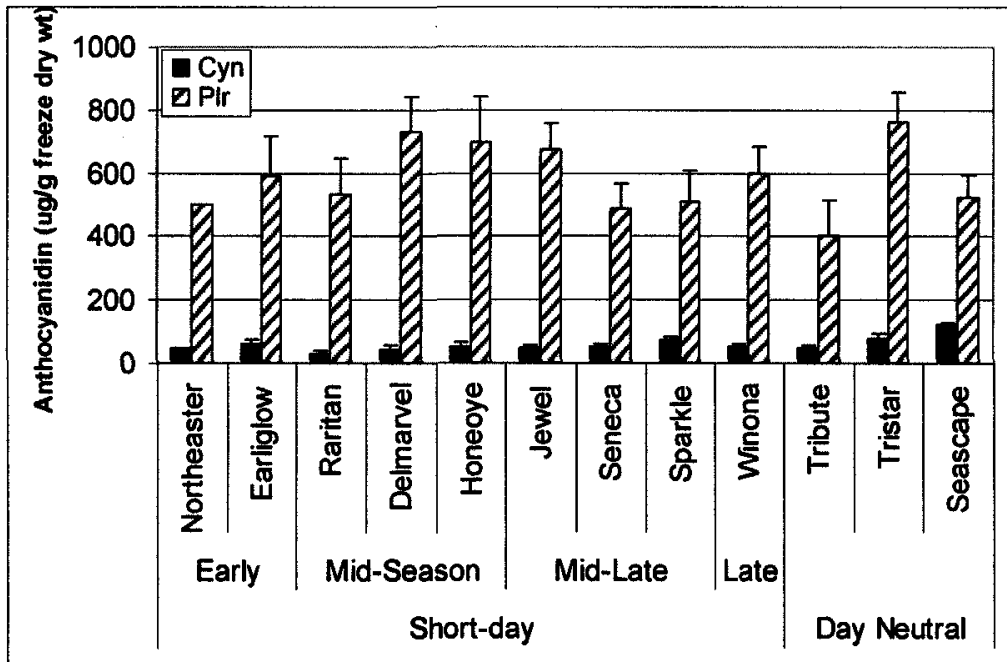

Figure 3.14 Anthocyanidin content in ripe fruit of Fragaria $\times$ ananassa cultivars.

Cyanidin and pelargonidin contents $(\mu \mathrm{g} / \mathrm{g} F \mathrm{FD} \pm \mathrm{SE})$ in fruit collected from plants at the UNH horticultural farm. In a Tukey ${ }^{\circledR}$ multiple pairwise comparison, cyanidin content was significantly variable at both the cultivar level $\left(P=0.000^{* *}\right)$ and at the day-length preference level $\left(P=0.002^{* *}\right)$. Pelargonidin content was not significantly variable at either the cultivar level $(P=0.150)$ or at the level of daylength preference $(P=0.659)$. 


\section{Octoploid 'Bountiful', 'Pink Panda' and B-PP Accessions}

The fruit cyanidin content in 'Bountiful' (B) was $54 \mu \mathrm{g} / \mathrm{g}$ and in 'Pink Panda' (PP) was $305 \mu \mathrm{g} / \mathrm{g}$, with respective pelargonidin content of $355 \mu \mathrm{g} / \mathrm{g}$ and 507 $\mu \mathrm{g} / \mathrm{g}$. Fruit set varied considerably but was sufficient to allow at least two replications for all but six of the $F_{1}$ plants. In the $F_{1}$ population of a cross between B and PP consisting of forty-three individuals (B-PP) accessions, both the cyanidin and pelargonidin contents varied significantly (Table 3.13 and Figure 3.15). The cyanidin content averaged $92 \mu \mathrm{g} / \mathrm{g}$ and varied from 32 to $259 \mu \mathrm{g} / \mathrm{g}$, and the pelargonidin content averaged $493 \mu \mathrm{g} / \mathrm{g}$ and varied from 139 to 1688 $\mu \mathrm{g} / \mathrm{g}$. 
Table 3.13 Octoploid B-PP accessions, ripe fruit anthocyanidin content. B-PP accessions consist of an $F_{1}$ population, which resulted from a hybridization of 'Bountiful' (B), an $F . \times$ ananassa variety, and 'Pink Panda' (PP), an ornamental cross of $F . \times$ ananassa $\times$ Potentilla palustris. Ripe fruit harvested from plants at the UNH greenhouse and field. Individual sample data along with Phase protocol in use is provided in Table C.6.

\begin{tabular}{|c|c|c|c|c|c|c|}
\hline \multirow{3}{*}{ Plant ID } & \multirow{3}{*}{$\mathbf{N}$} & \multicolumn{5}{|c|}{ Anthocyanidin ( $\mu \mathrm{g} / \mathrm{g}$ FDW) } \\
\hline & & \multicolumn{3}{|c|}{ Means } & \multicolumn{2}{|c|}{ SE } \\
\hline & & Cyn & Plr & Cyn + Plr & Cyn & Plr \\
\hline Bountiful & 4 & 54 & 355 & 409 & 17 & 123 \\
\hline B-PP-072 & 2 & 32 & 269 & 301 & 24 & 175 \\
\hline B-PP-037 & 3 & 44 & 502 & 546 & 19 & 143 \\
\hline B-PP-112 & 4 & 45 & 162 & 207 & 17 & 123 \\
\hline B-PP-017 & 5 & 48 & 460 & 508 & 15 & 110 \\
\hline B-PP-057 & 1 & 49 & 146 & 195 & 33 & 247 \\
\hline B-PP-109 & 4 & 53 & 168 & 221 & 17 & 123 \\
\hline B-PP-200 & 3 & 53 & 239 & 291 & 19 & 143 \\
\hline B-PP-016 & 1 & 55 & 298 & 353 & 33 & 247 \\
\hline B-PP-201? & 2 & 57 & 216 & 272 & 24 & 175 \\
\hline B-PP-110 & 3 & 58 & 139 & 196 & 19 & 143 \\
\hline B-PP-005 & 2 & 69 & 398 & 467 & 24 & 175 \\
\hline B-PP-064? & 4 & 71 & 712 & 783 & 17 & 123 \\
\hline B-PP-103 & 3 & 71 & 438 & 509 & 19 & 143 \\
\hline B-PP-077 & 7 & 75 & 352 & 427 & 13 & 93 \\
\hline B-PP-105 & 6 & 77 & 504 & 581 & 14 & 101 \\
\hline B-PP-101 & 2 & 78 & 414 & 491 & 24 & 175 \\
\hline B-PP-102? & 4 & 80 & 310 & 390 & 17 & 123 \\
\hline B-PP-059 & 2 & 83 & 382 & 464 & 24 & 175 \\
\hline B-PP-062 & 5 & 83 & 780 & 863 & 15 & 110 \\
\hline B-PP-044 & 2 & 83 & 357 & 440 & 24 & 175 \\
\hline B-PP-038 & 6 & 85 & 372 & 457 & 14 & 101 \\
\hline B-PP-024 & 8 & 85 & 622 & 706 & 12 & 87 \\
\hline B-PP-078 & 2 & 87 & 489 & 576 & 24 & 175 \\
\hline B-PP-104 & 3 & 91 & 295 & 386 & 19 & 143 \\
\hline B-PP-030 & 5 & 91 & 549 & 641 & 15 & 110 \\
\hline B-PP-106 & 3 & 92 & 727 & 820 & 19 & 143 \\
\hline
\end{tabular}


Table 3.13 continued.

\begin{tabular}{|c|c|c|c|c|c|c|}
\hline \multirow{3}{*}{ Plant ID } & \multirow{3}{*}{$\mathrm{N}$} & \multicolumn{5}{|c|}{ Anthocyanidin $(\mu \mathrm{g} / \mathrm{g}$ FDW $)$} \\
\hline & & \multicolumn{3}{|c|}{ Means } & \multicolumn{2}{|c|}{ SE } \\
\hline & & Cyn & $\mathrm{Plr}$ & Cyn + Plr & Cyn & PIr \\
\hline B-PP-069 & 4 & 93 & 248 & 340 & 17 & 123 \\
\hline B-PP-023 & 4 & 94 & 513 & 607 & 17 & 123 \\
\hline B-PP-108 & 1 & 98 & 174 & 272 & 33 & 247 \\
\hline B-PP-031 & 4 & 100 & 947 & 1047 & 17 & 123 \\
\hline B-PP-081? & 1 & 100 & 186 & 286 & 33 & 247 \\
\hline B-PP-007 & 6 & 101 & 517 & 618 & 14 & 101 \\
\hline B-PP-107 & 2 & 104 & 360 & 464 & 24 & 175 \\
\hline B-PP-039 & 4 & 104 & 392 & 496 & 17 & 123 \\
\hline B-PP-036 & 1 & 107 & 772 & 879 & 33 & 247 \\
\hline B-PP-055 & 5 & 109 & 553 & 662 & 15 & 110 \\
\hline B-PP-009 & 4 & 125 & 647 & 772 & 17 & 123 \\
\hline B-PP-068 & 3 & 125 & 590 & 715 & 19 & 143 \\
\hline B-PP-111? & 4 & 127 & 1688 & 1815 & 17 & 123 \\
\hline B-PP-070 & 2 & 128 & 423 & 551 & 24 & 175 \\
\hline B-PP-067 & 2 & 148 & 421 & 569 & 24 & 175 \\
\hline B-PP-047? & 2 & 162 & 706 & 868 & 24 & 175 \\
\hline B-PP-003 & 1 & 259 & 659 & 918 & 33 & 247 \\
\hline Pink Panda & 4 & 305 & 507 & 812 & 17 & 123 \\
\hline Overall & 150 & 92 & 493 & & 3 & 20 \\
\hline \multicolumn{7}{|c|}{ B-PP ANOVA $(N=150)$} \\
\hline $\begin{array}{l}\text { Dependent } \\
\text { Variable }\end{array}$ & Source & SS & df & MS & F-ratio & $\mathbf{P}$ \\
\hline Cyn & $\begin{array}{l}\text { BPP } \\
\text { Error }\end{array}$ & $\begin{array}{l}312991 \\
117440\end{array}$ & $\begin{array}{c}44 \\
105\end{array}$ & $\begin{array}{l}7113 \\
1118\end{array}$ & 6.36 & $0.000^{\star *}$ \\
\hline Plr & $\begin{array}{l}\text { BPP } \\
\text { Error }\end{array}$ & $\begin{array}{c}1.08 E+07 \\
6 . E+06\end{array}$ & $\begin{array}{c}44 \\
105\end{array}$ & $\begin{array}{c}246300 \\
60934\end{array}$ & 4.042 & $0.000^{* *}$ \\
\hline Cyn:(Cyn+PIr) & $\mathrm{BPP}$ & 0.709 & 44 & 0.016 & 4.915 & $0.000^{\star \star}$ \\
\hline & Error & 0.344 & 105 & 0.003 & & \\
\hline
\end{tabular}




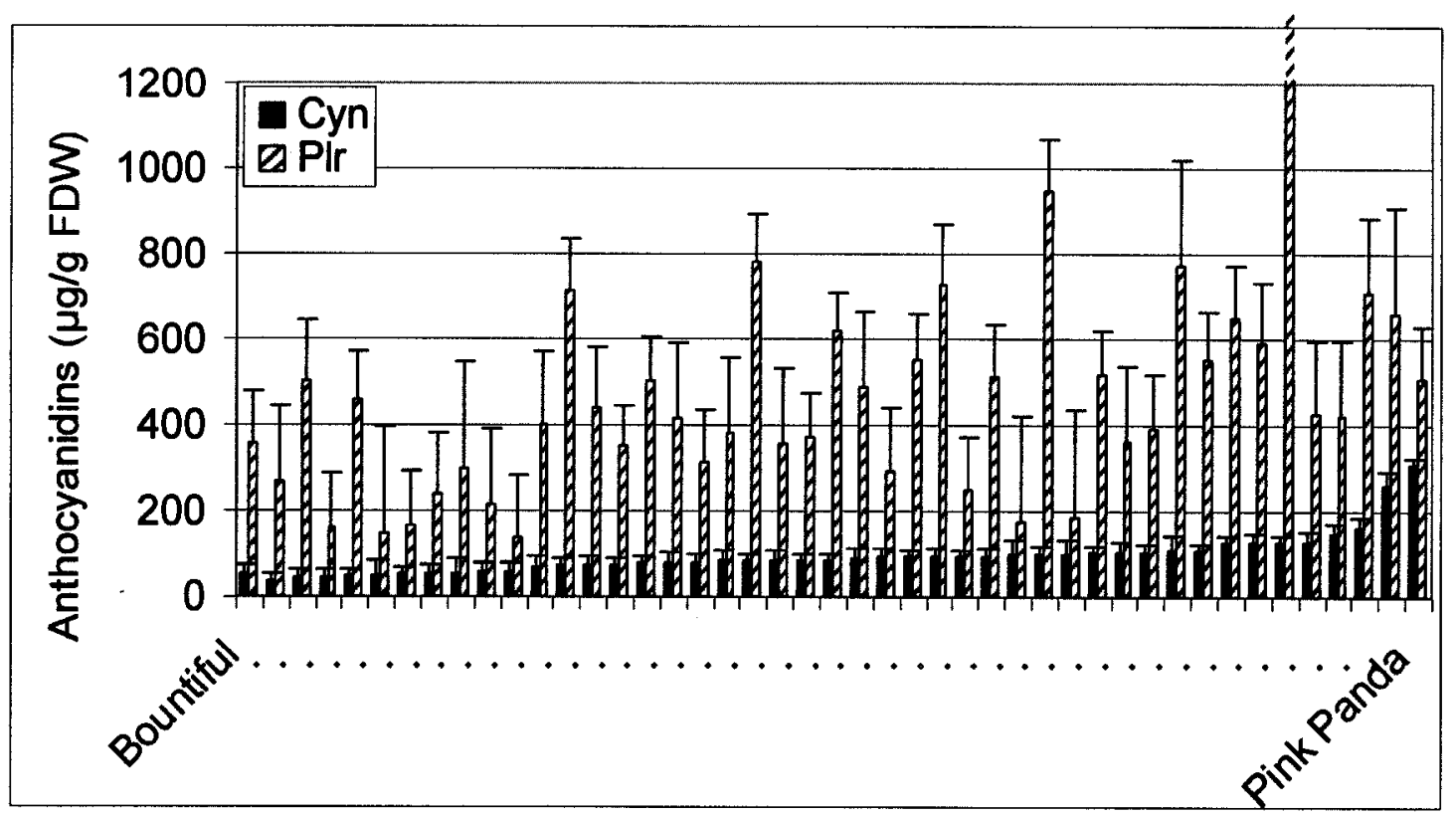

Figure 3.15 Anthocyanidin content in the ripe fruit of octoploid B-PP accessions.

Cyanidin and pelargonidin contents ( $\mu \mathrm{g} / \mathrm{g} F \mathrm{FD} \pm \mathrm{SE}$ ) in fruit of 'Bountiful' (B) and 'Pink Panda' (PP) and of their $F_{1}$ population collected from plants at the UNH greenhouse and horticultural farm. The individual pairs of bars in Figure 3.15 represent cyanidin and pelargonidin levels in unique $F_{1}$ plants. As a group, there were significant differences in both cyanidin and pelargonidin contents $\left(P=0.000^{* *}\right)$ 


\section{CHAPTER 4}

\section{DISCUSSION}

\section{Overview}

The analytical method for determining the contents of cyanidin and pelargonidin in strawberry fruit was developed incrementally after a literature search of currently practiced methods. As detailed in the methods section, alternate procedural options were considered at various stages of the process, and various criteria were employed as a basis for choosing the option to be employed. Among these criteria were consideration for the number of types and quantity of chemicals, the number of single use items, as well as the processing time and consideration of health, safety and the environment. In most instances, limitations on time and resources precluded systematic experimental comparisons among options, and the effort was focused simply on establishing an overall procedure that gave satisfactory and reproducible results. Overall, the final set of procedures outlined in the Materials and Methods chapter appeared to be effective, and these procedures are recommended for use in future investigations.

The methodology was developed in phases distinguished by modifications that were adopted due to changing circumstances. At the outset (Phase 1), a centrifuge with a maximum speed of $1200 \mathrm{xg}$ was used to extract the pigments from the hydrolyzed samples, and these samples were assayed in $20 \mu$ l volumes. 
A shift to $5 \mu \mathrm{l}$ assay volumes during the optimization of the HPLC operation marked the transition to Phase 2, and a shift to use of a new centrifuge that permitted an RCF of $15500 \mathrm{xg}$ marked the onset of Phase 3. Accessions that were sampled during at least two of the three phases were compared in order to develop factors that could be used to normalize and pool the data for ANOVA of the treatment groups. A comparison of accession data showed an increase in anthocyanidin recovery with each new phase. Both cyanidin and pelargonidin recovery results were significantly increased, by a factor of 2.7 in going from Phase 1 to Phase 2, and by a factor of 1.9 in going from Phase 2 to Phase 3, such that overall anthocyanidin content measurements were increased by a factor of 5.1 in going from Phase 1 to Phase 3 (Table 3.7). Fortunately, a large percentage of the samples (68\%) was analyzed in Phase 3, with less $(20 \%)$ analyzed in Phase 2 and even less (12\%) in Phase 1.

The impact of the phased protocol development on the results for the germplasm is as follows. The results for the diploids were most affected: $65 \%$ were analyzed in Phase 1, 25\% in Phase 2 and only $10 \%$ in Phase 3 . All of the fruit from the Supercore Collection was analyzed in Phase 3, and so these results were unaffected by the phased development of the method. The cultivars were analyzed mostly in Phase $3(87 \%)$, with only $13 \%$ analyzed in Phase 2. B-PP fruit was collected and analyzed during all three Phases $(21 \%$ in Phase 1, $38 \%$ in Phase 2, and $41 \%$ in Phase 3). Therefore, it was the results from the BPP accessions that provided the most opportunity to evaluate the impact of a shift in methods with the different Phases (Table 3.7). 


\section{Methods Development}

\section{Sample Preparation for Anthocyanidin Assay}

The strawberry fruit was lyophilized for this study, and although no loss or change in color was visible, a prior study found that the total phenolic compounds in strawberry fruit were significantly reduced during freeze-drying compared to freezing at $-20^{\circ} \mathrm{C}$ (Asami et al., 2003). It is possible that the anthocyanidin content of fruit were also reduced during the freeze-drying process used in the present investigation. However, it is likely that both cyanidin and pelargonidin would have been affected similarly, as they were in the stability studies performed on cyanidin and pelargonidin mixtures of standards solutions and on the 'Jewel' extract. Therefore it is assumed any losses incurred in freeze-drying should have affected both pigments similarly and should not have affected the comparisons among accessions that constitute the key conclusions of this study.

Activating the Sep-Pak® C18 cartridge with just the acidified methanol worked very well, as no color was observed in the rinse during the anthocyanidin binding or purification steps, in contrast to observations by (Rodriguez-Saona and Wrolstad, 2001) who included additional rinses and observed color in the rinses, suggesting loss of anthocyanidins. It is important for the cartridges to be thoroughly activated, as was discovered in the present study, and this cannot be overemphasized.

Although prior studies did not include a filtration step, filtering the anthocyanidin supernatant was very effective in preventing solids from plugging the Sep-Pak® C18 cartridge. The filtering also facilitated near perfect recovery 
of the extract; only solids with no visible liquid remained in the centrifuge tube and filtering the supernatant is recommended in future investigations.

Controlling the $\mathrm{HPLC}$ at $30^{\circ} \mathrm{C}$, just above normal range of room temperature, is recommended in future investigations, as the room temperature did tend to vary considerably. There was no evident need to control the column at a higher temperature such as the $40^{\circ} \mathrm{C}$ set by (Miyazawa et al., 1999) as evidenced by reproducible results with the 'Jewel' cultivar external standard (Table 3.3 and Figure 3.6).

\section{Stability of Anthocyanidin Standard Solutions and Mixtures}

The assay results of freshly made mixtures of cyanidin and pelargonidin at room temperature over an eleven hour period showed an increase [Cyn] and $[P I r]$, with the exception of the mixture with $[C y n]_{0}=51.9:[P \mid r]_{0}=9.0$ containing the highest concentration of cyanidin. These results suggest that two factors acted in opposing ways to affect the concentration results. The generally observed increase in concentration may have been the result of a loss of the sample solvent, methanol, due to evaporation. In the exceptional case, the observed declined in concentration may be explained by a higher degradation rate due to

the higher concentration of cyanidin. Thus solvent evaporation may be a constant while solute degradation is a function of concentration.

The degradation of standards and mixtures at room temperature following cold storage was evident, thus the degradation rate was higher following cold storage compared to that of freshly made standards and mixtures and was not offset by any evaporation of the methanol. There was not any evidence of 
precipitation of the pigments from the solution. The hypothesis that the evaporation of methanol is masking the degradation rate is supported by evident loss of concentration of the mixture with the highest contents of pelargonidin and cyanidin, as higher degradation rates with increasing concentrations are a typical chemical phenomenon.

The higher degradation rate at room temperature of the standards and mixtures following cold storage, which was more evident following storage at $-80^{\circ} \mathrm{C}$ compared to storage at $-20^{\circ} \mathrm{C}$, could have been the result of a supercritical sublimation of the solvent at $-80^{\circ} \mathrm{C}$ causing a more rapid degradation. A second comparison of two sets of standard solutions (Figure 3.5) of comparable concentration supports the hypothesis that the cold storage hastened the degradation of the standard solutions and mixtures and that the colder the storage, the higher was the degradation rate.

As a result of the stability studies, fruit samples continued to be analyzed immediately upon completion of sample preparation to assure maximum retention of cyanidin and pelargonidin contents of fruit. In addition, aliquots of cultivar 'Jewel' fruit anthocyanidin extract used as an external standard during Phase 3 were warmed from $-80^{\circ} \mathrm{C}$ to room temperature for only 15 to 30 minutes prior to assay during each HPLC run. The 'Jewel' fruit anthocyanidin extracts were stable in cold storage over a three month test period with respect to their cyanidin and pelargonidin contents (Table 3.3 and Figure 3.6). The stability results of the 'Jewel' extract, as anthocyanidins (without sugars), agreed well with results with results with the individual anthocyanins, cyanidin-3-glucoside and 
pelargonidin-3-glucoside reported in the literature, which were stable at a pH of $1-3$, even after 60 days of storage, measured by UV max absorbance at $10^{\circ} \mathrm{C}$ (Cabrita et al., 2000).

\section{Comparison of Greenhouse and Field Fruit}

Fruit was collected from both greenhouse and field accessions in order to have fruit for sampling 1) early in the investigation, before any accessions were planted in the field 2) from accessions which rarely produce fruit, and 3) during the off-season. Collecting fruit from both the greenhouse and the field maximized the amount of fruit available for this investigation. The drawback to the combined sampling of field and greenhouse is that another variable was introduced, another potential source of error. Although the ANOVA comparison of greenhouse and field fruit does not show a significant difference between the two cultural systems, it would have been more desirable to have all fruit samples collected from the field in the same two seasons to minimize the sources of error and variability.

\section{Effect of Degree of Ripeness}

Although a sharp increase in total anthocyanidin content from underripe to overripe strawberry fruit was documented by others (Cheng and Breen, 1991), the absolute contents of the individual cyanidin and pelargonidin pigments were not measured in their study. In the present study, we observed that the pelargonidin content continued to increase with increasing degree of ripeness, but that cyanidin remained relatively constant. Therefore the individual cyanidin and pelargonidin contents were documented throughout the investigation, in 
addition to calculating the cyanidin-to-pelargonidin ratio as initially intended based on the earliest reference of a 1:1 cyanidin to pelargonidin ratio in $F$. vesca (Sondheimer and Karash, 1956). Cyanidin and pelargonidin contents and ratios (Cyn to PIr and Cyn to total Anth) were determined for all sampled germplasm accessions.

\section{Anthocyanidin Content in Fruit}

\section{Fragaria Diploids}

This set of assays was done early in the investigation and the results were hampered by two factors 1) methodology was being developed and changed and 2) the opportunity for replication was limited by lack of fruit. As a consequence, even though the observed values varied over a wide range, few of the differences were statistically significant. Now that satisfactory methodology has been established it would be desirable to expand the replicate testing of diploids accessions in a future investigation. However, some important conclusions can be drawn from the existing data in relation to the goals of the investigation:

1) High cyanidin to pelargonidin ratios were found in the diploid Fragaria germplasm. The tested ratio expressed as [Cyn]:[Cyn]+[PIr] $\geq 0.5$ equivalent to $[\mathrm{Cyn}]:[\mathrm{PIr}] \geq 1.0$ was exceeded in all but two of the twelve surveyed red-fruited accessions. Of the diploids surveyed, only Fragaria vesca ssp. vesca $B S$ and one of the $F$. vesca $\times F$. viridis $B Q S$ accessions had [Cyn]:[PIr] $<1.0$.

2) High cyanidin content were found in the diploid Fragaria germplasm, and a 1:1 [Cyn]:[PIr] ratio was exceeded due to high cyanidin as well as 
due to low pelargonidin. In F. viridis, the high cyanidin $(2805 \mu \mathrm{g} / \mathrm{g})$ and low pelargonidin $(146 \mu \mathrm{g} / \mathrm{g}$ ) sample were determined using the Phase 3 protocol and although there were no replicates, the high cyanidin content was consistent with the observation that the red fruit had a bluish/purplish hue. Although the absolute magnitude of the content is uncertain, the data indicate that $F$. vesca ssp. americana WC8 contained both high cyanidin and pelargonidin contents of $2111 \mu \mathrm{g} / \mathrm{g}$ and $912 \mu \mathrm{g} / \mathrm{g}$ respectively. The exact magnitude of the high contents of both pelargonidin and cyanidin is uncertain because the WC8 accession fruit sample was analyzed very early in the investigation with only one sample using Phase 1 protocol, and visual observations of fruit color were not photographically documented.

3) In the BQS population, the presence of yellow fruited accessions indicates segregation for anthocyanidin biosynthesis. A prior study suggested that yellow fruit color in $F$. vesca was due to a mutation in the F3H gene (Deng and Davis, 2001). Further, significant difference in cyanidin content between two accessions, BQS4 and BQS31, in a Tukey 8 multiple pairwise comparison, indicates possible segregation for cyanidin content, which could be ascertained with additional sampling.

\section{Octoploid Supercore Collection of Fragaria Wild Species}

This set of assays was completed later in the investigation (Phase 3) when the methodology had been developed and had become routine. Additionally, because Supercore accessions generally produced more fruit than 
the diploids and the fact that the Supercore Collection was planted in the field, as well as being maintained in the greenhouse, two replicates samples were obtained for twelve of sixteen accessions, translating to at least three replicates for seven out of the eight subspecies that produced fruit.

The low cyanidin content found in Fragaria virginiana and in both of the South American F. chiloensis accessions (167 and $220 \mu \mathrm{g} / \mathrm{g}$ ) surveyed combined with Chile being the well-documented provenance of $F$. chiloensis in F. $\times$ ananassa and aptly named 'White Chilean' (Dale et al., 2001) support the speculation that high cyanidin content was not lost in $F . \times$ ananassa but that high cyanidin capability was never introduced.

The results show that higher cyanidin content is present in some wild octoploid germplasm, specifically in $F$. chiloensis ssp. lucida $(592 \mu \mathrm{g} / \mathrm{g})$. The data suggest a possible opportunity for breeding higher cyanidin content by introgression of $F$. chiloensis ssp. lucida into the cultivated strawberry.

The results also suggest that the genetic determinants of high pelargonidin content in $F . \times$ ananassa came from $F$. virginiana, wherein pelargonidin content was significantly higher than in F. chiloensis. Fragaria virginiana generally contained low cyanidin and high pelargonidin contents, as is found in $F . \times$ ananassa. Therefore, the results also suggest that pelargonidin content could be further increased in $F . \times$ ananassa through introgression of F. virginiana ssp. virginiana from the North, which although not statistically significant, generally registered a higher pelargonidin content $(671 \mu \mathrm{g} / \mathrm{g})$ when 
compared to the average $(365 \mu \mathrm{g} / \mathrm{g})$ in $F$. virginiana from the South, the reputed provenance of $F$. virginiana in $F . \times$ ananassa.

\section{Octoploid Fragaria $\times$ ananassa Cultivars}

This set of assays was completed late in the investigation when the methodology development had been completed and become routine; only ten out of seventy-nine total assays were completed during Phase 2, the rest were completed in Phase 3 (Table 3.7). Additionally, this data set contains the most replication, with at least three replicate samples for each accession. Replication was possible because the cultivars produced considerably more fruit than the wild octoploid germplasm and were planted in the field in four replicate plots. As a group, the day-neutrals contained significantly more cyanidin than the shortday cultivars, but this was primarily because of 'Seascape'. In the fruit of cultivars, the anthocyanidin content was comprised of $5 \%$ to $10 \%$ (by weight) cyanidin, in agreement with other studies (Kalt et al., 2001; Wang et al., 2003), with the exception of 'Seascape', which contained $19 \%$ cyanidin. The relatively high cyanidin content in 'Seascape' could be the result of the introgression of F. virginiana ssp. glauca in its development (Bringhurst, 1991). Although both accessions of $F$. virginiana ssp. glauca failed to produce any fruit and the putative hybrid $F$. virginiana ssp. glauca $x$ ssp. virginiana accessions contained relatively low levels of cyanidin (Table 3.10 ), F. virginiana ssp. glauca might have contributed the relatively high cyanidin in 'Seascape'. Survey of fruit collected from the pedigree of 'Seascape' would help to definitively answer this question. 


\section{Octoploid 'Bountiful', 'Pink Panda', and B-PP Accessions}

This set of assays was conducted throughout the course of this investigation (Table 3.7). Although, the B-PP accessions produced a variable amount of fruit, at a least two replicate samples were obtained from thirty-eight out of forty-three accessions. 'Bountiful', 'Pink Panda' and the B-PP accessions, the $F_{1}$ population, were planted in the field in addition to being maintained in the greenhouse. Significant variability in cyanidin and pelargonidin contents is present to suggest that the B-PP $F_{1}$ population is segregating for both cyanidin and pelargonidin contents. Although the population was segregating for flower color with varying shades of pink and white, no correlation was observed between fruit cyanidin content and flower color (data not shown). The source of high cyanidin in the B-PP accessions is particularly interesting because 'Pink Panda' is an intergeneric hybrid with Potentilla palustris, which has pink flowers (Ellis, 1991). The variability in cyanidin content suggests that high cyanidin can

be bred into cultivars by introgression of wild germplasm and even by interspecific hybridization. 


\section{CHAPTER 5}

\section{CONCLUSIONS}

An effective methodology was developed to assess the cyanidin and pelargonidin contents in strawberry fruit. We discovered significant variation in cyanidin content both within and between wild strawberry species, and germplasm accessions were identified that contained high levels and proportions of cyanidin. In the diploids surveyed, two accessions, one each of $F$. vesca and F. viridis were identified that contain markedly high cyanidin and with a cyanidin to pelargonidin ratio of greater than one. In the wild octoploid germplasm, an F. chiloensis ssp. lucida accession (CFRA 1691) was identified with exceptionally high cyanidin content (707 $\mu \mathrm{g} / \mathrm{g}$ FDW) and a cyanidin to pelargonidin ratio of greater than one. In contrast, the highest cyanidin content among the cultivated germplasm, in cultivar 'Seascape', was only $120 \mu \mathrm{g} / \mathrm{g}$ FDW, and the cyanidin to pelargonidin ratio was less than one.

It is reasonable to speculate that the generally low cyanidin content in the cultivated strawberry, as found in the present and prior studies, likely results from the absence of high cyanidin content in the particular wild germplasm that comprised its original pedigree. Considering the known ancestors of $F$. $\times$ ananassa, wild $F$. virginiana ssp. virginiana accessions contained little cyanidin, and $F$. chiloensis accessions surveyed from South America (provenance of $F$. chiloensis in the cultivated strawberry) also contained low 
cyanidin. In contrast, an F. chiloensis ssp. lucida from Oregon was identified that contained exceptionally high cyanidin, as did one accession (WC8) of $F$. vesca, a putative diploid ancestor of the octoploids. Thus, the genetic determinants of high cyanidin content exist in at least some wild germplasm that are closely related to the cultivated species. This reasoning prompts optimism that high cyanidin cultivars could be developed via introgression of genes from specific, high cyanidin wild octoploid accessions.

We also discovered segregation for cyanidin content in an octoploid $F_{1}$ population, suggesting that cyanidin content could be increased via selection in breeding populations. The $F_{1}$ population which resulted from a cross F. $\times$ ananassa 'Bountiful' and 'Pink Panda' involved an intergeneric hybridization in the pedigree of 'Pink Panda'. The ornamental strawberry 'Pink Panda' included an intergeneric hybridization of $F . \times$ ananassa with Potentilla palustris (Ellis, 1962). Thus, interspecific and even intergeneric hybridization could be used with advantage as a starting point for introgression of high cyanidin determinants. Overall, the results presented here show that specific wild strawberry germplasm has the potential to be useful in future strawberry breeding programs aimed at enhancing the cyanidin content, and therefore the antioxidant potential, of strawberry cultivars, perhaps contributing to their healthful properties.

The data reported here will be contributed to the GRIN system to add to the descriptions of Fragaria accessions held in the USDA germplasm system, and will be submitted for publication in a journal of the American Horticultural 
Society. In addition, interesting germplasm in the UNH collection that is not currently held by the USDA-NCGR system will be offered for donation to that system.

\section{Potential Future Implications of this Work}

The study focused on two anthocyanins. Because the associated biosynthetic enzymes are known for both cyanidin and pelargonidin, the respective genes can be targeted for molecular marker development. The anthocyanin biosynthetic pathway step at which pelargonidin and cyanidin biosynthesis diverge has not been studied in strawberry. Identification of wild strawberry species with high levels of the cyanidin pigment constitutes a first step toward the dissection of this biosynthetic pathway in strawberry, and the molecular identification and cloning of genes for high cyanidin content. Advances made by this study could lead to the development of molecular tools allowing marker assisted selection for high cyanidin content in strawberry breeding programs. The immediate goal of further work will be to assess the correlation between cyanidin content and the alleles of the F3'H gene, which marks the first committed step toward cyanidin biosynthesis. Projected genetic studies will include the sequencing and comparison the F3' $H$ genes from sources with high and low levels of cyanidin to detect differences in nucleotide sequences which may account for a functional loss in $\mathrm{F}^{\prime} \mathrm{H}$ function in species/varieties with low levels of cyanidin. 


\section{REFERENCES}

Almeida, J.R.M., F. Mourgues, and C. Rosati. 2004. Characterization of flavonoid pathway genes in strawberry: Fragaria $x$ ananassa flavanone 3-hydroxylase (FHT) mRNA, complete cds. [Online].

Asami, D.K., Y.-J. Hong, D.M. Barrett, and A.E. Mitchell. 2003. Comparison of the total phenolic and ascorbic acid content of freeze-dried and air-dried marionberry, strawberry, and corn grown using conventional, organic, and sustainable agricultural practices. Journal Agricultural and Food Chemistry 2003:1237-1241.

Bakker, J., P. Bridle, and S.J. Bellsworthy. 1994. Strawberry Juice Colour: A study of the quantitative and qualitative pigment composition of juices from 39 genotypes. Journal of Science, Food, and Agriculture 64:31-37.

Bridle, P., and C. Garcia-Viguera. 1997. Analysis of anthocyanins in strawberries and elderberries. A comparison of capillary zone electrophoresis and HPLC. Food Chemistry 59:299-304.

Bringhurst, R.S. 1991. The future of the strawberry industry in North America Timber Press, Portland Oregon.

Cabrita, L., T. Fossen, and O.M. Anderson. 2000. Colour and stability of the six common anthocyanidin 3-glucosides in aqueous solutions. Food Chemistry 68:101-107.

Cheng, G.W., and P.J. Breen. 1991. Activity of phenylalanine ammonia-lyase (PAL) and concentrations of anthocyanins and phenolics in developing strawberry fruit. Journal American Society Horticultural Science 116:865-869.

Crosby, K., and J. Jifon. 2007. Breeding vegetables for optimum levels of phytochemicals. ISHS Acta Horticulturae, Quebec City.

Crow, G.E., and C.B. Hellquist. 2000. Aquatic and Wetland Plants of Northeastern North America. Univ. of Wisconsin Press, Madison, Wisconsin.

Dale, A., J.J. Luby, C.E. Finn, S.C. Hokanson, and K.E. Hummer. 2001. From the Andes to the Rockies: Native strawberry collection and utilization. HortScience 36:221-225.

Darrow, G.M. 1966. The Strawberry: History, breeding and physiology. Holt, Rinehart, and Winston, New York. 
Davis, T.M., B. Denoyes-Rothan, and E. Lerceteau-Kohler. 2007. Strawberry., p. 189-205, In C. Kole, ed. Genome mapping and molecular breeding in plants, Vol. 4, Chapter 8. Springer-Verlag, Berlin, Heidelberg.

Deng, C., and T.M. Davis. 2001. Molecular identification of the yellow fruit color (c) locus in diploid strawberry: a candidate gene approach. Theoretical and Applied Genetics 103:316-322.

Durst, R.W., and R.E. Wrolstad. 2001. Separation and characterization of anthocyanins by HPLC. John Wiley \& Sons, Inc., New York.

Ellis, J.R. 1962. Fragaria - Potentilla intergeneric hybridization and evolution of Fragaria. Proceedings of the Linnean Society of London 173:99-106.

Ellis, J.R. 1991. Fragaria 'Frel'. Patent 75981991.

Folta, K.M., and T.M. Davis. 2006. Strawberry genes and genomics. Critical Reviews in Plant Sciences 25:399-415.

Hammer, K., and K. Pistrick. 2003. New versus old scientific names in strawberries (Fragaria L.). Genetic Resources and Crop Evolution 50:789-791.

Hancock, J.F. 1999. Strawberries. CABI Publishing, Wallingford, Oxon, UK and New York.

Hancock, J.F., and J.J. Luby. 1993. Genetic resources at our doorstop: The wild strawberries. Bioscience 43:141-147.

Hancock, J.F., S.C. Hokanson, C.E. Finn, and K.E. Hummer. 2000. Introducing a supercore collection of wild octoploid strawberries. Acta Horticulturae:77-79.

Hancock, J.F., C.A. Finn, S.C. Hokanson, J.J. Luby, B.L. Goulart, K. Demchak, P.W. Callow, S. Serce, A.M.C. Schilder, and K.E. Hummer. 2001. A multistage comparison of native octoploid strawberries from North and South America. Journal American Society Horticultural Science 126:579-586.

Harborne, J.B. 1958. The chromatographic identification of anthocyanin pigments. Journal of Chromatography 1:473-488.

Heinonen, M.I., A.S. Meyer, and E.N. Frankel. 1998. Antioxidant activity of berry phenolics on human low-density liposome oxidation. Journal Agricultural and Food Chemistry 46:4107-4112.

Holton, T.A., and E.C. Cornish. 1995. Genetics and biochemistry of anthocyanin biosynthesis. The Plant Cell 7:1071-1083. 
Hong, V., and R.E. Wrolstad. 1990. Use of HPLC Separation/Photodiode array detection for characterization of anthocyanins. Journal Agricultural and Food Chemistry 38:708-715.

Judd, W.S., C.S. Campbell, E.A. Kellogg, P.F. Stevens, and M.J. Donoghue. 2002. Plant Systematics: A phylogenetic approach. 2 ed. Sinauer Associates, Inc., Sunderland Massachusetts.

Just, B.J. 2004. Breeding for nutritional quality. Marcel Dekker, Inc., New York.

Kalt, W., A. Howell, J.C. Duy, C.F. Forney, and J.E. McDonald. 2001. Horticultural factors affecting antioxidant capacity of blueberries and other small fruit. HortTechnology 11:523-528.

Keough, G.R. 2007. New England Fruits and Vegetables 2006 Crop., In N. E. A. Statistics, (ed.). United States Department of Agriculture.

Khanizadeh, S., B. Ehsani-Moghaddam, R. Tsao, Y. Desjardins, and A. Gosselin. 2007. Strategy for breeding fruits with higher content in bioactive compounds. ISHS Acta Horticulturae.

Kikoku, Y., K. Fukuhara, I. Saito, and H. Oota. 1995. Identification and High Performance Liquid Chromatographic determination of strawberry anthocyanin pigments. Nippon Shokuhin Kagaku Kogaku Kaishi 42:118-123.

Kurilich, A., B. Clevidence, S. Britz, and J. Dura-Novotny. 2005. Plasma and urine responses are lower for acylated vs nonacylated anthocyanins from raw and cooked purple carrot. Journal Agricultural and Food Chemistry 53:65376542 .

Mazza, G., J.E. Cacace, and C.D. Kay. 2004. Methods of analysis for anthocyanins in plants and biological fluids. Journal of AOAC International $87: 129-145$.

Merken, H.M., and G.R. Beecher. 2000. Measurement of food flavonoids by High-Performance Liquid Chromatography: A Review. Journal Agricultural and Food Chemistry 48:577-599.

Miyazawa, T., K. Nakagawa, K. Miyuki, K. Muraishi, and K. Someya. 1999. Direct intestinal absorption of red fruit anthocyanins, cyanidin-3-glucoside and cyanidin3,5-diglucoside, into rats and humans. Journal Agricultural and Food Chemistry 47:1083-1091.

Moss, G.P. 2001. Flavonoid biosynthesis. [Online] (verified April 30, 2007). 
Moyer, R.A., K.E. Hummer, C.E. Finn, B. Frei, and R.E. Wrolstad. 2002. Anthocyanins, phenolics, and antioxidant capacity in diverse small fruits: vaccinium, rubus, and ribes. Journal of Agricultural and Food Chemistry 50:519525.

Nyman, N.A., and J.T. Kumpulainen. 2001. Determination of Anthocyanidins in Berries and Red Wine by High-Performance Liquid Chromatography. Journal Agricultural and Food Chemistry 49:4183-4187.

Perez, A.C. 2005. The United States leads in world strawberry production. [Online]. Available by USDA

(verified July 28).

Perez, A.C., and B. Toland. 2006. United States Strawberry Industry. [Online]. Available by USDA.

Pietta, P.-G. 2000. Flavonoids as antioxidants. Journal of Natural Products 63:1037.

Pike, L. 2005. Carrots of color: Pallette of Phytochemicals provided through Texax research. [Online]. Available by Texas A\&M University,Agricultural Communications (posted April 21, 2005).

Rodriguez-Saona, L.E., and R.E. Wrolstad. 2001. Extraction, isolation, and purification of anthocyanins. John Wiley \& Sons, Inc., New York.

Scalzo, J., A. Capocasa, M. Palandrani, M. Battino, and B. Mezzetti. 2007. Quality and nutritional value in strawberry breeding and cultivar evalution. ISHS Acta Horticulturae, Quebec City.

Shishehgarha, F., J. Makhlouf, and C. Ratti. 2002. Freeze-drying characteristics of strawberries. Drying Technology 20:131-145.

Simon, P.W. 1997. Plant pigments for color and nutrition. HortScience 32:12-13.

Simon, P.W. 2005. Pigment power in carrot colors: How pigments promote good health. [Online]. Available by USDA (posted 11/08/2005; verified 8/7/2007).

Sondheimer, E., and C.B. Karash. 1956. The major anthocyanin pigments of wild strawberry. Nature 178:648-649.

Staudt, G. 1999. Systematics and geographic distribution of the American strawberry species: taxonomic studies of the genus Fragaria. University of California Press, Berkeley and Los Angelos, California. 
Wang, H., G. Cao, and R.L. Prior. 1997. Oxygen radical absorbing capacity of anthocyanins. Journal of Agricultural and Food Chemistry 45:305-309.

Wang, S.Y., and H.-S. Lin. 2000. Antioxidant activity of fruits and leaves of blackberry, raspberry, and strawberry varies with cultivar and developmental stage. Journal of Agricultural and Food Chemistry 48:140-146.

Wang, S.Y., and M.J. Camp. 2000. Temperature after bloom affect plant growth and fruit quality of strawberry. Scientia Horticulturae 85:183-199.

Wang, S.Y., and W. Zheng. 2001. Effect of plant growth temperature on antioxidant capacity of strawberry. Journal of Agricultural and Food Chemistry 49:4977-4982.

Wang, S.Y., and H.-S. Lin. 2003. Compost as a soil supplement increases the level of antioxidant compounds and oxygen radical absorbance capacity in strawberries. Journal of Agricultural and Food Chemistry 51:6844-6850.

Wang, S.Y., W. Zheng, and G.J. Galleta. 2002. Cultural system affects fruit quality and antioxidant capacity in strawberries. Journal of Agricultural and Food Chemistry 50:6534-6542.

Wang, S.Y., J.A. Bunce, and J.L. Maas. 2003. Elevated carbon dioxide increases content of antioxidant compounds in field-grown strawberries. Journal American Society Horticultural Science 51:4315-4320.

Williamson, S.C. 1993. Germplasm development and assessment in the diploid strawberry species Fragaria vesca L., University of New Hampshire, Durham, $\mathrm{NH}$.

Wu, X., and R.L. Prior. 2005. Systematic identification and characterization of anthocyanins by HPLC-ESI-MS/MS in common foods in the United States: Fruits and berries. Journal Agricultural and Food Chemistry 53:2589-2599.

Yoo, S.K., L. Pike, B.S. Patil, K. Leskavar, K. Crosby, and S. King. 2007. Challenges of phytochemical analysis and its application in developing new fruits and vegetables with improved health benefits. ISHS Acta Horticulturae, Quebec City.

Yu, H., and T.M. Davis. 1995. Genetic linkage between runnering and phosphosglucoisomerase allozymes, and systematic distortion of monogenic segregation ratios in diploid strawberry. Journal American Society Horticultural Science 120:687-690. 


\section{APPENDICES}




\section{APPENDIX A}

\section{GREENHOUSE POTS AND FIELD PLOT LAYOUTS}


Figure A.1 Supercore Collection greenhouse pot and field plot layouts. A plot of each Supercore Collection accession (shaded-boxed numbers) was planted at the UNH horticultural farm, and a pot of each Supercore Collection accession (circled numbers) was maintained at the UNH greenhouses.

The numbers and the suffix letters within the boxes and circles are the accession NCGR CFRA inventory ID numbers and species designated as ' $C$ ' for $F$. chiloensis or ' $V$ ' for $F$. virginiana.

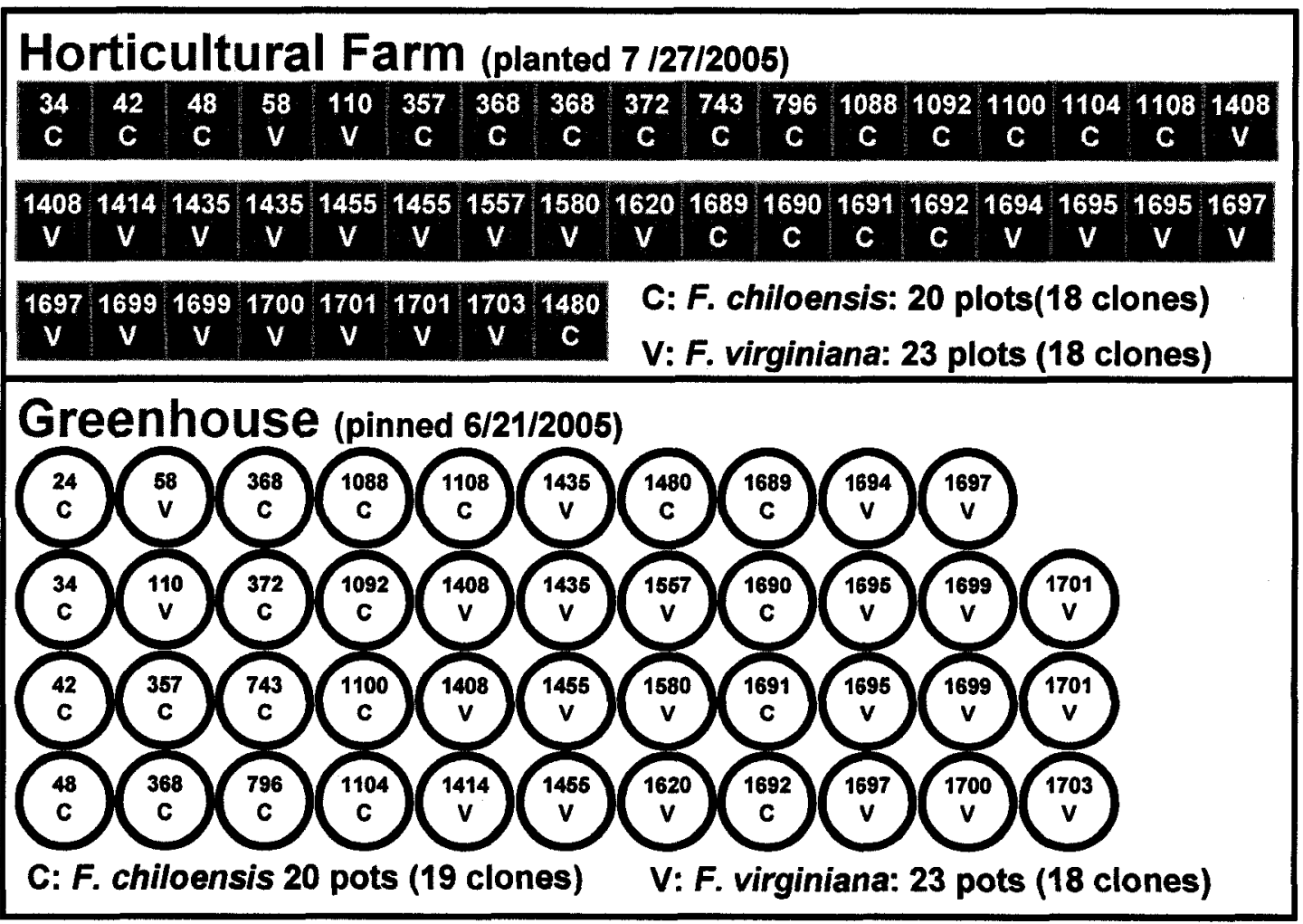


Figure A.2 Fragaria $\times$ ananassa cultivar field plot layouts.

A number was pre-assigned for each plot (number 1 through 33 ) to be planted, at the horticultural farm. Three replicate plots of each of the 11 cultivar (listed as Clone 1, 2, and 3) were planted, at the horticultural farm. Numbers representing a cultivar and clone combination were randomly drawn, and planted in the plots (shaded-boxed numbers) as shown. An additional plot of each cultivar, Clone 4 and Clone 5, was planted at the Rockingham Botanical Gardens and at the Organic Garden respectively. Clone 4 plots are not shown as fruit was not collected from these clones.

\begin{tabular}{|c|c|c|c|c|c|c|c|c|c|c|}
\hline \multicolumn{8}{|c|}{ Horticultural Farm } & \multicolumn{3}{|c|}{ Organic Garden } \\
\hline 32 & 33 & Plot: & Cultivar & Clone & Plot \# & Cultivar & Clone & Plot: & Cultivar & Clone \\
\hline 27 & 30 & 1 & Earliglow & 1 & 19 & Seneca & 1 & 1 & Earliglow & 5 \\
\hline 23 & 3 & $\begin{array}{l}2 \\
3\end{array}$ & Earliglow & 2 & 20 & Seneca & 2 & 2 & Honeoye & 5 \\
\hline & & 4 & Honeoye & 1 & 22 & Sparkle & 3 & $\begin{array}{l}3 \\
4\end{array}$ & $\begin{array}{l}\text { Jewel } \\
\text { Northeaster }\end{array}$ & $\begin{array}{l}5 \\
5\end{array}$ \\
\hline 29 & 15 & 5 & Honeoye & 2 & 23 & Sparkle & 2 & 5 & Raritan & 5 \\
\hline 12 & 2 & 6 & Honeoye & 3 & 24 & Sparkle & 3 & 6 & Seascape & 5 \\
\hline 31 & 10 & 7 & Jewel & 1 & 25 & Tribute & 1 & 7 & Seneca & 5 \\
\hline & & 8 & Jowel & 2 & 26 & Trlbute & 2 & 8 & Sparkle & 5 \\
\hline 11 & 9 & 9 & Jewel & 3 & 27 & Tribute & 3 & 9 & Tribute & 5 \\
\hline 22 & 19 & 10 & Northeaster & 1 & 28 & Trlstar & 1 & 10 & Tristar & 5 \\
\hline & & 11 & Northeaster & 2 & 29 & Tristar & 2 & & Winona & 5 \\
\hline 26 & 34 & 12 & Northeaster & 3 & 30 & Tristar & 3 & Planter & $6 / 7 / 2005$ & \\
\hline 4 & 7 & $\begin{array}{l}13 \\
14\end{array}$ & Rarltan & 1 & 31 & Winona & 1 & & & \\
\hline 24 & 5 & $\begin{array}{l}14 \\
15\end{array}$ & Raritan & 2 & 32 & Winona & 2 & & & \\
\hline 24 & $\mathbf{b}$ & $\begin{array}{l}16 \\
16\end{array}$ & Raritan & 3 & 33 & Winona & 3 & & & \\
\hline 16 & 1 & 17 & Seascape & $\begin{array}{l}1 \\
2\end{array}$ & 34 & None & & & & \\
\hline 18 & 8 & 18 & Seascape & 3 & & Planted 5 & 2005 & & & \\
\hline 17 & 21 & & & & & & & & & \\
\hline 14 & 20 & & & & & & & & & \\
\hline 13 & 6 & & 3 p & ots o & f eac & h clone & & $1 \mathrm{plc}$ & th of each & Ione \\
\hline 28 & 25 & & & & & & & & & \\
\hline
\end{tabular}


Figure A.3 Bountiful, Pink Panda, and B-PP accessions greenhouse pot and field plot layouts.

$A$ pot (circled letters with numbers) and a plot (shaded-boxed letters with numbers) of 'Bountiful' (B), Pink Panda (PP) and of each BxPP $F_{1}$ progeny (BPP) was respectively maintained at the UNH greenhouses and planted at the UNH horticultural farm. The suffix number following the letters in the green circles or boxes represent an individual numbered $F_{1}$ plant.

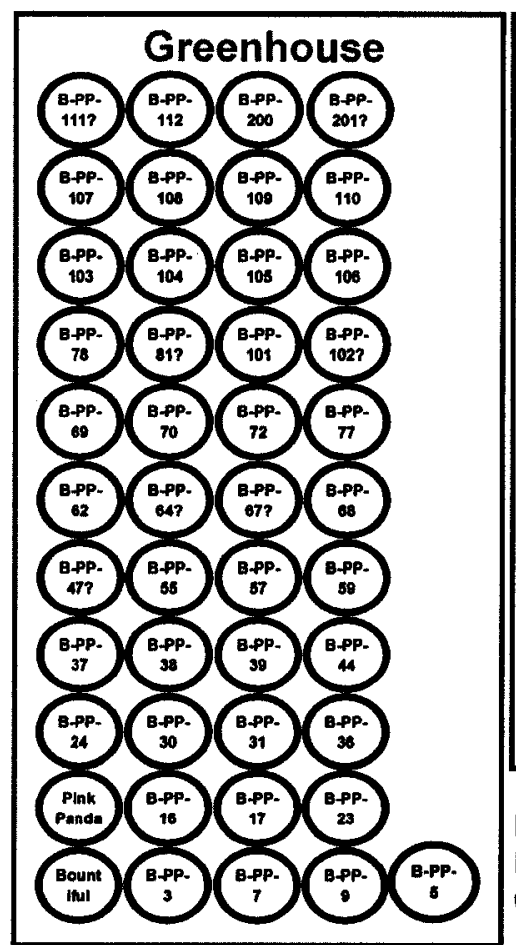

\begin{tabular}{||l|l|l|}
\hline \multicolumn{3}{|c|}{ Horticultural Farm } \\
\hline B-PP-3 & B-PP-62 & B-PP-108 \\
\hline B-PP-7 & B-PP-64? & B-PP-109 \\
\hline B-PP-9 & B-PP-67 & B-PP-110 \\
\hline B-PP-16 & B-PP-68 & B-PP-111? \\
\hline B-PP-17 & B-PP-69 & B-PP-112 \\
\hline B-PP-23 & B-PP-70 & B-PP-47? \\
\hline B-PP-24 & B-PP-72 & B-PP-200 \\
\hline B-PP-30 & B-PP-77 & B-PP-201? \\
B-PP-31 & B-PP-78 & Bountiful \\
\hline B-PP-36 & B-PP-81? & Pink Panda \\
\hline B-PP-37 & B-PP-101 & \\
\hline B-PP-38 & B-PP-102? & Planted \\
\hline B-PP-39 & B-PP-103 & summer 2004 \\
\hline B-PP-44 & B-PP-104 & \\
\hline B-PP-55 & B-PP-105 & \\
B-PP-57 & B-PP-106 & \\
B-PP-59 & B-PP-107 & \\
\hline
\end{tabular}

Bountiful, Pink Panda, and B-PP F, Population Horticultural Farm Layout: 1 plot of each clone Greenhouse: 1 pot of each clone 


\section{APPENDIX B}

CHEMICAL AND STOCK SOLUTIONS 
Table B.1 Chemicals and stock solutions.

\begin{tabular}{|c|c|c|c|}
\hline \multicolumn{2}{|l|}{ Chemicals } & \multicolumn{2}{|c|}{ Manufacturer / Supplier } \\
\hline \multicolumn{2}{|c|}{$\begin{array}{l}\text { Methanol, HPLC grade, } 0.2 \mu \mathrm{m} \\
\text { filtered, specific gravity }=0.7875 \mathrm{~g} / \mathrm{ml}\end{array}$} & \multicolumn{2}{|c|}{ Fisher Scientific Inc., Fair Lawn NJ } \\
\hline \multicolumn{2}{|c|}{$\begin{array}{l}\text { Formic Acid, } 88 \% \text { min by acidimetry } \\
\text { ACSgrade }\end{array}$} & \multicolumn{2}{|c|}{$\begin{array}{l}\text { J.T. Baker Analyzed Reagent / WWR } \\
\text { International West Chester, PA }\end{array}$} \\
\hline \multicolumn{2}{|c|}{ Hydrochloric Acid, ACS grade, $12.1 \mathrm{~N}$} & \multirow{2}{*}{\multicolumn{2}{|c|}{$\begin{array}{l}\text { EMD }{ }^{\mathrm{TM}} \text { Chemicals / } \\
\text { VWR International West Chester, PA } \\
\text { Indofine Chemicals Company, Inc., } \\
\text { Hillsborough NJ }\end{array}$}} \\
\hline $\begin{array}{l}\text { Pelargonidin Chlorid } \\
\text { Standard, Certificate } \\
(\text { COA })=99.8 \%\end{array}$ & $\begin{array}{l}\text { e Powder } \\
\text { of Analysis }\end{array}$ & & \\
\hline \multicolumn{2}{|c|}{$\begin{array}{l}\text { Cyanidin Chloride Standard, } \\
\text { Certificate of Analysis }(\mathrm{COA})=97.2 \%\end{array}$} & \multicolumn{2}{|c|}{$\begin{array}{l}\text { Indofine Chemicals Company, Inc., } \\
\text { Hillsborough NJ }\end{array}$} \\
\hline Stock Solutions & Concentration & & Recipe \\
\hline $\begin{array}{l}\text { Acidified methanol } \\
\mathrm{pH}=1.0\end{array}$ & $\begin{array}{l}0.01 \% \mathrm{HCl} \text { in } \\
\text { Methanol }\end{array}$ & & $\begin{array}{l}10 \mu \mathrm{l} \text { of } 12.1 \mathrm{~N} \mathrm{HCl} \text { per } 100 \mathrm{ml} \text { of } \\
\mathrm{HPLC} \text { grade methanol. } 12.1 \mathrm{~N} \mathrm{HCl} \\
\text { assumed as containing } 100 \% \mathrm{HCl} \text {. }\end{array}$ \\
\hline Hydrolysis Acid & $\mathrm{HCl} 2 \mathrm{~N}$ & & $\begin{array}{l}16.5 \mathrm{ml} \text { of } 12.1 \mathrm{~N} \mathrm{HCl} \text { per } 100 \mathrm{ml} \text { of } \\
\text { solution. }\end{array}$ \\
\hline Extraction Acid & $3 \%$ Formic Acid (aq) & & $\begin{array}{l}34 \mathrm{ml} \text { of } 88 \% \text { formic acid in } \mathrm{DI} \\
\text { water per } 100 \mathrm{ml} \text { of solution. }\end{array}$ \\
\hline Mobile Phase A: & $\begin{array}{l}\text { Formic Acid }(0.3 \%) \text {, } \\
\mathrm{pH} 2.8\end{array}$ & & $\begin{array}{l}3400 \mu \mathrm{l} \text { of } 88 \% \text { formic acid in DI } \\
\text { water per liter of solution filtered } \\
\text { through } 0.2 \mu \mathrm{m} \text { filter. }\end{array}$ \\
\hline Mobile Phase B: & Methanol (95\%) & & $\begin{array}{l}950 \mathrm{ml} \text { of methanol and } 50 \mathrm{ml} \text { of } \mathrm{DI} \\
\text { water filtered through } 0.2 \mu \mathrm{m} \text { filter. }\end{array}$ \\
\hline $\begin{array}{l}\text { Pelargonidin } \\
\text { Standard Solution }\end{array}$ & $\begin{array}{l}1000 \mu \mathrm{g} / \mathrm{g} \text { in acidifie } \\
\text { methanol }\end{array}$ & ied & $\begin{array}{l}1000 \mu \mathrm{g} / \mathrm{g} \times 0.7875 \mathrm{~g} / \mathrm{ml} \text { of acidified } \\
\text { methanol } / 0.998=789.1 \mu \mathrm{g} \\
\text { standard } / \mathrm{ml} \text { of methanol. Weighed } \\
\text { out standard and added amount of } \\
\text { methanol required to achieve } 1000 \\
\mu \mathrm{g} / \mathrm{g} \text { concentration }(1000 \mathrm{ug} / \mathrm{g}= \\
787.5 \mathrm{~g} / \mathrm{ml}) \text {. }\end{array}$ \\
\hline $\begin{array}{l}\text { Cyanidin Standard } \\
\text { Solution }\end{array}$ & $\begin{array}{l}1000 \mu \mathrm{g} / \mathrm{g} \text { in acidifie } \\
\text { methanol }\end{array}$ & ied & $\begin{array}{l}1000 \mu \mathrm{g} / \mathrm{g} \times 0.7875 \mathrm{~g} / \mathrm{ml} \text { of acidified } \\
\text { methanol } / 0.972=810.2 \mu \mathrm{g} \\
\text { standard } / \mathrm{ml} \text { of methanol. Weighed }\end{array}$ \\
\hline
\end{tabular}


APPENDIX C

DATA

92

Reproduced with permission of the copyright owner. Further reproduction prohibited without permission. 
Table C.1a Comparison of GH and HF HPLC results.

[Cyn] and [PIr] concentrations ( $\mu \mathrm{g} / \mathrm{g}$ FDW) and ratio of [Cyn] to [Cyn] and [PIr] determined using the Phase 3 protocol in ripe fruit collected from accessions in greenhouse (GH) and field (HF). The Run \# refers to the HPLC identification in the data records.

\begin{tabular}{|c|c|c|c|c|c|c|c|c|}
\hline Samples & $\begin{array}{c}\text { Collection } \\
\text { Year }\end{array}$ & Run \# & Accession & $\begin{array}{c}\text { No of } \\
\text { Berries }\end{array}$ & $\begin{array}{l}\text { Collection } \\
\text { Location }\end{array}$ & [Cyn] & [PIr] & {$[$ Cyn]/([Cyn]+[PIr])) } \\
\hline 1 & 2006 & 6153 & Bountifil & 1 & $\mathrm{GH}$ & 39 & 430 & 0.08 \\
\hline 2 & 2005 & 5094 & Bountifu & 2 & $\mathrm{HF}$ & 55 & 426 & 0.11 \\
\hline 6 & 2005 & 6092 & Bounilit & 3 & $11 F$ & 31 & 291 & 0.10 \\
\hline 4 & 2005 & 5093 & Bountiul & 4 & $\mathrm{HF}$ & 92 & 273 & 0.25 \\
\hline 5 & 2006 & 6134 & B-PP-024 & $?$ & GH & 49 & 546 & 0.08 \\
\hline 6 & 2005 & 5110 & B-PP-024 & 6 & $\mathrm{HF}$ & 65 & 555 & 0.10 \\
\hline 7 & 2005 & 5111 & B-PP-024 & 6 & HF & 69 & 474 & 0.13 \\
\hline 8 & 2005 & 5117 & $8 P P_{044}$ & 3 & $\mathrm{GH}$ & 76 & 416 & 0.15 \\
\hline 9 & 2005 & 5140 & $\mathrm{BDP} \cdot 044$ & 4. & $\mathrm{HF}$ & 90 & 298. & 0.23 \\
\hline 10 & 2005 & 5118 & B-PP-077 & 3 & GH & 132 & 802 & 0.14 \\
\hline 11 & 2005 & 5108 & B-PP-077 & 2 & $\mathrm{HF}$ & 77 & 320 & 0.19 \\
\hline 12 & 2006 & $6148 c$ & FRAOS72 & 1 & $\mathrm{GH}$ & 215 & 67 & 0.76 \\
\hline 13 & 2006 & 6085 & FRAO372 & 2 & HF & 181. & 149 & 0.55 \\
\hline 14 & 2006 & 6036 & FRA0372 & 1 & $\mathrm{AF}$ & 264 & 182 & 0.59 \\
\hline 15 & 2006 & $6150 \mathrm{~A}$ & FRA1697 & 1 & GH & 137 & 475 & 0.22 \\
\hline 16 & 2006 & 6131 & FRA1697 & 2 & GH & 84 & 315 & 0.21 \\
\hline 17 & 2006 & 6133 & FRA1697 & 3 & GH & 152 & 847 & 0.15 \\
\hline 18 & 2006 & 6093 & FRA1697 & 3 & HF & 144 & 405 & 0.26 \\
\hline 19 & 2006 & 6007 & FRA1697 & 5 & HF & 78 & 215 & 0.27 \\
\hline 20 & 2006 & 6008 & FRA1697 & 7 & HF & 62 & 163 & 0.27 \\
\hline 21 & 2006 & 6048 & FRA1697 & 10 & HF & 150 & 230 & 0.39 \\
\hline 22 & 2006 & 6132 & FRA1700 & 2 & $\mathrm{GH}$ & 256 & 1090 & 0.19 \\
\hline 23 & 2006 & 6050 & $\mathrm{ERA} 1700$ & 2 & $M F$ & 234 & 651 & 0.26 \\
\hline 24 & 2006 & 6152 & FRA1701 & 1 & GH & 68 & 741 & 0.08 \\
\hline 25 & 2006 & 6010 & FRA1701 & 5 & HF & 57 & 303 & 0.16 \\
\hline 26 & 2006 & 6011 & FRA1701 & 5 & HF & 49 & 189 & 0.20 \\
\hline 27 & 2006 & 6051 & FRA1701 & 4 & $\mathrm{HF}$ & 82 & 466 & 0.15 \\
\hline 28 & 2006 & 6123 & FRA1701 & 14 & $\mathrm{HF}$ & 85 & 571 & 0.13 \\
\hline 29 & 2006 & 6146 & Tribute & 1 & $\mathrm{GH}$ & 66 & 298 & 0.18 \\
\hline 30 & 2006 & 6187 & Tribute & 1 & $\mathrm{GH}$ & 80 & 490 & 0,14 \\
\hline 31 & 2006 & 6054 & Tribute & 2 & HF & 37 & 454 & 0.07 \\
\hline 82 & 2006 & 6017 & Tijoute & 3 & $\mathrm{HF}^{2}$ & 39 & 385 & 0.09 \\
\hline 33 & 2006 & 6064 & Tribute & 4 & HF & 46 & 505 & 0.08 \\
\hline 84 & 2006 & 6080 & Tiloute & 5 & $H \mathrm{HF}$ & 27 & 354 & 0.07 \\
\hline
\end{tabular}


Table C.1b Comparison of GH and HF accession means.

The ripe fruit in this comparison were all assayed using the Phase 3 protocol.

\begin{tabular}{clccrrc}
\hline Samples & Accession & $\begin{array}{c}\text { Collection } \\
\text { Location }\end{array}$ & $\begin{array}{c}\text { No. of } \\
\text { Samples }\end{array}$ & [Cyn] & [PIr] & $\begin{array}{c}{[\text { Cyn]] }} \\
\text { [[Cyn]+[PIr]) }\end{array}$ \\
\hline 1 & Bountiful & GH & 1 & 39 & 430 & 0.080 \\
2 & Bountiful & HF & 3 & 59 & 330 & 0.153 \\
3 & B-PP-024 & GH & 1 & 49 & 546 & 0.080 \\
4 & B-PP-024 & HF & 2 & 67 & 515 & 0.115 \\
5 & B-PP-044 & GH & 1 & 76 & 416 & 0.150 \\
6 & B-PP-044 & HF & 1 & 90 & 298 & 0.230 \\
7 & B-PP-077 & GH & 1 & 132 & 802 & 0.140 \\
8 & B-PP-077 & HF & 1 & 77 & 320 & 0.190 \\
9 & FRA0372 & GH & 1 & 215 & 67 & 0.760 \\
10 & FRA0372 & HF & 2 & 223 & 166 & 0.570 \\
11 & FRA1697 & GH & 3 & 124 & 546 & 0.193 \\
12 & FRA1697 & HF & 4 & 109 & 253 & 0.298 \\
13 & FRA1700 & GH & 1 & 256 & 1090 & 0.190 \\
14 & FRA1700 & HF & 1 & 234 & 651 & 0.260 \\
15 & FRA1701 & GH & 1 & 68 & 741 & 0.080 \\
16 & FRA1701 & HF & 4 & 68 & 382 & 0.160 \\
17 & Tribute & GH & 2 & 73 & 394 & 0.160 \\
18 & Tribute & HF & 4 & 37 & 425 & 0.078
\end{tabular}


Table C.2a Comparison of Phase 1 and Phase 2 HPLC results.

[Cyn] and [PIr] concentrations ( $\mu \mathrm{g} / \mathrm{g}$ FDW) and ratio of [Cyn] to [Cyn] and [PIr] collected from accessions with HPLC sample volume decreased from $20 \mu \mathrm{l}$ in Phase 1 to $5 \mu \mathrm{l}$ in Phase 2. Extraction of anthocyanidin conducted with centrifuge RCF of $1,200 \mathrm{xg}$ E during both phases. The Run \# refers to the HPLC identification in the data records.

\begin{tabular}{|c|c|c|c|c|c|c|c|c|}
\hline Samples & $\begin{array}{c}\text { Collection } \\
\text { Year }\end{array}$ & Run \# & Phase & Accession & $\begin{array}{l}\text { Collection } \\
\text { Location }\end{array}$ & [Cyn] & [PIr] & $\begin{array}{c}{[\text { Cyn }] /} \\
([\text { Cyn }]+[\text { PIr }])\end{array}$ \\
\hline 1 & 2004 & 56 & 1 & B-PP-007 & $\mathrm{GH}$ & 19 & 131 & 0.128 \\
\hline 2 & 2005 & 5044 & 2 & B-PP-007 & $\mathrm{HF}$ & 45 & 143 & 0.239 \\
\hline 3 & 2005 & 5053 & 2 & B-PP-007 & HF & 79 & 225 & 0.260 \\
\hline 4 & 2005 & 5056 & 2 & B-PP-007 & HF & 54 & 268 & 0.167 \\
\hline 5 & 2004 & 48 & 1 & BPPDOOS & $\mathrm{GH}$ & 31 & 172 & 0.154 \\
\hline 6 & 2005 & 5033 & 2 & BPPD009 & HF & 51 & 319 & 0.137 \\
\hline 7 & 2005 & 5035 & 2 & B-PP-009 & HF & 63 & 303 & 0.173 \\
\hline 8 & 2005 & 5049 & 2 & BPP:009 & HF & 68 & 292 & 0.189 \\
\hline 9 & 2004 & 58 & 1 & B-PP-017 & $\mathrm{GH}$ & 0 & 91 & 0.003 \\
\hline 10 & 2005 & 5040 & 2 & B-PP-017 & HF & 30 & 198 & 0.133 \\
\hline 11 & 2005 & 5041 & 2 & B-PP-017 & HF & 24 & 196 & 0.109 \\
\hline 12 & 2005 & 5057 & 2 & B-PP-017 & HF & 38 & 332 & 0.104 \\
\hline 13 & 2005 & 5059 & 2 & B-PP-017 & $\mathrm{HF}$ & 33 & 248 & 0.118 \\
\hline 14 & 2004 & 26 & 1. & B-PP-023 & $\mathrm{GH}$ & 23 & 78 & 0.229 \\
\hline 15 & 2005 & 5037 & 2 & $B=P P-023$ & $\mathrm{HF}$ & 72 & 413 & 0.149 \\
\hline $16=$ & 2005 & 5042 & 2 & BEPP=023 & $\mathrm{HF}$ & 33 & 134 & 0.195 \\
\hline 17 & 2005 & 5048 & 2 & B=PP-023 & $\mathrm{HF}$ & 33 & 328 & 0.092 \\
\hline 18 & 2004 & 50 & 1 & B-PP-024 & GH & 20 & 88 & 0.187 \\
\hline 19 & 2005 & 5036 & 2 & B-PP-024 & HF & 24 & 173 & 0.122 \\
\hline 20 & 2005 & 5039 & 2 & B-PP-024 & HF & 58 & 353 & 0.140 \\
\hline 21 & 2005 & 5054 & 2 & B-PP-024 & $\mathrm{HF}$ & 66 & 452 & 0.128 \\
\hline 22 & 2005 & 5055 & 2 & B-PP-024 & $\mathrm{HF}$ & 60 & 583 & 0.094 \\
\hline 23 & 2004 & 43 & 1 & $B=P=030$ & $\mathrm{GH}$ & 16 & 148 & 0.098 \\
\hline 24 & 2005 & 5034 & 2 & $B=030$ & $\mathrm{HF}$ & 48 & 196 & 0.198 \\
\hline 26 & 2005 & 5038 & 2 & BEP 030 & HF & 39 & 226 & 0.146 \\
\hline 26 & 2005 & 5043 & 2. & B-PP-030 & HF & 42 & 228 & 0.156 \\
\hline 27 & 2004 & 60 & 1 & B-PP-038 & GH & 27 & 163 & 0.142 \\
\hline 28 & 2005 & 5003 & 2 & B-PP-038 & HF & 30 & 72 & 0.293 \\
\hline 29 & 2005 & 5006 & 2 & B-PP-038 & $\mathrm{HF}$ & 35 & 54 & 0.395 \\
\hline 30 & 2005 & 5050 & 2 & B-PP-038 & HF & 41 & 277 & 0.130 \\
\hline 31. & 2004 & 33 & 7 & B-PP-069 & $\mathrm{GH}$ & 22 & 46 & 0.322 \\
\hline 32 & 2005 & 5061 & 2 & B-PP-069 & HF & 41 & 118 & 0.259 \\
\hline 33 & 2005 & 5062 & 2 & BPP-069 & HF & 38 & 106 & 0.265 \\
\hline 34 & 2004 & 34 & 1 & B-PP-070 & GH & 20 & 70 & 0.225 \\
\hline 35 & 2005 & 5024 & 2 & B-PP-070 & HF & 82 & 263 & 0.237 \\
\hline 36 & 2004 & 35 & 1 & BPP-072 & GH & 0 & 51 & 0.006 \\
\hline 37 & 2006 & 6070 & 2. & B-PP-072 & HF & 33 & 151 & 0.178 \\
\hline 38 & 2004 & 21 & 1 & B-PP-077 & $\mathrm{GH}$ & 0 & 10 & 0.010 \\
\hline 39 & 2005 & 5004 & 2 & B-PP-077 & $\mathrm{HF}$ & 74 & 167 & 0.307 \\
\hline 40 & 2005 & 5025 & 2 & B-PP-077 & HF & 45 & 233 & 0.163 \\
\hline
\end{tabular}


Table C.2a continued: Comparison of Phase 1 and Phase 2 HPLC results.

\begin{tabular}{|c|c|c|c|c|c|c|c|c|}
\hline Samples & $\begin{array}{l}\text { Collection } \\
\text { Year }\end{array}$ & Run \# & Phase & Accession & $\begin{array}{l}\text { Collection } \\
\text { Location }\end{array}$ & [Cyn] & [PIr] & $\begin{array}{c}{[\text { Cyn] }]} \\
([\text { Cyn]+[PIr }]\end{array}$ \\
\hline 41 & 2005 & 5026 & 2 & B-PP-077 & HF & 36 & 228 & 0.136 \\
\hline 42 & 2005 & 5027 & 2 & B-PP-077 & HF & 20 & 124 & 0.138 \\
\hline 43 & 2005 & 5028 & 2 & B-PP-077 & $\mathrm{HF}$ & 32 & 142 & 0.184 \\
\hline 44 & 2004 & 36 & 1 & B-PP-078 & $\mathrm{GH}$ & 16 & 34 & 0.327 \\
\hline 45 & 2005 & 5063 & 2 & BPP078 & $H F$ & 0 & 48 & 0.000 \\
\hline 46 & 2005 & 5065 & 2 & BPPOT: & HF & 49 & 428 & 0.103 \\
\hline 47 & 2004 & 22 & 1 & B-PP-102? & GH & 10 & 35 & 0.223 \\
\hline 48 & 2005 & 5073 & 2 & B-PP-102? & $\mathrm{HF}$ & 50 & 160 & 0.239 \\
\hline 49 & 2005 & 5074 & 2 & B-PP-102? & HF & 40 & 204 & 0.163 \\
\hline 50 & 2005 & 5075 & 2 & B-PP-102? & HF & 52 & 200 & 0.206 \\
\hline 51 & 2004 & 66 & 1 & $B P P-111 ?$ & $\mathrm{GH}$ & 29 & 414 & 0.066 \\
\hline 52 & 2005 & 5010 & 2 & $B-P P-1112$ & $\mathrm{HF}$ & 86 & 1300 & 0.068 \\
\hline 53 & 2005 & 6011 & 2 & BAPE $=1112$ & HF & 50 & 655 & 0.071 \\
\hline 54 & 2005 & $5016=$ & 2 & BPP-111? & HF & 45 & 522 & 0.080 \\
\hline 55 & 2004 & 24 & 1 & B-PP-112 & GH & 8 & 17 & 0.319 \\
\hline 56 & 2005 & 5012 & 2 & B-PP-112 & HF & 24 & 132 & 0.154 \\
\hline 57 & 2005 & 5013 & 2 & B-PP-112 & HF & 28 & 121 & 0.188 \\
\hline 58 & 2004 & 20 & 1 & B-PP-200 & $\mathrm{GH}$ & 12 & 54 & 0.186 \\
\hline 59 & 2005 & 5014 & 2 & B-PP-200 & $\mathrm{HF}$ & 29 & 164 & 0.151 \\
\hline 60 & 2005 & $5016=$ & 2. & B-PP-200 & $\mathrm{HF}$ & 22 & 74 & 0.229 \\
\hline
\end{tabular}


Table C.2b Comparison of Phase 1 and Phase 2 accession means.

\begin{tabular}{cccccccrc}
\hline Samples & $\begin{array}{c}\text { Collection } \\
\text { Year }\end{array}$ & Phase & Accession & $\begin{array}{c}\text { No. of } \\
\text { Samples }\end{array}$ & $\begin{array}{c}\text { Collection } \\
\text { Location }\end{array}$ & [Cyn] & [PIr] & $\begin{array}{c}{[\text { Cyn] }} \\
\text { ([Cyn]+[PIr]) }\end{array}$ \\
\hline 1 & 2004 & 1 & B-PP-007 & 1 & GH & 19 & 131 & 0.128 \\
2 & 2005 & 2 & B-PP-007 & 3 & HF & 59 & 212 & 0.222 \\
3 & 2004 & 1 & B-PP-009 & 1 & GH & 31 & 172 & 0.154 \\
4 & 2005 & 2 & B-PP-009 & 3 & HF & 61 & 305 & 0.166 \\
5 & 2004 & 1 & B-PP-017 & 1 & GH & 0.3 & 91 & 0.003 \\
6 & 2005 & 2 & B-PP-017 & 4 & HF & 31 & 244 & 0.116 \\
7 & 2004 & 1 & B-PP-023 & 1 & GH & 23 & 78 & 0.229 \\
8 & 2005 & 2 & B-PP-023 & 3 & HF & 46 & 292 & 0.145 \\
9 & 2004 & 1 & B-PP-024 & 1 & GH & 20 & 88 & 0.187 \\
10 & 2005 & 2 & B-PP-024 & 4 & HF & 52 & 390 & 0.121 \\
11 & 2004 & 1 & B-PP-030 & 1 & GH & 16 & 148 & 0.098 \\
12 & 2005 & 2 & B-PP-030 & 3 & HF & 43 & 217 & 0.167 \\
13 & 2004 & 1 & B-PP-038 & 1 & GH & 27 & 163 & 0.142 \\
14 & 2005 & 2 & B-PP-038 & 3 & HF & 35 & 134 & 0.273 \\
15 & 2004 & 1 & B-PP-069 & 1 & GH & 22 & 46 & 0.322 \\
16 & 2005 & 2 & B-PP-069 & 2 & HF & 40 & 112 & 0.262 \\
17 & 2004 & 1 & B-PP-070 & 1 & GH & 20 & 70 & 0.225 \\
18 & 2005 & 2 & B-PP-070 & 1 & HF & 82 & 263 & 0.237 \\
19 & 2004 & 1 & B-PP-072 & 1 & GH & 0.1 & 51 & 0.006 \\
20 & 2005 & 2 & B-PP-072 & 1 & HF & 33 & 151 & 0.178 \\
21 & 2004 & 1 & B-PP-077 & 1 & GH & 0 & 10 & 0.010 \\
22 & 2005 & 2 & B-PP-077 & 5 & HF & 41 & 179 & 0.186 \\
23 & 2004 & 1 & B-PP-078 & 1 & GH & 16 & 34 & 0.327 \\
24 & 2005 & 2 & B-PP-078 & 2 & HF & 24 & 238 & 0.103 \\
25 & 2004 & 1 & B-PP-102? & 1 & GH & 10 & 35 & 0.223 \\
26 & 2005 & 2 & B-PP-102? & 3 & HF & 47 & 188 & 0.203 \\
27 & 2004 & 1 & B-PP-111? & 1 & GH & 29 & 414 & 0.066 \\
28 & 2005 & 2 & B-PP-111? & 3 & HF & 64 & 826 & 0.073 \\
29 & 2004 & 1 & B-PP-112 & 1 & GH & 8 & 17 & 0.319 \\
30 & 2005 & 2 & B-PP-112 & 2 & HF & 26 & 126 & 0.171 \\
31 & 2004 & 1 & B-PP-200 & 1 & GH & 12 & 54 & 0.186 \\
32 & 2005 & 2 & B-PP-200 & 2 & HF & 26 & 119 & 0.190 \\
& & & & & & & &
\end{tabular}


Table C.3a Comparison of Phase 2 and Phase 3 HPLC results.

[Cyn] and [PIr] concentrations ( $\mu \mathrm{g} / \mathrm{g}$ FDW) and ratio of [Cyn] to [Cyn] and [PIr] with the anthocyanidin extraction conducted with a centrifuge RCF of 1,200 in Phase 2 and increased to $15,500 \mathrm{xg}$ with a new centrifuge in Phase 3 . The HPLC sample volume was $5 \mu$ in both phases. The Run \# refers to the HPLC identification in the data records.

\begin{tabular}{|c|c|c|c|c|c|c|c|c|c|}
\hline Samples & $\begin{array}{l}\text { Collection } \\
\text { Year }\end{array}$ & $\begin{array}{l}\text { Run } \\
\#\end{array}$ & Phase & Accession & $\begin{array}{l}\text { No of } \\
\text { Berries }\end{array}$ & $\begin{array}{l}\text { Collection } \\
\text { Location }\end{array}$ & [Cyn] & [PIr] & $\begin{array}{c}{[\text { Cyn] }] /} \\
([\text { Cyn]+[PIr] })\end{array}$ \\
\hline 1 & 2005 & 5044 & 2 & B PPD007 & 3 & HF & 45 & 143 & 024 \\
\hline 2 & 2005 & 5053 & 2 & BPPP-007 & 4 & $\mathrm{HF}$ & 79 & 225 & 026 \\
\hline 3 & 2005 & 5056 & 2 & BPP 007 & 4 & $H F$ & 54 & 268 & 0.17 \\
\hline 4 & 2005 & 5106 & 3. & BPP.007 & 6 & HF & 87 & 528 & 0.14 \\
\hline 5 & 2005 & 5107 & 3 & BPPD007 & 6 & $\mathrm{HF}$ & 87 & 719 & 0.11 \\
\hline 6 & 2005 & 5036 & 2 & B-PP-024 & 2 & HF & 24 & 173 & 0.12 \\
\hline 7 & 2005 & 5039 & 2 & B-PP-024 & 4 & $\mathrm{HF}$ & 58 & 353 & 0.14 \\
\hline 8 & 2005 & 5054 & 2 & B-PP-024 & 4 & $\mathrm{HF}$ & 66 & 452 & 0.13 \\
\hline 9 & 2005 & 5055 & 2 & B-PP-024 & 4 & $\mathrm{HF}$ & 60 & 583 & 0.09 \\
\hline 10 & 2005 & 5110 & 3 & B-PP-024 & 6 & HF & 65 & 555 & 0.10 \\
\hline 11 & 2005 & 5111 & 3 & B-PP-024 & 6 & HF & 69 & 474 & 0.13 \\
\hline 12 & 2005 & 5034 & 2 & BPP 030 & 3 & $\mathrm{HF}$ & 48 & 196 & 0.20 \\
\hline 13 & 2005 & 5038 & 2 & B.PPO 030 & 0 & GE & 39 & 226 & 0.15 \\
\hline 14 & 2005 & 8043 & 2 & B-PEDoso & 4 & HE & 42 & 229 & 016 \\
\hline 15 & 2005 & 5112 & 8 & B-PP 030 & 8 & MF & 131 & 777 & 0.14 \\
\hline 16 & 2005 & 5003 & 2 & B-PP-038 & 2 & HF & 30 & 72 & 0.29 \\
\hline 17 & 2005 & 5006 & 2 & B-PP-038 & 2 & HF & 35 & 54 & 0.39 \\
\hline 18 & 2005 & 5050 & 2 & B-PP-038 & 2 & HF & 41 & 277 & 0.13 \\
\hline 19 & 2005 & 5130 & 3 & B-PP-038 & 8 & $\mathrm{HF}$ & 104 & 472 & 0.18 \\
\hline 20 & 2005 & 6025 & 2 & B P P 077 & 3 & HF & 45 & 233 & 0.16 \\
\hline 21 & 2005 & 5026 & 2 & B-PP. 077 & 4 & $H F$ & 36 & 228 & 0.14 \\
\hline 22 & 2005 & 5027 & 2 & B.PPDOTh & 4 & HF & 20 & 124 & 0.14 \\
\hline 23 & 2005 & 5028 & 2 & BPP07T & 4 & $H^{2}$ & 32 & 142 & 0.18 \\
\hline 24 & 2005 & 5108 & 3 & BPP OT & 2 & HF & 77 & 320 & 0.19 \\
\hline 25 & 2005 & 5084 & 2 & Seascape & 2 & HF & 116 & 422 & 0.22 \\
\hline 26 & 2005 & 5132 & 3 & Seascape & 2 & $\mathrm{HF}$ & 132 & 535 & 0.20 \\
\hline 27 & 2005 & 5120 & 3 & Seascape & 1 & $\mathrm{HF}$ & 222 & 342 & 0.39 \\
\hline 28 & 2005 & 5081 & 2 & Tristar & 2 & HF & 56 & 377 & 0.13 \\
\hline 29 & 2005 & 6007 & 2 & Tristar & 2 & $14 F$ & 36 & 253 & 0,12 \\
\hline 30 & 2005 & 5020 & 2 & Tristar & 1 & $\mathrm{HF}$ & 35 & 293 & 0.11 \\
\hline 31 & 2005 & 5058 & 2 & Tristar & 1 & $4 F$ & 60 & 713 & 0.08 \\
\hline 32 & 2005 & 5083 & 2 & Tristar & 3 & HF & 88 & 704 & 0.11 \\
\hline 33 & 2005 & 5129 & 3. & Tristar & 2 & $H F$ & 133 & 1053 & 0.11 \\
\hline 34 & 2005 & 5131 & 3 & Tristar & 2 & HF & 123 & 1420 & 0.08 \\
\hline 35 & 2005 & 5119 & 3 & Tristar & 1 & $\| \mathrm{F}$ & 111 & 692 & 0.14 \\
\hline
\end{tabular}


Table C.3b Comparison of Phase 2 and Phase 3 accession means.

\begin{tabular}{ccccrrc}
\hline Samples & Phase & Accession & $\begin{array}{c}\text { No. of } \\
\text { Samples }\end{array}$ & [CYN] & [PLR] & $\begin{array}{c}\text { [Cyn] } \\
\text { [Cyn]+[PIr]) }\end{array}$ \\
\hline 1 & 2 & B-PP-007 & 3 & 59 & 212 & 0.223 \\
2 & 3 & B-PP-007 & 2 & 87 & 624 & 0.125 \\
3 & 2 & B-PP-024 & 4 & 52 & 390 & 0.120 \\
4 & 3 & B-PP-024 & 2 & 67 & 515 & 0.115 \\
5 & 2 & B-PP-030 & 3 & 43 & 217 & 0.170 \\
6 & 3 & B-PP-030 & 1 & 131 & 777 & 0.140 \\
7 & 2 & B-PP-038 & 3 & 35 & 134 & 0.270 \\
8 & 3 & B-PP-038 & 1 & 104 & 472 & 0.180 \\
9 & 2 & B-PP-077 & 4 & 33 & 182 & 0.155 \\
10 & 3 & B-PP-077 & 1 & 77 & 320 & 0.190 \\
11 & 2 & Seascape & 1 & 116 & 422 & 0.220 \\
12 & 3 & Seascape & 2 & 177 & 439 & 0.295 \\
13 & 2 & Tristar & 5 & 55 & 468 & 0.110 \\
14 & 3 & Tristar & 3 & 122 & 1055 & 0.110 \\
\hline
\end{tabular}


Table C.4 Octoploid species Supercore Collection ripe fruit anthocyanidin content.

The Supercore Collection ripe fruit were assayed using the Phase 3 protocol. The Run \# refers to the HPLC identification in the data records.

\begin{tabular}{|c|c|c|c|c|c|c|c|c|c|c|}
\hline \multirow[b]{2}{*}{ Case } & \multirow[b]{2}{*}{ Run } & \multirow[b]{2}{*}{ Species subspecies } & \multirow[b]{2}{*}{ Origin } & \multirow{2}{*}{$\begin{array}{c}\text { Accession } \\
\text { CFRA }\end{array}$} & \multirow{2}{*}{$\begin{array}{c}\text { Number } \\
\text { of } \\
\text { Berries }\end{array}$} & \multirow[b]{2}{*}{ Loc } & \multicolumn{4}{|c|}{ Anthocyanidin ( $\mu \mathrm{g} / \mathrm{g}$ dry FDW) } \\
\hline & & & & & & & [Cyn] & [PIr] & [Anth] & $\begin{array}{c}\text { [Cyn]/ } \\
\text { ([Anth]) }\end{array}$ \\
\hline & & F. chiloensis & & & & & & & & \\
\hline 1 & 6001 & ssp. pacifica & Alaska & 368.002 & 2 & HF & 56 & 205 & 261 & 0.213 \\
\hline 2 & 6002 & ssp. pacifica & Alaska & 368.005 & 5 & $\mathrm{HF}$ & 88 & 237 & 325 & 0.270 \\
\hline 3 & 6118 & ssp. pacifica & Alaska & 368.005 & 3 & $\mathrm{HF}$ & 98 & 152 & 250 & 0.393 \\
\hline 4 & 6124 & ssp. pacifica & Alaska & 368.005 & 4 & $\mathrm{HF}$ & 122 & 400 & 522 & 0.235 \\
\hline & & & Washingto & & & & & & & \\
\hline 5 & 6094 & ssp lucida & $\mathbf{n}$ & 42.001 & 3 & $\mathrm{HF}$ & 362 & 52 & 414 & 0.875 \\
\hline 6 & 6091 & ssp lucida & Oregon & 1691.001 & 1 & HF & 524 & 159 & 683 & 0.768 \\
\hline 7 & 6130 & ssp lucida & Oregon & 1691.001 & 3 & $\mathrm{HF}$ & 889 & 243 & 1132 & 0.785 \\
\hline 8 & $6148 \mathrm{C}$ & f.chiloensis & Peru & 372.002 & 1 & $\mathrm{GH}$ & 215 & 67 & 282 & 0.762 \\
\hline 9 & 6085 & f.chiloensis & Peru & 372.002 & 2 & $\mathrm{HF}$ & 181 & 149 & 331 & 0.548 \\
\hline 10 & 6036 & f.chiloensis & Peru & 372.002 & 1 & $\mathrm{HF}$ & 264 & 182 & 446 & 0.592 \\
\hline 11 & 6095 & f.patagonica & Chilé & 1100.002 & 2 & $\mathrm{HF}$ & 167 & 233 & 400 & 0.417 \\
\hline & & F. virginiana & & & & & & & & \\
\hline 12 & 6154 & ssp virginiana(N) & Ontario & 1694.001 & 1 & $\mathrm{HF}$ & 165 & 749 & 915 & 0.181 \\
\hline 13 & 6009 & ssp virginiana(N) & Ontario & 1699.001 & 4 & $\mathrm{HF}$ & 67 & 434 & 501 & 0.134 \\
\hline 14 & 6069 & ssp virginiana(N) & Ontario & 1699.001 & 1 & $\mathrm{HF}$ & 379 & 1497 & 1876 & 0.202 \\
\hline 15 & 6113 & ssp virginiana(N) & Ontario & 1699.001 & 5 & HF & 100 & 447 & 547 & 0.182 \\
\hline 16 & 6122 & ssp virginiana(N) & Ontario & 1699.001 & 6 & $\mathrm{HF}$ & 209 & 961 & 1171 & 0.179 \\
\hline 17 & 6097 & ssp virginiana(N) & Ontario & 1695.001 & 2 & $\mathrm{HF}$ & 198 & 321 & 519 & 0.381 \\
\hline 18 & 6098 & ssp virginiana(N) & Ontario & 1695.001 & 1 & HF & 314 & 869 & 1183 & 0.266 \\
\hline 19 & 6155 & ssp virginiana(N) & Ontario & 1695.001 & 1 & HF & 176 & 213 & 389 & 0.453 \\
\hline 20 & 6037 & ssp virginiana(N) & Ontario & 1695.002 & 2 & $\mathrm{HF}$ & 610 & 1004 & 1613 & 0.378 \\
\hline 21 & 6129 & ssp virginiana(N) & Ontario & 1695.002 & 2 & HF & 169 & 899 & 1067 & 0.158 \\
\hline 22 & 6010 & ssp virginiana(N) & Minnesota & 1701.001 & 5 & HF & 57 & 303 & 360 & 0.160 \\
\hline 23 & 6011 & ssp virginiana(N) & Minnesota & 1701.001 & 5 & HF & 49 & 189 & 238 & 0.204 \\
\hline
\end{tabular}


Table C.4 Octoploid species Supercore Collection ripe fruit anthocyanidin content continued.

\begin{tabular}{|c|c|c|c|c|c|c|c|c|c|c|}
\hline \multirow[b]{2}{*}{ Case } & \multirow[b]{2}{*}{ Run } & \multirow[b]{2}{*}{ Species subspecies } & \multirow[b]{2}{*}{ Origin } & \multirow{2}{*}{\multicolumn{2}{|c|}{$\begin{array}{cc}\text { Accession } & \text { Number } \\
\text { CFRA } & \text { of } \\
\text { Berries }\end{array}$}} & \multirow[b]{2}{*}{ Loc } & \multicolumn{4}{|c|}{ Anthocyanidin ( $\mu \mathrm{g} / \mathrm{g}$ dry FDW) } \\
\hline & & & & & & & [Cyn] & [PIr] & [Anth] & $\begin{array}{c}\text { [Cyn]/ } \\
\text { ([Anth]) }\end{array}$ \\
\hline & & \multicolumn{9}{|l|}{ F. virginiana continued } \\
\hline 24 & 6051 & ssp virginiana(N) & Minnesota & 1701.001 & 4 & $\mathrm{HF}$ & 82 & 466 & 548 & 0.149 \\
\hline 25 & 6123 & ssp virginiana(N) & Minnesota & 1701.001 & 14 & $\mathrm{HF}$ & 85 & 571 & 655 & 0.129 \\
\hline 26 & 6152 & ssp virginiana(N) & Minnesota & 1701.001 & 1 & $\mathrm{GH}$ & 68 & 741 & 809 & 0.084 \\
\hline 27 & 6050 & ssp virginiana(N) & Minnesota & 1700.001 & 2 & $\mathrm{HF}$ & 234 & 651 & 885 & 0.265 \\
\hline 28 & 6132 & ssp virginiana(N) & Minnesota & 1700.001 & 2 & $\mathrm{GH}$ & 256 & 1090 & 1346 & 0.190 \\
\hline 29 & 6006 & ssp virginiana(S) & S. Carolina & 1580.001 & 5 & $\mathrm{HF}$ & 93 & 232 & 325 & 0.286 \\
\hline 30 & 6049 & ssp virginiana(S) & S. Carolina & 1580.001 & 2 & $\mathrm{HF}$ & 109 & 225 & 334 & 0.327 \\
\hline 31 & 6068 & ssp virginiana(S) & S. Carolina & 1580.001 & 7 & $\mathrm{HF}$ & 107 & 244 & 351 & 0.305 \\
\hline 32 & 6112 & ssp virginiana(S) & S. Carolina & 1580.001 & 3 & $\mathrm{HF}$ & 117 & 343 & 460 & 0.255 \\
\hline 33 & 6121 & ssp virginiana(s) & S. Carolina & 1580.001 & 9 & $\mathrm{HF}$ & 103 & 218 & 322 & 0.322 \\
\hline 34 & 6005 & ssp virginiana(S) & Georgia & 1455.001 & 2 & $\mathrm{HF}$ & 87 & 512 & 599 & 0.145 \\
\hline 35 & 6067 & ssp virginiana(S) & Georgia & 1455.001 & 2 & $\mathrm{HF}$ & 137 & 588 & 725 & 0.188 \\
\hline 36 & 6128 & ssp virginiana(S) & Florida & 1435.002 & 1 & $\mathrm{HF}$ & 222 & 561 & 784 & 0.284 \\
\hline 37 & $6150 \mathrm{~A}$ & ssp glauca×virginiana & Montana & 1697.001 & 1 & $\mathrm{GH}$ & 137 & 475 & 612 & 0.223 \\
\hline 38 & 6093 & ssp glauca virginiana & Montana & 1697.001 & 3 & $\mathrm{HF}$ & 144 & 405 & 549 & 0.262 \\
\hline 39 & 6131 & ssp glaucaxvirginiana & Montana & 1697.001 & 2 & $\mathrm{GH}$ & 84 & 315 & 399 & 0.210 \\
\hline 40 & 6133 & ssp glauca×virginiana & Montana & 1697.001 & 3 & $\mathrm{GH}$ & 152 & 847 & 999 & 0.152 \\
\hline 41 & 6007 & ssp glauca virginiana & Montana & 1697.002 & 5 & $\mathrm{HF}$ & 78 & 215 & 293 & 0.265 \\
\hline 42 & 6008 & ssp glauca xvirginiana & Montana & 1697.002 & 7 & $\mathrm{HF}$ & 62 & 163 & 225 & 0.275 \\
\hline 43 & 6048 & ssp glaucaxvirginiana & Montana & 1697.002 & 10 & $\mathrm{HF}$ & 150 & 230 & 380 & 0.395 \\
\hline 44 & 6066 & ssp grayana & Mississippi & 1414.001 & 3 & $\mathrm{HF}$ & 57 & 175 & 232 & 0.247 \\
\hline 45 & 6120 & ssp grayana & Mississippi & 1414.001 & 1 & $H F$ & 70 & 176 & 246 & 0.283 \\
\hline 46 & 6127 & ssp grayana & Mississippi & 1414.001 & 1 & $\mathrm{HF}$ & 104 & 329 & 433 & 0.240 \\
\hline 47 & 6003 & ssp grayana & Mississippi & 1408.001 & 2 & $\mathrm{HF}$ & 93 & 185 & 279 & 0.335 \\
\hline 48 & 6125 & ssp grayana & Mississippi & 1408.001 & 5 & $\mathrm{HF}$ & 98 & 329 & 427 & 0.229 \\
\hline
\end{tabular}


Table C.4 Octoploid species Supercore Collection ripe fruit anthocyanidin content continued.

\begin{tabular}{|c|c|c|c|c|c|c|c|c|c|c|}
\hline \multirow[b]{2}{*}{ Case } & \multirow[b]{2}{*}{ Run } & \multirow[b]{2}{*}{ Species subspecies } & \multirow[b]{2}{*}{ Origin } & \multirow{2}{*}{$\begin{array}{c}\text { Accession } \\
\text { CFRA }\end{array}$} & \multirow{2}{*}{$\begin{array}{c}\text { Number } \\
\text { of } \\
\text { Berries }\end{array}$} & \multirow[b]{2}{*}{ Loc } & \multicolumn{4}{|c|}{ Anthocyanidin ( $\mu \mathrm{g} / \mathrm{g}$ dry FDW) } \\
\hline & & & & & & & [Cyn] & [PIr] & [Anth] & $\begin{array}{c}\text { [Cyn]l] } \\
\text { ([Anth]) }\end{array}$ \\
\hline $\begin{array}{l}49 \\
50 \\
51 \\
52 \\
53\end{array}$ & $\begin{array}{l}6086 \\
6004 \\
6065 \\
6119 \\
6126 \\
\end{array}$ & $\begin{array}{l}\text { F. virginiana continued } \\
\text { ssp grayana } \\
\text { ssp grayana } \\
\text { ssp grayana } \\
\text { ssp grayana } \\
\text { ssp grayana } \\
\end{array}$ & $\begin{array}{l}\text { Mississippi } \\
\text { Mississippi } \\
\text { Mississippi } \\
\text { Mississippi } \\
\text { Mississippi }\end{array}$ & $\begin{array}{l}1408.001 \\
1408.002 \\
1408.002 \\
1408.002 \\
1408.002\end{array}$ & $\begin{array}{l}3 \\
1 \\
4 \\
4 \\
5\end{array}$ & $\begin{array}{l}\mathrm{HF} \\
\mathrm{HF} \\
\mathrm{HF} \\
\mathrm{HF} \\
\mathrm{HF}\end{array}$ & $\begin{array}{r}176 \\
242 \\
71 \\
91 \\
123\end{array}$ & $\begin{array}{l}561 \\
577 \\
170 \\
278 \\
611\end{array}$ & $\begin{array}{l}737 \\
819 \\
241 \\
369 \\
734\end{array}$ & $\begin{array}{l}0.238 \\
0.296 \\
0.296 \\
0.248 \\
0.167\end{array}$ \\
\hline
\end{tabular}


Table C.5 Octoploid Fragaria $\times$ ananassa ripe fruit anthocyanidin content.

Most of the assays of the cultivars were conducted using Phase 3 protocol 69 out of 79 assays, with the remaining 10 assays conducted using the Phase 2 protocol. The Run \# refers to the HPLC identification in the data records.

\begin{tabular}{|c|c|c|c|c|c|c|c|c|c|c|}
\hline \multirow[b]{2}{*}{ Case } & \multirow[b]{2}{*}{$\begin{array}{c}\text { Collection } \\
\text { Year }\end{array}$} & \multirow[b]{2}{*}{ Phase } & \multirow[b]{2}{*}{$\begin{array}{c}\text { Run } \\
\#\end{array}$} & \multirow[b]{2}{*}{ Accession } & \multirow[b]{2}{*}{$\begin{array}{l}\text { No of } \\
\text { Berries }\end{array}$} & \multirow{2}{*}{$\begin{array}{l}\text { Collection } \\
\text { Location }\end{array}$} & \multicolumn{4}{|c|}{ Anthocyanidins ( $\mu \mathrm{g} / \mathrm{g}$ FDW) } \\
\hline & & & & & & & [Cyn] & [PIr] & [Anth] & [Cyn]/[Anth] \\
\hline 1 & 2006 & 3 & 6138 & Delmarvel & 1 & $\mathrm{GH}$ & 51 & 616 & 667 & 0.076 \\
\hline 2 & 2006 & 3 & 6139 & Delmarvel & 1 & $\mathrm{GH}$ & 48 & 634 & 682 & 0.070 \\
\hline 3 & 2006 & 3 & 6144 & Delmarvel & 1 & $\mathrm{GH}$ & 47 & 1210 & 1257 & 0.037 \\
\hline 4 & 2006 & 3 & 6012 & Earliglow & 5 & HF & 65 & 834 & 900 & 0.073 \\
\hline 5 & 2006 & 3 & 6027 & Earliglow & 5 & HF & 69 & 664 & 733 & 0.094 \\
\hline 6 & 2006 & 3 & 6047 & Earliglow & 3 & $\mathrm{HF}$ & 77 & 413 & 491 & 0.157 \\
\hline 7 & 2006 & 3 & 6078 & Earliglow & 5 & HF & 56 & 554 & 611 & 0.092 \\
\hline 8 & 2006 & 3 & 6116 & Earliglow & 5 & $\mathrm{HF}$ & 41 & 476 & 516 & 0.079 \\
\hline 9 & 2006 & 3 & 6013 & Honeoye & 5 & $\mathrm{HF}$ & 41 & 692 & 733 & 0.056 \\
\hline 10 & 2006 & 3 & 6028 & Honeoye & 5 & $\mathrm{HF}$ & 57 & 865 & 922 & 0.062 \\
\hline 11 & 2006 & 3 & 6045 & Honeoye & 5 & $\mathrm{HF}$ & 61 & 820 & 882 & 0.070 \\
\hline 12 & 2006 & 3 & 6071 & Honeoye & 5 & $\mathrm{HF}$ & 49 & 625 & 674 & 0.073 \\
\hline 13 & 2006 & 3 & 6072 & Honeoye & 5 & $\mathrm{HF}$ & 44 & 366 & 410 & 0.106 \\
\hline 14 & 2006 & 3 & 6106 & Honeoye & 5 & $\mathrm{HF}$ & 51 & 707 & 758 & 0.067 \\
\hline 15 & 2006 & 3 & 6114 & Honeoye & 5 & HF & 44 & 448 & 492 & 0.090 \\
\hline 16 & 2006 & 3 & 6115 & Honeoye & 5 & $\mathrm{HF}$ & 51 & 1056 & 1108 & 0.046 \\
\hline 17 & 2006 & 3 & 6014 & Jewel & 5 & $\mathrm{HF}$ & 34 & 692 & 727 & 0.047 \\
\hline 18 & 2006 & 3 & 6021 & Jewel & 5 & HF & 46 & 772 & 818 & 0.056 \\
\hline 19 & 2006 & 3 & 6022 & Jewel & 1 & HF & 56 & 848 & 904 & 0.062 \\
\hline 20 & 2006 & 3 & 6038 & Jewel & 3 & $\mathrm{HF}$ & 45 & 462 & 508 & 0.089 \\
\hline 21 & 2006 & 3 & 6041 & Jewel & 2 & $\mathrm{HF}$ & 47 & 518 & 565 & 0.083 \\
\hline 22 & 2006 & 3 & 6062 & Jewel & 5 & $\mathrm{HF}$ & 39 & 720 & 759 & 0.051 \\
\hline 23 & 2006 & 3 & 6063 & Jewel & 4 & HF & 91 & 875 & 967 & 0.094 \\
\hline 24 & 2006 & 3 & 6073 & Jewel & 5 & HF & 30 & 295 & 325 & 0.093 \\
\hline 25 & 2006 & 3 & 6107 & Jewel & 3 & HF & 46 & 854 & 901 & 0.052 \\
\hline
\end{tabular}




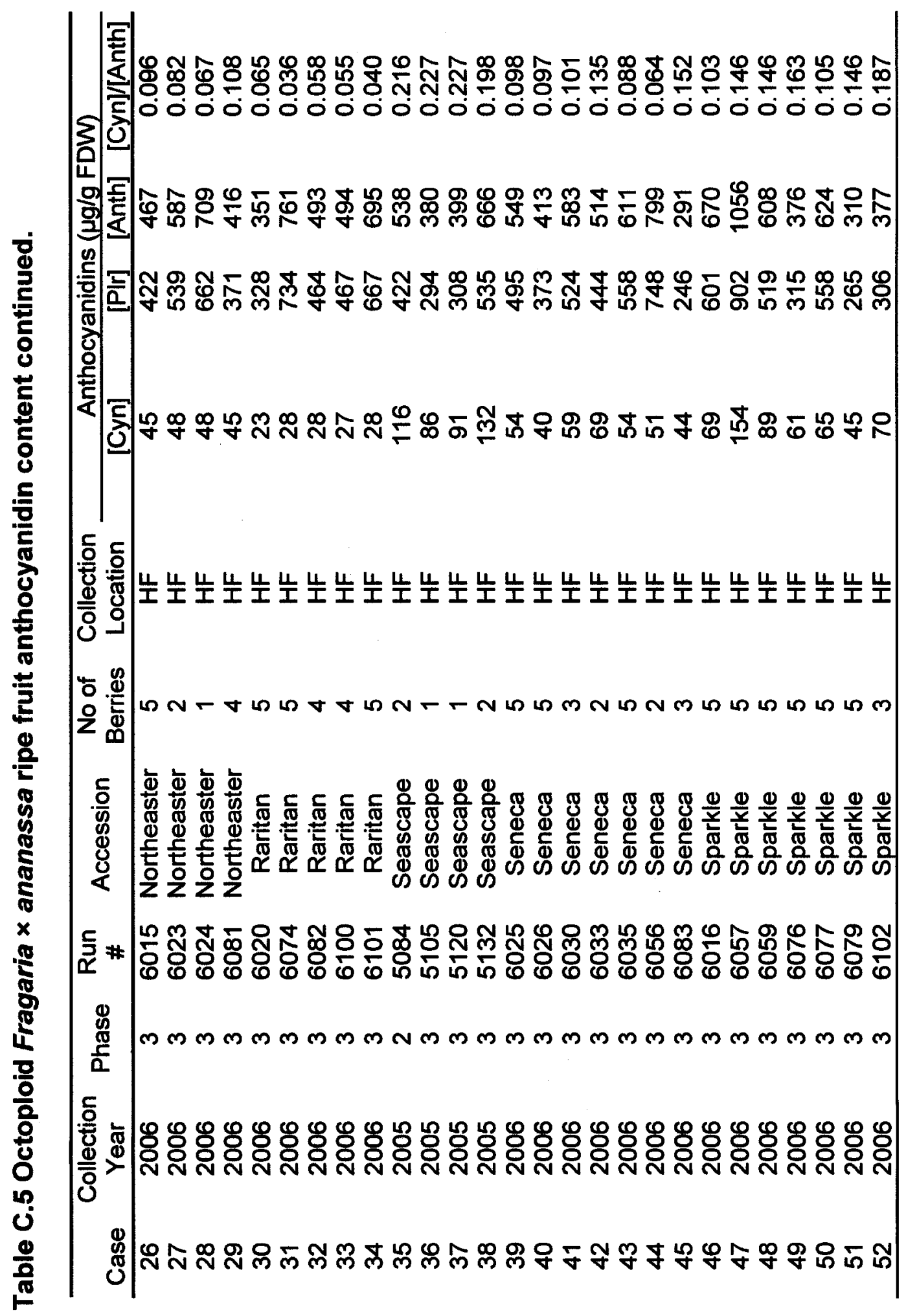


Table C.5 Octoploid Fragaria $\times$ ananassa ripe fruit anthocyanidin content continued.

\begin{tabular}{|c|c|c|c|c|c|c|c|c|c|c|}
\hline \multirow{2}{*}{ Case } & \multirow{2}{*}{$\begin{array}{c}\text { Collection } \\
\text { Year }\end{array}$} & \multirow{2}{*}{ Phase } & \multirow{2}{*}{$\begin{array}{c}\text { Run } \\
\#\end{array}$} & \multirow{2}{*}{ Accession } & \multirow{2}{*}{$\begin{array}{l}\text { No of } \\
\text { Berries }\end{array}$} & \multirow{2}{*}{$\begin{array}{l}\text { Collection } \\
\text { Location }\end{array}$} & \multicolumn{4}{|c|}{ Anthocyanidins ( $\mu \mathrm{g} / \mathrm{g}$ FDW } \\
\hline & & & & & & & [Cyn] & [PIr] & [Anth] & [Cyn]/[Anth] \\
\hline 53 & 2006 & 3 & 6103 & Sparkle & $\overline{5}$ & $\mathrm{HF}$ & 70 & 698 & 768 & 0.091 \\
\hline 54 & 2006 & 3 & 6117 & Sparkle & 2 & HF & 41 & 441 & 482 & 0.086 \\
\hline 55 & 2005 & 2 & 5046 & Tribute & & HF & 21 & 326 & 347 & 0.061 \\
\hline 56 & 2006 & 3 & 6017 & Tribute & 3 & HF & 39 & 385 & 424 & 0.091 \\
\hline 57 & 2006 & 3 & 6054 & Tribute & 2 & HF & 37 & 454 & 491 & 0.075 \\
\hline 58 & 2006 & 3 & 6064 & Tribute & 4 & HF & 46 & 505 & 551 & 0.083 \\
\hline 59 & 2006 & 3 & 6080 & Tribute & 5 & HF & 27 & 354 & 381 & 0.072 \\
\hline 60 & 2006 & 3 & 6137 & Tribute & 1 & GH & 80 & 490 & 570 & 0.141 \\
\hline 61 & 2006 & 3 & 6146 & Tribute & 1 & GH & 66 & 298 & 364 & 0.180 \\
\hline 62 & 2005 & 2 & 5007 & Tristar & 2 & HF & 36 & 253 & 289 & 0.123 \\
\hline 63 & 2005 & 2 & 5008 & Tristar & 1 & HF & 23 & 135 & 158 & 0.143 \\
\hline 64 & 2005 & 2 & 5009 & Tristar & 1 & HF & 17 & 109 & 126 & 0.134 \\
\hline 65 & 2005 & 2 & 5020 & Tristar & 1 & HF & 35 & 293 & 328 & 0.107 \\
\hline 66 & 2005 & 2 & 5058 & Tristar & 1 & HF & 60 & 713 & 773 & 0.078 \\
\hline 67 & 2005 & 2 & 5081 & Tristar & 2 & HF & 56 & 377 & 433 & 0.129 \\
\hline 68 & 2005 & 2 & 5082 & Tristar & 3 & HF & 21 & 308 & 329 & 0.064 \\
\hline 69 & 2005 & 2 & 5083 & Tristar & 3 & HF & 88 & 704 & 791 & 0.111 \\
\hline 70 & 2005 & 3 & 5119 & Tristar & 1 & HF & 89 & 716 & 806 & 0.111 \\
\hline 71 & 2005 & 3 & 5129 & Tristar & 2 & HF & 133 & 1053 & 1186 & 0.112 \\
\hline 72 & 2005 & 3 & 5131 & Tristar & 2 & HF & 123 & 1420 & 1543 & 0.080 \\
\hline 73 & 2006 & 3 & 6018 & Tristar & 5 & HF & 75 & 733 & 808 & 0.093 \\
\hline 74 & 2006 & 3 & 6046 & Tristar & 1 & HF & 138 & 864 & 1002 & 0.138 \\
\hline 75 & 2006 & 3 & 6060 & Winona & 5 & HF & 42 & 521 & 563 & 0.075 \\
\hline 76 & 2006 & 3 & 6061 & Winona & 5 & HF & 55 & 789 & 844 & 0.065 \\
\hline 77 & 2006 & 3 & 6099 & Winona & 2 & HF & 44 & 403 & 447 & 0.099 \\
\hline 78 & 2006 & 3 & 6104 & Winona & $\overline{1}$ & HF & 49 & 670 & 719 & 0.068 \\
\hline 79 & 2006 & 3 & 6111 & Winona & 3 & HF & 62 & 606 & 669 & 0.093 \\
\hline
\end{tabular}


Table C.6 Octoploid 'Bountiful', 'Pink Panda' and B-PP Accessions ripe fruit anthocyanidin content.

These accessions were analyzed during the phases of devepment. The Run \# refers to the HPLC identification in the data records.

\begin{tabular}{|c|c|c|c|c|c|c|c|c|c|c|}
\hline & Collection & & & & No of & Collection & $\overline{A n}$ & ocya & idins $(\mu$ & /g FDW) \\
\hline Case & Year & Run \# & Phase & Accession & Berries & Location & [Cyn] & [Plr] & [Anth] & [Cyn]/[Anth] \\
\hline 1 & 2005 & 5091 & 3 & Bountiful & 2 & $\overline{\mathrm{HF}}$ & 55 & 426 & 481 & 0.114 \\
\hline 2 & 2005 & 5092 & 3 & Bountiful & 3 & HF & 31 & 291 & 322 & 0.096 \\
\hline 3 & 2005 & 5093 & 3 & Bountiful & 4 & HF & 92 & 273 & 365 & 0.252 \\
\hline 4 & 2006 & 6153 & 3 & Bountiful & 1 & $\mathrm{GH}$ & 39 & 430 & 468 & 0.083 \\
\hline 5 & 2004 & 25 & 1 & B-PP-003 & & $\mathrm{GH}$ & 52 & 133 & 185 & 0.282 \\
\hline 6 & 2005 & 5045 & 2 & B-PP-005 & 4 & $\mathrm{GH}$ & 42 & 265 & 307 & 0.137 \\
\hline 7 & 2005 & 5047 & 2 & B-PP-005 & 2 & HF & 30 & 154 & 184 & 0.163 \\
\hline 8 & 2004 & 56 & 1 & B-PP-007 & & $\mathrm{GH}$ & 19 & 131 & 150 & 0.128 \\
\hline 9 & 2005 & 5044 & 2 & B-PP-007 & 3 & HF & 45 & 143 & 188 & 0.239 \\
\hline 10 & 2005 & 5053 & 2 & B-PP-007 & 4 & HF & 79 & 225 & 304 & 0.260 \\
\hline 11 & 2005 & 5056 & 2 & B-PP-007 & 4 & HF & 54 & 268 & 322 & 0.167 \\
\hline 12 & 2005 & 5106 & 3 & B-PP-007 & 6 & HF & 87 & 528 & 615 & 0.142 \\
\hline 13 & 2005 & 5107 & 3 & B-PP-007 & 6 & HF & 87 & 719 & 806 & 0.108 \\
\hline 14 & 2004 & 48 & 1 & B-PP-009 & & $\mathrm{GH}$ & 31 & 172 & 204 & 0.154 \\
\hline 15 & 2005 & 5033 & 2 & B-PP-009 & & HF & 51 & 319 & 370 & 0.137 \\
\hline 16 & 2005 & 5035 & 2 & B-PP-009 & 4 & HF & 63 & 303 & 367 & 0.173 \\
\hline 17 & 2005 & 5049 & 2 & B-PP-009 & 5 & HF & 68 & 292 & 360 & 0.189 \\
\hline 18 & 2004 & 57 & 1 & B-PP-016 & & $\mathrm{GH}$ & 0 & & 0 & NA \\
\hline 19 & 2005 & 5109 & 3 & B-PP-016 & 4 & HF & 55 & 298 & 353 & 0.155 \\
\hline 20 & 2004 & 58 & 1 & B-PP-017 & & $\mathrm{GH}$ & 0 & 91 & 91 & 0.003 \\
\hline 21 & 2005 & 5040 & 2 & B-PP-017 & 3 & HF & 30 & 198 & 229 & 0.133 \\
\hline 22 & 2005 & 5041 & 2 & B-PP-017 & 3 & HF & 24 & 196 & 219 & 0.109 \\
\hline 23 & 2005 & 5057 & 2 & B-PP-017 & 3 & $\mathrm{HF}$ & 38 & 332 & 370 & 0.104 \\
\hline 24 & 2005 & 5059 & 2 & B-PP-017 & 3 & HF & 33 & 248 & 281 & 0.118 \\
\hline 25 & 2004 & 26 & 1 & B-PP-023 & & $\mathrm{GH}$ & 23 & 78 & 102 & 0.229 \\
\hline 26 & 2005 & 5037 & 2 & B-PP-023 & 4 & HF & 72 & 413 & 485 & 0.149 \\
\hline
\end{tabular}


Table C.6 Octoploid 'Bountiful', 'Pink Panda' and B-PP Accessions ripe fruit anthocyanidin content continued.

\begin{tabular}{|c|c|c|c|c|c|c|c|c|c|c|}
\hline \multirow{2}{*}{ Case } & \multirow{2}{*}{$\begin{array}{c}\text { Collection } \\
\text { Year }\end{array}$} & \multirow{2}{*}{ Run \# } & \multirow{2}{*}{ Phase } & \multirow{2}{*}{ Accession } & \multirow{2}{*}{$\begin{array}{l}\text { No of } \\
\text { Berries }\end{array}$} & \multirow{2}{*}{$\begin{array}{l}\text { Collectio } \\
\text { Location }\end{array}$} & \multicolumn{4}{|c|}{ Anthocyanidins ( $\mu \mathrm{g} / \mathrm{g}$ FDW) } \\
\hline & & & & & & & [Cyn] & {$[\mathrm{Plr}]$} & [Anth] & [Cyn]/[Anth] \\
\hline 27 & 2005 & 5042 & 2 & B-PP-023 & 4 & $\mathrm{HF}$ & 33 & 134 & 167 & 0.195 \\
\hline 28 & 2005 & 5048 & 2 & B-PP-023 & 4 & HF & 33 & 328 & 361 & 0.092 \\
\hline 29 & 2004 & 50 & 1 & B-PP-024 & & GH & 20 & 88 & 108 & 0.187 \\
\hline 30 & 2005 & 5036 & 2 & B-PP-024 & 2 & HF & 24 & 173 & 197 & 0.122 \\
\hline 31 & 2005 & 5039 & 2 & B-PP-024 & 4 & HF & 58 & 353 & 410 & 0.140 \\
\hline 32 & 2005 & 5039 & 2 & B-PP-024 & & HF & 56 & 336 & 392 & 0.142 \\
\hline 33 & 2005 & 5054 & 2 & B-PP-024 & 4 & HF & 66 & 452 & 518 & 0.128 \\
\hline 34 & 2005 & 5055 & 2 & B-PP-024 & 4 & HF & 60 & 583 & 644 & 0.094 \\
\hline 35 & 2006 & 6134 & 3 & B-PP-024 & $?$ & $\mathrm{GH}$ & 49 & 546 & 594 & 0.082 \\
\hline 36 & 2005 & 5110 & 3 & B-PP-024 & 6 & HF & 65 & 555 & 620 & 0.105 \\
\hline 37 & 2005 & 5111 & 3 & B-PP-024 & 6 & HF & 69 & 474 & 544 & 0.128 \\
\hline 38 & 2004 & 43 & 1 & B-PP-030 & & $\mathrm{GH}$ & 16 & 148 & 164 & 0.098 \\
\hline 39 & 2005 & 5034 & 2 & B-PP-030 & 3 & $\mathrm{HF}$ & 48 & 196 & 245 & 0.198 \\
\hline 40 & 2005 & 5038 & 2 & B-PP-030 & 3 & HF & 39 & 226 & 265 & 0.146 \\
\hline 41 & 2005 & 5043 & 2 & B-PP-030 & 4 & HF & 42 & 229 & 272 & 0.156 \\
\hline 42 & 2005 & 5112 & 3 & B-PP-030 & 3 & HF & 131 & 777 & 908 & 0.144 \\
\hline 43 & 2004 & 68 & 1 & B-PP-031 & & $\mathrm{GH}$ & 33 & 288 & 320 & 0.102 \\
\hline 44 & 2005 & 5113 & 3 & B-PP-031 & 3 & HF & 66 & 416 & 481 & 0.136 \\
\hline 45 & 2005 & 5145 & 3 & B-PP-031 & 2 & HF & 78 & 608 & 686 & 0.114 \\
\hline 46 & 2005 & 5146 & 3 & B-PP-031 & 3 & HF & 92 & 1341 & 1432 & 0.064 \\
\hline 47 & 2004 & 49 & 1 & B-PP-036 & & $\mathrm{GH}$ & 22 & 156 & 178 & 0.122 \\
\hline 48 & 2004 & 27 & 1 & B-PP-037 & & $\mathrm{GH}$ & 0 & 126 & 127 & 0.002 \\
\hline 49 & 2005 & 5147 & 3 & B-PP-037 & 4 & HF & 51 & 367 & 419 & 0.122 \\
\hline 50 & 2005 & 5148 & 3 & B-PP-037 & 4 & HF & 78 & 513 & 591 & 0.132 \\
\hline 51 & 2004 & 60 & 1 & B-PP-038 & & $\mathrm{GH}$ & 27 & 163 & 190 & 0.142 \\
\hline 52 & 2005 & 5003 & 2 & B-PP-038 & 2 & HF & 30 & 72 & 102 & 0.293 \\
\hline 53 & 2005 & 5006 & 2 & B-PP-038 & 2 & HF & 35 & 54 & 88 & 0.395 \\
\hline
\end{tabular}




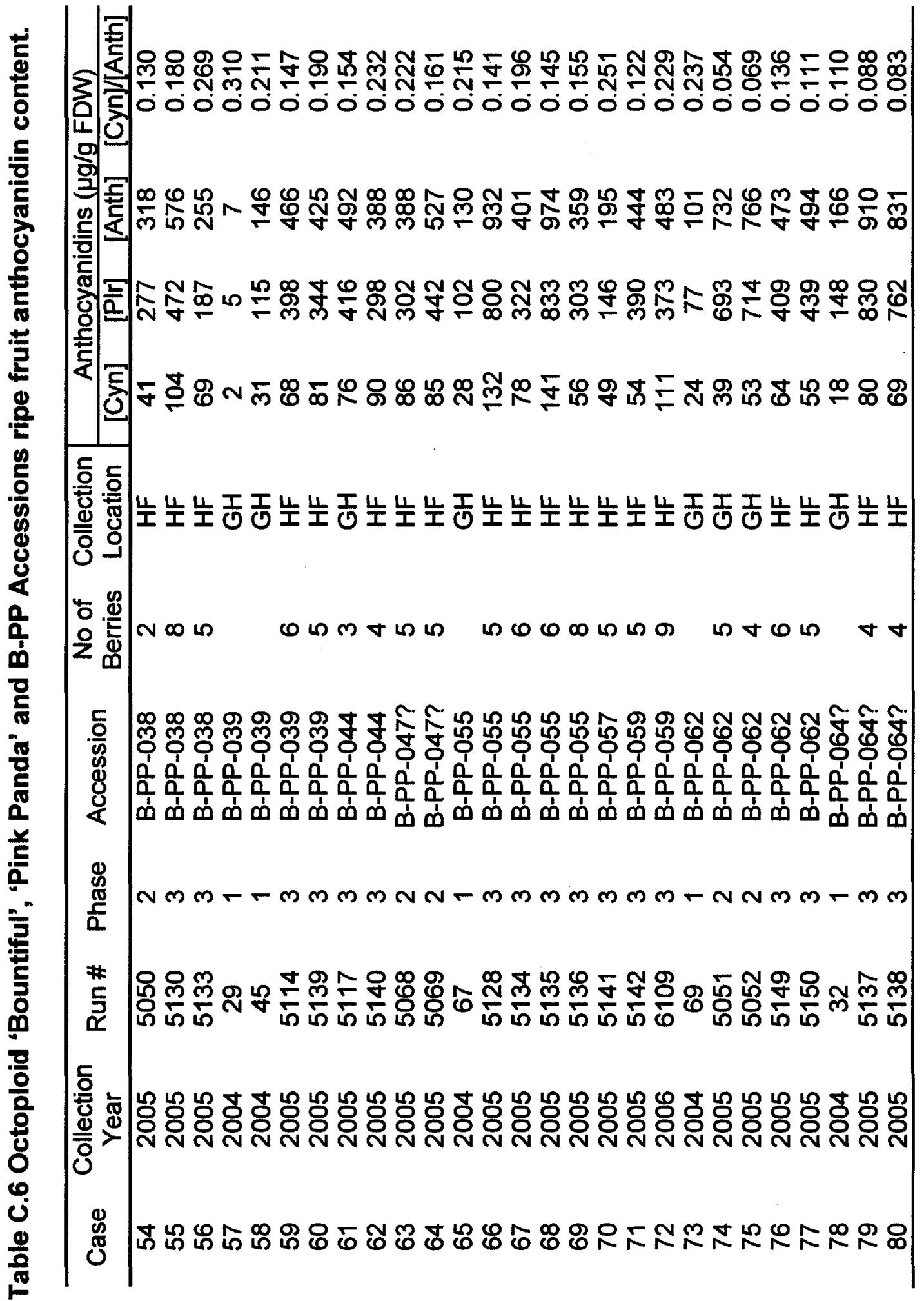


Table C.6 Octoploid 'Bountiful', 'Pink Panda' and B-PP Accessions ripe fruit anthocyanidin content.

\begin{tabular}{|c|c|c|c|c|c|c|c|c|c|c|}
\hline \multirow{2}{*}{ Case } & \multirow{2}{*}{$\begin{array}{c}\text { Collection } \\
\text { Year }\end{array}$} & \multirow{2}{*}{ Run \# } & \multirow{2}{*}{ Phase } & \multirow{2}{*}{ Accession } & \multirow{2}{*}{$\begin{array}{l}\text { No of } \\
\text { Berries }\end{array}$} & \multirow{2}{*}{$\begin{array}{c}\text { Collection } \\
\text { Location }\end{array}$} & \multicolumn{4}{|c|}{ Anthocyanidins ( $\mu \mathrm{g} / \mathrm{g}$ FDW) } \\
\hline & & & & & & & [Cyn] & [PIr] & [Anth] & [Cyn]/[Anth] \\
\hline 81 & 2005 & 5143 & 3 & B-PP-064? & 4 & $\mathrm{HF}$ & 46 & 523 & 569 & 0.082 \\
\hline 82 & 2004 & 70 & 1 & B-PP-067 & & GH & 39 & 138 & 177 & 0.222 \\
\hline 83 & 2005 & 5144 & 3 & B-PP-067 & 3 & $\mathrm{HF}$ & 102 & 160 & 262 & 0.390 \\
\hline 84 & 2005 & 5021 & 2 & B-PP-068 & 4 & HF & 82 & 321 & 402 & 0.203 \\
\hline 85 & 2005 & 5022 & 2 & B-PP-068 & 3 & HF & 68 & 331 & 399 & 0.171 \\
\hline 86 & 2005 & 5023 & $\overline{2}$ & B-PP-068 & 3 & HF & 48 & 281 & 329 & 0.145 \\
\hline 87 & 2004 & 33 & 1 & B-PP-069 & & GH & 22 & 46 & 67 & 0.322 \\
\hline 88 & 2004 & 62 & 1 & B-PP-069 & & $\mathrm{GH}$ & 23 & 69 & 91 & 0.248 \\
\hline 89 & 2005 & 5061 & 2 & B-PP-069 & 4 & $\mathrm{HF}$ & 41 & 118 & 159 & 0.259 \\
\hline 90 & 2005 & 5062 & 2 & B-PP-069 & 5 & HF & 38 & 106 & 145 & 0.265 \\
\hline 91 & 2004 & 34 & 1 & B-PP-070 & & $\mathrm{GH}$ & 20 & 70 & 90 & 0.225 \\
\hline 92 & 2005 & 5024 & 2 & B-PP-070 & 2 & $\mathrm{HF}$ & 82 & 263 & 345 & 0.237 \\
\hline 93 & 2004 & 35 & 1 & B-PP-072 & & GH & 0 & 51 & 51 & 0.006 \\
\hline 94 & 2005 & 5070 & 2 & B-PP-072 & 3 & HF & 33 & 151 & 183 & 0.178 \\
\hline 95 & 2004 & 21 & 1 & B-PP-077 & & GH & 0 & 10 & 10 & 0.010 \\
\hline 96 & 2005 & 5004 & 2 & B-PP-077 & 1 & HF & 74 & 167 & 241 & 0.307 \\
\hline 97 & 2005 & 5025 & 2 & B-PP-077 & 3 & HF & 45 & 233 & 279 & 0.163 \\
\hline 98 & 2005 & 5026 & 2 & B-PP-077 & 4 & HF & 36 & 228 & 264 & 0.136 \\
\hline 99 & 2005 & 5027 & 2 & B-PP-077 & 4 & HF & 20 & 124 & 144 & 0.138 \\
\hline 100 & 2005 & 5028 & 2 & B-PP-077 & 4 & HF & 32 & 142 & 175 & 0.184 \\
\hline 101 & 2005 & 5118 & 3 & B-PP-077 & 3 & GH & 26 & 53 & 78 & 0.327 \\
\hline 102 & 2005 & 5108 & 3 & B-PP-077 & 2 & HF & 77 & 320 & 398 & 0.194 \\
\hline 103 & 2004 & 36 & 1 & B-PP-078 & & $\mathrm{GH}$ & 16 & 34 & 50 & 0.327 \\
\hline 104 & 2005 & 5065 & 2 & B-PP-078 & 5 & HF & 49 & 428 & 477 & 0.103 \\
\hline 105 & 2005 & 5155 & 3 & B-PP-081? & 3 & HF & 100 & 186 & 286 & 0.350 \\
\hline 106 & 2005 & 5071 & 2 & B-PP-101 & 4 & HF & 41 & 305 & 346 & 0.118 \\
\hline 107 & 2005 & 5072 & 2 & B-PP-101 & 4 & HF & 41 & 131 & 171 & 0.238 \\
\hline
\end{tabular}


Table C.6 Octoploid 'Bountiful', 'Pink Panda' and B-PP Accessions ripe fruit anthocyanidin content.

\begin{tabular}{|c|c|c|c|c|c|c|c|c|c|c|}
\hline \multirow{2}{*}{ Case } & \multirow{2}{*}{$\begin{array}{c}\text { Collection } \\
\text { Year }\end{array}$} & \multirow{2}{*}{ Run \# } & \multirow{2}{*}{ Phase } & \multirow{2}{*}{ Accession } & \multirow{2}{*}{$\begin{array}{l}\text { No of } \\
\text { Berries }\end{array}$} & \multirow{2}{*}{$\begin{array}{c}\text { Collection } \\
\text { Location }\end{array}$} & \multicolumn{4}{|c|}{ Anthocyanidins $(\mu \mathrm{g} / \mathrm{g}$ FDW) } \\
\hline & & & & & & & [Cyn] & [PIr] & [Anth] & [Cyn]/[Anth] \\
\hline 108 & 2004 & 22 & 1 & B-PP-102? & & $\mathrm{GH}$ & 10 & 35 & 45 & 0.223 \\
\hline 109 & 2005 & 5073 & 2 & B-PP-102? & 5 & $\mathrm{HF}$ & 50 & 160 & 210 & 0.239 \\
\hline 110 & 2005 & 5074 & 2 & B-PP-102? & 5 & HF & 40 & 204 & 243 & 0.163 \\
\hline 111 & 2005 & 5075 & 2 & B-PP-102? & 4 & HF & 52 & 200 & 252 & 0.206 \\
\hline 112 & 2004 & 37 & 1 & B-PP-103 & & GH & 19 & 68 & 87 & 0.219 \\
\hline 113 & 2005 & 5151 & 3 & B-PP-103 & 5 & HF & 67 & 613 & 680 & 0.098 \\
\hline 114 & 2005 & 5156 & 3 & B-PP-103 & 5 & $\mathrm{HF}$ & 53 & 364 & 417 & 0.128 \\
\hline 115 & 2004 & 38 & 1 & B-PP-104 & & GH & 24 & 67 & 91 & 0.265 \\
\hline 116 & 2005 & 5152 & 3 & B-PP-104 & 4 & $\mathrm{HF}$ & 63 & 226 & 289 & 0.218 \\
\hline 117 & 2005 & 5157 & 3 & B-PP-104 & 4 & $\mathrm{HF}$ & 90 & 328 & 418 & 0.215 \\
\hline 118 & 2004 & 65 & 1 & B-PP-105 & & $\mathrm{GH}$ & 24 & 180 & 204 & 0.120 \\
\hline 119 & 2005 & 5100 & 3 & B-PP-105 & 9 & $\mathrm{HF}$ & 36 & 323 & 359 & 0.101 \\
\hline 120 & 2005 & 5101 & 3 & B-PP-105 & 9 & HF & 60 & 376 & 436 & 0.137 \\
\hline 121 & 2005 & 5102 & 3 & B-PP-105 & 9 & HF & 85 & 470 & 555 & 0.152 \\
\hline 122 & 2005 & 5153 & 3 & B-PP-105 & 3 & $\mathrm{HF}$ & 83 & 607 & 689 & 0.120 \\
\hline 123 & 2005 & 5158 & 3 & B-PP-105 & 5 & $\mathrm{HF}$ & 78 & 359 & 437 & 0.179 \\
\hline 124 & 2004 & 39 & 1 & B-PP-106 & & $\mathrm{GH}$ & 27 & 212 & 239 & 0.112 \\
\hline 125 & 2005 & 5154 & 3 & B-PP-106 & 3 & HF & 99 & 789 & 888 & 0.112 \\
\hline 126 & 2005 & 5159 & 3 & B-PP-106 & 4 & HF & 45 & 344 & 389 & 0.116 \\
\hline 127 & 2004 & 47 & 1 & B-PP-107 & & GH & 32 & 117 & 149 & 0.213 \\
\hline 128 & 2005 & 5160 & 3 & B-PP-107 & 5 & HF & 51 & 140 & 191 & 0.266 \\
\hline 129 & 2004 & 64 & 1 & B-PP-108 & & $\mathrm{GH}$ & 20 & 35 & 55 & 0.360 \\
\hline 130 & 2004 & 40 & 1 & B-PP-109 & & $\mathrm{GH}$ & 19 & 45 & 64 & 0.300 \\
\hline 131 & 2005 & 5097 & 3 & B-PP-109 & 4 & HF & 48 & 187 & 235 & 0.203 \\
\hline 132 & 2005 & 5098 & 3 & B-PP-109 & 4 & $\mathrm{HF}$ & 41 & 155 & 196 & 0.209 \\
\hline 133 & 2005 & 5099 & 3 & B-PP-109 & 3 & $\mathrm{HF}$ & 26 & 109 & 135 & 0.191 \\
\hline 134 & 2005 & 5094 & 3 & B-PP-110 & 4 & HF & 57 & 165 & 222 & 0.257 \\
\hline
\end{tabular}




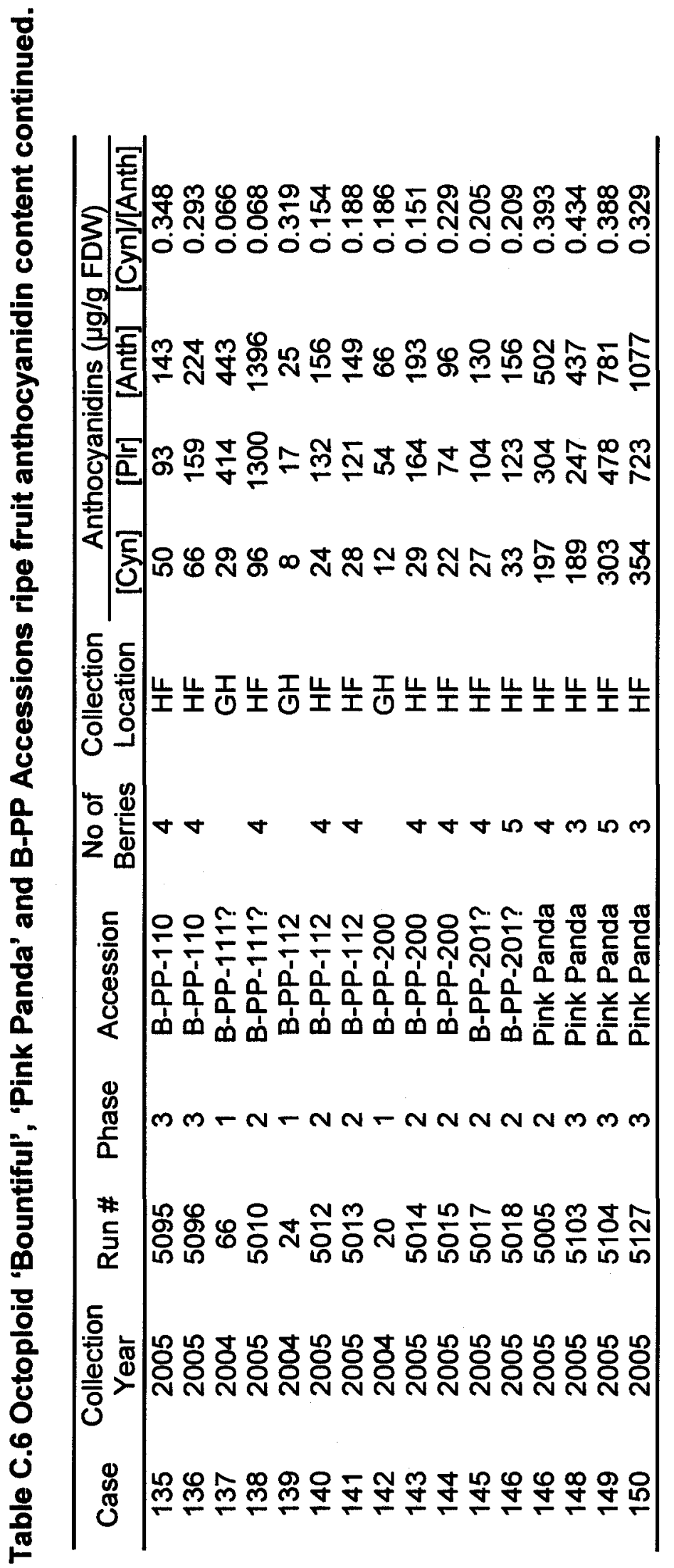

